\title{
Real Time Pricing as a Default or Optional Service for C\&I Customers: A Comparative Analysis of Eight Case Studies
}

\author{
G. Barbose, C. Goldman, R. Bharvirkar, N. Hopper, and M. Ting \\ Lawrence Berkeley National Laboratory \\ B. Neenan \\ Neenan Associates \\ Ernest Orlando Lawrence Berkeley National Laboratory \\ 1 Cyclotron Road, MS90R4000 \\ Berkeley, CA 94720-8136
}

August 2005

This work described in this report was coordinated by the Demand Response Research Center and funded by the California Energy Commission, Public Interest Energy Research Program, under Work for Others Contract No. 500-03-026 and by the U.S. Department of Energy under Contract No. DE-AC02-05CH11231. 
Prepared By: Charles A. Goldman

Lawrence Berkeley National Laboratory

Berkeley, California

Contract No. 500-03-026

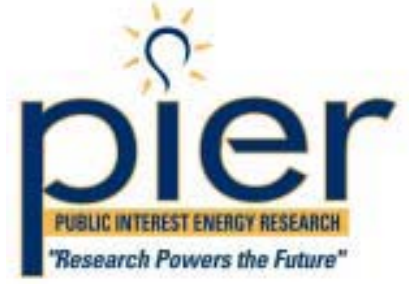

Prepared For:

California Energy Commission

Public Interest Energy Research (PIER)

Program

Dave Michel

Contract Manager

Mark Rawson

Program Area Team Lead

Martha Krebs

Deputy Director

ENERGY RESEARCH AND DEVELOPMENT

DIVISION

\section{B.B. Blevins \\ Executive Director}

The work described in this report was coordinated by the Demand Response Research Center and funded by the California Energy Commission, Public Interest Energy Research Program, under Work for Others Contract No. 500-03-026 and by the U.S. Department of Energy under Contract No. DEAC02-05CH11231.

\section{DISCLAIMER}

This report was prepared as the result of work sponsored by the California Energy Commission. It does not

necessarily represent the views of the Energy

Commission, its employees or the State of California. The

Energy Commission, the State of California, its

employees, contractors and subcontractors make no

warrant, express or implied, and assume no legal liability

for the information in this report; nor does any party

represent that the uses of this information will not infringe

upon privately owned rights. This report has not been

approved or disapproved by the California Energy

Commission nor has the California Energy Commission

passed upon the accuracy or adequacy of the information

in this report. 


\section{PREFACE}

The Public Interest Energy Research (PIER) Program supports public interest energy research and development that will help improve the quality of life in California by bringing environmentally safe, affordable, and reliable energy services and products to the marketplace.

The PIER Program, managed by the California Energy Commission (Commission), annually awards up to $\$ 62$ million to conduct the most promising public interest energy research by partnering with Research, Development, and Demonstration (RD\&D) organizations, including individuals, businesses, utilities, and public or private research institutions.

PIER funding efforts are focused on the following six RD\&D program areas:

- Buildings End-Use Energy Efficiency

- Industrial/Agricultural/Water End-Use Energy Efficiency

- Renewable Energy

- Environmentally-Preferred Advanced Generation

- Energy-Related Environmental Research

- Energy Systems Integration

What follows is one of two final reports for the Program and Tariffs Research Project, 500-03026 Task 3.2, conducted by the Lawrence Berkeley National Laboratory. The report is entitled "Real Time Pricing as a Default or Optional Service for C\&I Customers: A Comparative Analysis of Eight Case Studies”. This project contributes to the Energy Systems Integration Program.

For more information on the PIER Program, please visit the Commission's Web site at: http://www.energy.ca.gov/research/index.html or contact the Commission's Publications Unit at 916-654-5200. 


\section{Acknowledgements}

This work described in this report was coordinated by the Demand Response Research Center and funded by the California Energy Commission (CEC), Public Interest Energy Research (PIER) Program, under Work for Others Contract No. 500-03-026 and by the U.S. Department of Energy under Contract No. DE-AC02-05CH11231.

We also thank the following individuals and organizations for their support of this research project: Laurie Ten Hope (CEC), Mary Ann Piette (LBNL/CEC PIER Demand Response Research Center), Dave Hungerford (CEC) and Mike Jaske (CEC).

We also thank the members of our Technical Advisory Committee: Bruce Kaneshiro (CPUC), Scott Cauchois (California Office of Ratepayer Advocates), David Hungerford (CEC), Glen Perez (CAISO), Andrew Bell and Dewey Seeto (PG\&E), Mark Wallenrod (SCE), Suzie Sides and Paul Borkovich (SDG\&E), Barbara Barkovich (CLECA), Karen Lindh (CMA), Doug Lutzy (NYPSC), Dave Coup and Peter Douglas (NYSERDA), Dave Lawrence and Aaron Breidenbaugh (NYISO), Catherine McDonough (NMPC) and Larry Dewitt (Pace University) for their input, suggestions and comments. We also acknowledge the helpful comments provided by peer reviewers on a draft of this report: Barbara Barkovich, Chris King, Roger Levy, Glen Perez, Dan Delurey, and Lynne Kiesling. 


\section{Table of Contents}

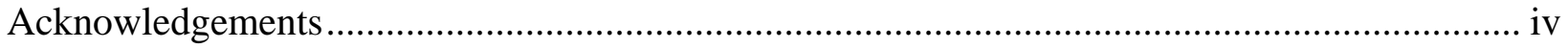

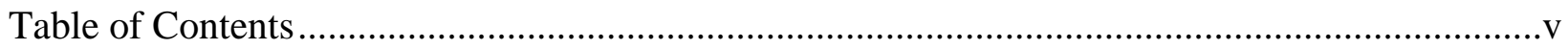

List of Figures, Tables and Text Boxes ...................................................................................... vii

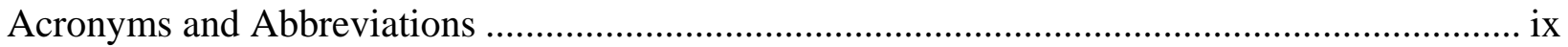

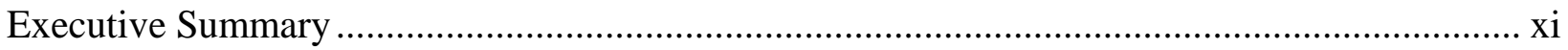

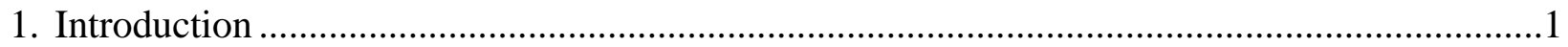

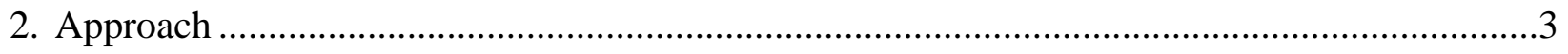

3. Conceptual Background ...........................................................................................

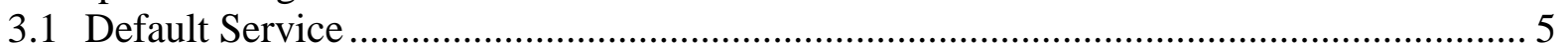

3.2 Typology of Retail Demand Response Mechanisms …………………………….............. 5

3.2.1 Dynamic pricing of retail services .................................................................... 6

3.2.2 Unbundled DR programs ............................................................................. 8

3.3 Accounting for DR Resources................................................................................... 11

4. RTP as a Default or Optional Utility Service: Case Studies ..................................................13

4.1 Case Study Overview .................................................................................................... 13

4.2 Market and Regulatory Context ................................................................................. 16

4.2.1 Retail market structure and development ............................................................. 16

4.2.2 Wholesale market structure and development ...................................................... 17

4.2.3 Policy context and impetus for RTP implementation ............................................ 17

4.2.4 State regulatory policies on demand response ..................................................... 18

4.3 RTP Implementation Process and Stakeholder Support................................................... 20

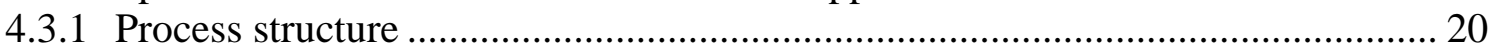

4.3.2 Stakeholder views on default and optional RTP service ..................................... 23

4.4 Tariff Design and Implementation Details ................................................................... 27

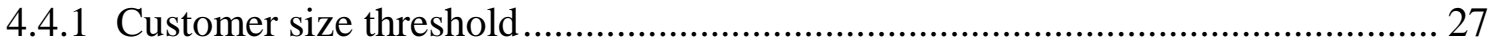

4.4.2 Interval metering deployment ......................................................................... 30

4.4.3 Pricing structure and terms .................................................................................. 30

4.5 Customer Education and Assistance to Support RTP Participation and Price Response 36

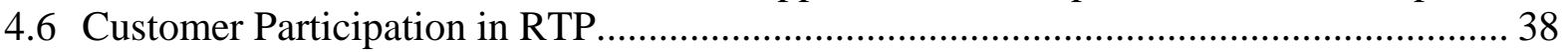

4.6.1 Eligible/Default customer population ................................................................ 39

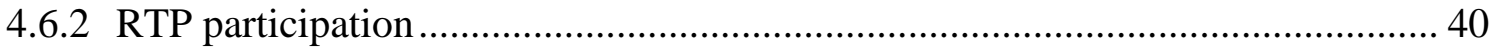

4.7 Price Response from RTP Participants .......................................................................... 42

4.8 Other DR Mechanisms for Large C\&I Customers .......................................................... 44

4.8.1 DR programs and interruptible service rates ..................................................... 44

4.8.2 DR program participation and demonstrated load reductions ............................... 47

5. Demand Response from Competitive Retail Supplier Product Offerings..................................51

5.1 DR-Related Products and Services Offered by Competitive Retail Suppliers................. 52 


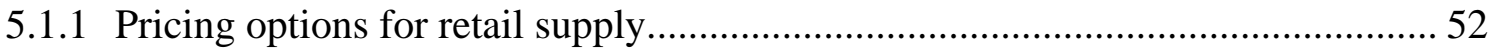

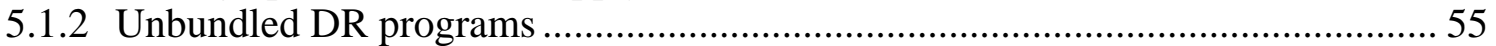

5.1.3 Products and services to build DR capabilities.................................................. 56

5.2 DR from Customers on Spot Market Indexed Contracts with Competitive Suppliers ... 57

5.2.1 Market penetration of spot market indexed pricing and DR programs for retail suppliers ............................................................................................ 57

5.2.2 Estimated total market penetration of spot market indexed pricing in three large

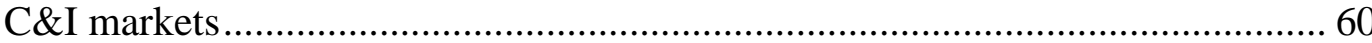

5.2.3 Price responsiveness of customers on spot market indexed contracts................. 62

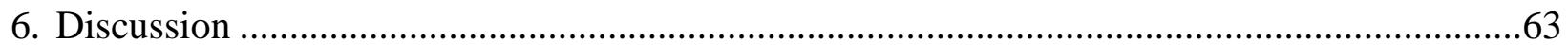

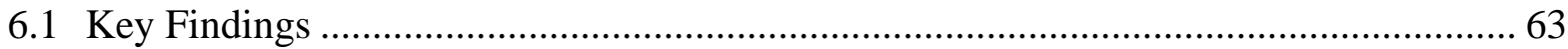

6.2 Policy Implications and Recommendations for Competitive Retail Markets ................ 70

6.3 Policy Implications and Recommendations for Regulated Retail Markets.................... 72

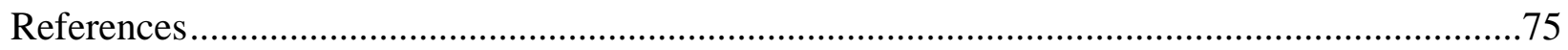

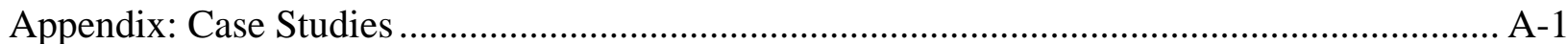

Georgia - Georgia Power Company .......................................................................... A-3

Illinois - Commonwealth Edison............................................................................. A-17

Maryland - All IOUs ................................................................................... A-27

New Jersey - All IOUs ................................................................................... A-36

New York - All IOUs except Niagara Mohawk Power Corporation ............................... A-45

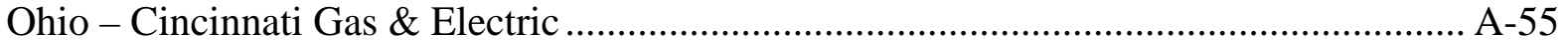

Oregon - Portland General Electric ......................................................................... A-65

Pennsylvania - Duquesne Light Company ................................................................. A-74 


\section{List of Figures, Tables and Text Boxes}

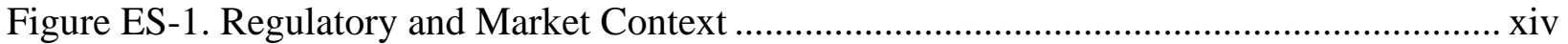

Figure ES-2. Enrollment in Optional RTP Tariffs in Late 2004/Early 2005 .................................

Figure ES-3. Enrollment in Default RTP Tariffs in Late 2004/Early 2005..............................xvii

Figure ES-4. Percent of System Peak Load Exposed to Hourly Spot Market Prices in Three

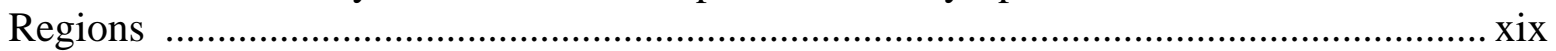

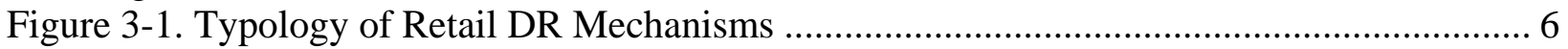

Figure 3-2. Customer populations exposed to price incentives for DR in vertically-integrated

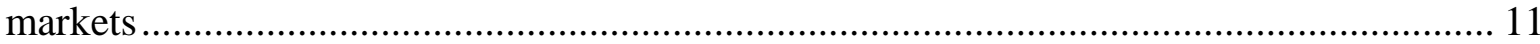

Figure 3-3. Customer populations exposed to price incentives for DR in competitive retail and

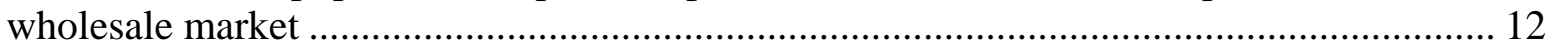

Figure 4-1. Regulatory and Market Context .................................................................... 16

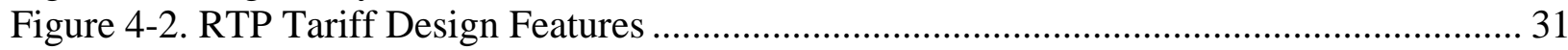

Figure 4-3. Customer Participation Rates in Default RTP in Early 2005................................. 40

Figure 4-4. Customer Participation in Optional RTP in Early 2005 ...................................... 42

Figure 4-5. DR Program Enrollment in 2004 as a Percent of System Peak Load ...................... 49

Figure 4-6. DR Program Maximum Load Reductions as a Percent of System Peak Load .......... 50

Figure 5-1. Estimated Market Penetration of Spot Market Indexed Pricing Arrangements in

Three Large C\&I Markets in Late 2004/Early 2005....................................................... 61

Figure 6-1. Percent of System Peak Load Exposed to Hourly Spot Market Prices in Three

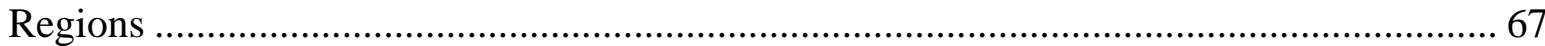

Table ES-1. Eight Case Studies of Default or Optional RTP .................................................. xii

Table 1-1. Eight Case Studies of Default or Optional RTP ..................................................... 2

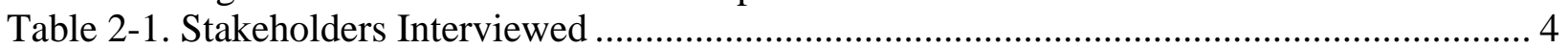

Table 3-1. Unbundled DR Program Features. ..................................................................... 9

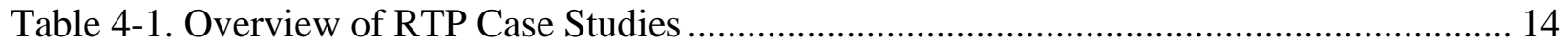

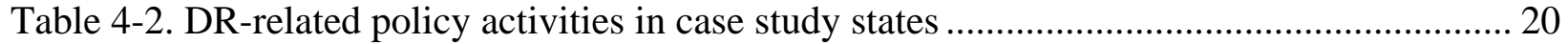

Table 4-3. Regulatory Process for RTP Implementation...................................................... 21

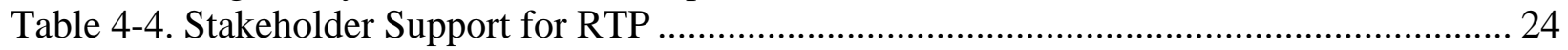

Table 4-5. Customer Size Threshold and Interval Metering Deployment................................... 29

Table 4-6. Publicly- and Ratepayer-Funded Activities Conducted in Support of RTP............... 37

Table 4-7. Optional and Default RTP Customer Population and Participation in Early 2005 ..... 39

Table 4-8. Utility and ISO/RTO DR Programs Applicable to C\&I Customers in 2004 ............. 45

Table 4-9. Demand Response Program Enrollment and Actual Performance............................. 48

Table 5-1. C\&I Market Share of Competitive Suppliers in Sample (2003) ............................... 51

Table 5-2. Retail Supply Pricing Options Offered by Retail Suppliers Interviewed................... 52

Table 5-3. ISO/RTO DR Program Participation among Retail Suppliers Interviewed ................ 56

Table 5-4. Products and Services to Build DR Capabilities .................................................... 57

Table 5-5. Market Penetration of Spot Market Indexed Pricing and DR Programs offered by Competitive Retail Suppliers .............................................................................. 58

Text Box 4-1. Overview of RTP Tariff Pricing Structure ......................................................... 32

Text Box 4-2. PJM and NYISO DR Programs .................................................................... 46

Text Box 6-1. How has Georgia Power been so successful with RTP? ..................................... 64 



\section{Acronyms and Abbreviations}

\begin{tabular}{|c|c|}
\hline ALM & Active Load Management \\
\hline BGE & Baltimore Gas \& Electric \\
\hline C\&I & commercial \& industrial \\
\hline CBL & customer baseline load \\
\hline CG\&E & Cincinnati Gas \& Electric \\
\hline CHG\&E & Central Hudson Gas \& Electric \\
\hline ComEd & Commonwealth Edison \\
\hline ConEd & Consolidated Edison \\
\hline COS & cost of service \\
\hline DADRP & Day-Ahead Demand Response Program \\
\hline DLC & Duquesne Light Company \\
\hline $\mathrm{DR}$ & demand response \\
\hline DRSP & demand response service provider \\
\hline DSM & demand side management \\
\hline EDRP & Emergency Demand Response Program \\
\hline ESCO & energy services company \\
\hline FERC & Federal Energy Regulatory Commission \\
\hline GPC & Georgia Power Company \\
\hline GPSC & Georgia Public Service Commission \\
\hline GW & gigawatt \\
\hline ICAP & Installed capacity \\
\hline ICAP/SCR & Installed Capacity/Special Case Resources \\
\hline ICC & Illinois Commerce Commission \\
\hline IOU & investor-owned utility \\
\hline IRP & integrated resource plan \\
\hline ISO & independent system operator \\
\hline ISO-NE & Independent System Operator - New England \\
\hline JCP\&L & Jersey Central Power \& Light \\
\hline $\mathrm{kW}$ & kilowatt \\
\hline kWh & kilowatt-hour \\
\hline LBNL & Lawrence Berkeley National Laboratory \\
\hline LSE & load serving entity \\
\hline MADRI & Mid-Atlantic Distributed Resources Initiative \\
\hline MDPSC & Maryland Public Service Commission \\
\hline MISO & Midwest Independent System Operator \\
\hline MW & megawatt \\
\hline MWa & average megawatt \\
\hline MWh & megawatt-hour \\
\hline NJBPU & New Jersey Board of Public Utilities \\
\hline NMPC & Niagara Mohawk Power Company \\
\hline NYISO & New York Independent System Operator \\
\hline NYPSC & New York Public Service Commission \\
\hline NYSEG & New York State Electric \& Gas \\
\hline NYSERDA & New York State Energy Research and Development Authority \\
\hline O\&R & Orange \& Rockland \\
\hline
\end{tabular}




$\begin{array}{ll}\text { OII } & \text { order instituting investigation } \\ \text { OIR } & \text { order instituting rulemaking } \\ \text { OPUC } & \text { Oregon Public Utilities Commission } \\ \text { PGE } & \text { Portland General Electric } \\ \text { POLR } & \text { provider of last resort } \\ \text { PPUC } & \text { Pennsylvania Public Utilities Commission } \\ \text { PSC } & \text { public service commission } \\ \text { PSE\&G } & \text { Public Service Electric \& Gas } \\ \text { PUC } & \text { public utilities commission } \\ \text { PUCO } & \text { Public Utilities Commission of Ohio } \\ \text { RG\&E } & \text { Rochester Gas \& Electric } \\ \text { RTO } & \text { regional transmission organization } \\ \text { RTP } & \text { real time pricing } \\ \text { T\&D } & \text { transmission \& distribution } \\ \text { TOU } & \text { time of use }\end{array}$




\section{Executive Summary}

Demand response (DR) is broadly recognized to be an integral component of well-functioning electricity markets, but currently underdeveloped in most regions. In recent years, there has been renewed interest among a number of public utility commissions (PUC) and utilities in implementing real-time pricing (RTP), typically for large commercial and industrial (C\&I) customers, as a strategy for developing greater levels of DR. Such efforts typically face a set of key policy and program design issues, including:

- How to organize the process for developing and implementing RTP in a manner that facilitates productive participation by the relevant stakeholder groups;

- Whether to designate RTP as an optional or default service, and for which customer classes; ${ }^{1}$

- What type of tariff design to adopt given prevailing policy objectives, wholesale market structure, ratemaking practices and standards, and customer preferences; and

- What types of supplemental activities (e.g., customer education, deployment of enabling technologies) are appropriate to facilitate customer participation and price response. Given resolution of these design and implementation issues, a key question for policymakers is how much DR can ultimately be expected from RTP, which requires analyzing customers' willingness to be exposed to dynamic hourly prices over a sustained time period and their actual price responsiveness.

State agencies, utilities, and customer groups in California have been engaged in an ongoing process to develop retail mechanisms for DR, including consideration of utility RTP tariffs. To provide information to policymakers and stakeholders in California and other jurisdictions, we conducted a comparative review of eight case study states where RTP has been implemented as a default and/or optional service for commercial and industrial (C\&I) customers. Each state has established some form of retail competition, although there are significant differences in regulatory and market environments.

For each case study, we reviewed related regulatory filings and other public documents and interviewed PUC staff, utilities, and competitive retail suppliers active in that state. We summarize and identify key trends related to:

- $\quad$ The policy context and objectives underlying RTP implementation;

- The regulatory process used to design and implement RTP;

- The level of support from and key positions of stakeholder groups;

- $\quad$ The RTP tariff structure;

- Enabling technology deployment and customer education efforts conducted to support RTP implementation;

- $\quad$ Enrollment in RTP and price response from participating customers;

- Utility and ISO/RTO DR program enrollment and load reductions; and

- $\quad$ DR impacts of products and services offered by competitive retail suppliers.

Drawing from these findings, we identify and discuss recommendations for policymakers seeking to support the development of DR in both competitive and regulated retail markets.

\footnotetext{
${ }^{1}$ We use default service to refer to any rate on which customers are automatically placed if they do not affirmatively choose some other option; and we use optional service to refer to any rate on which customers are placed only if they affirmatively choose that option. Said differently, an optional service is one where a customer must opt in. A default service is one where a customer would have to opt out, if such an option is offered.
} 


\section{ES-1. Overview of Case Studies: Regulatory and Market Context}

The eight case studies profiled in this report include default and optional RTP tariffs that have been adopted either by individual utilities or all investor-owned utilities in a particular state (see Table ES-1).

Table ES-1. Eight Case Studies of Default or Optional RTP

\begin{tabular}{|llcc|}
\hline \multicolumn{1}{|c}{ State } & \multicolumn{1}{c}{ Utilities } & Default RTP & Optional RTP \\
\hline New Jersey & All investor-owned utilities & Implemented (2003) & Implemented (2003) \\
\hline Maryland & All investor-owned utilities & Implemented (2005) & Implemented (2004) \\
\hline Pennsylvania & Duquesne Light Company (DLC) & Implemented (2005) & - \\
\hline New York & Niagara Mohawk Power Company (NMPC) & Implemented (1998) & - \\
\cline { 2 - 4 } & All other investor-owned utilities & Considered (2003) & Implemented (2001) \\
\cline { 2 - 4 } & Central Hudson Gas \& Electric (CHG\&E) & Implemented (2005) & Implemented (2001) \\
\hline Illinois & Commonwealth Edison (ComEd) & Planned (2006) & Implemented (1998) \\
\hline Ohio & Cincinnati Gas \& Electric (CG\&E) & Implemented (2005) & Proposed (2003) \\
\hline Oregon & Portland General Electric (PGE) & - & Implemented (2004) \\
\hline Georgia & Georgia Power Company (GPC) & - & Implemented (1992) \\
\hline
\end{tabular}

In six states (New Jersey, Maryland, Pennsylvania, New York, Illinois, and Ohio), full retail access is currently in place for all customers of the investor-owned utilities (IOU). In Oregon, only non-residential customers currently have retail choice. And in Georgia, a limited form of retail competition was established in 1973, whereby most new facilities with a connected load $>900 \mathrm{~kW}$ have a one-time choice of supplier, and the state's regulated IOUs are allowed to compete for this load.

New Jersey: In 2003, RTP became the only supply option for customers in the high voltage classes that had not contracted with a competitive supplier. In 2004 and 2005, the size threshold for default service RTP was reduced to $1,500 \mathrm{~kW}$ and $1,250 \mathrm{~kW}$, respectively. For other, smaller C\&I customers, the default service is an auction-based fixed-price rate although they are allowed to voluntarily opt onto RTP.

Maryland: In July 2002, RTP became the only supply option for customers of Baltimore Gas \& Electric (BGE) with a peak demand $>1,500 \mathrm{~kW}$ that had not contracted with a competitive supplier. This tariff was then supplanted by a statewide default service beginning in July 2004. All customers with a peak demand $>600 \mathrm{~kW}$ in Maryland were offered a temporary fixed-price default service for one year. During this period, RTP was available to customers in this class as an optional service. When the fixed price default service for customers $>600 \mathrm{~kW}$ ended in June 2005, RTP then became the default service for this group of customers.

Pennsylvania: In 2005, RTP became the default service for customers of Duquesne Light Company (DLC) with a peak demand $>300 \mathrm{~kW}$. An auction-based, fixed-price option is also available to this customer class, as an alternative to RTP, until mid-2007.

New York: RTP is currently the only utility supply option for Niagara Mohawk Power Company (NMPC) customers with a peak demand $>2,000 \mathrm{~kW}$ that have not switched to a competitive supplier. Since 2001, RTP has been offered as an optional service by the state's other five IOUs, 
and in 2003, the NYPSC considered making RTP mandatory for some of their customers, but decided against doing so. In 2005, the NYPSC adopted a proposal by Central Hudson Gas \& Electric (CHG\&E) to make RTP the only utility supply option for its customers with a peak demand $>1,000 \mathrm{~kW}$ that have not switched to a competitive supplier.

Illinois: ComEd has offered RTP as an optional service for all non-residential customers since 1998. In 2003, RTP became the only utility supply option for new ComEd customers with a peak demand $>3,000 \mathrm{~kW}$; and in 2007, it will become the only utility supply option for all ComEd customers with a peak demand $>3,000 \mathrm{~kW}$ (new and existing).

Ohio: In 2003, Cincinnati Gas \& Electric (CG\&E) proposed a portfolio of utility supply options, including several optional RTP tariffs, to be offered following the end of their rate cap period. This proposal was not adopted and, instead, a "market-based" fixed-price rate was adopted as the only utility supply option for customers with a peak demand $>100 \mathrm{~kW}$ as of January 2005. RTP was adopted as the only utility supply option for customers returning to CG\&E from a competitive supplier after that date.

Oregon: In 2004, Portland General Electric (PGE) introduced an optional RTP tariff for customers with a peak demand $>1,000 \mathrm{~kW}$. It is currently a pilot and is limited to a maximum of six customers.

Georgia: Georgia Power Company (GPC) began offering RTP in 1992 and currently offers two optional RTP tariffs, one with day-ahead price notice available to customers with a billing demand $>250 \mathrm{~kW}$ and another with hour-ahead price notice available to customers with a billing demand $>5,000 \mathrm{~kW}$.

The policy context surrounding implementation of RTP as well as the retail/wholesale market structure and status differs somewhat among the cases (see Figure ES-1). The basic context in states where default RTP was adopted was that the state's transition period, during which the utility offered an administratively-determined supply option after restructuring, was coming to an end. This condition prompted some type of regulatory process to establish the terms of the supply service to be provided thereafter to customers not taking their supply from a competitive retail supplier. As such, the primary policy objective guiding this process was to support retail market development; and DR was at most a secondary objective, although in many of these states it was being actively pursued through parallel policy initiatives.

In contrast, the optional RTP tariffs adopted by PGE and by IOUs in New York were developed in what might be broadly characterized as a resource planning or resource adequacy context, and the potential for RTP to induce DR was the key driving force behind its implementation.

Lastly, GPC developed its optional RTP tariffs in a rather unique context. Prior to introducing RTP, GPC offered a curtailable (i.e., interruptible) rate for large C\&I customers, whereby customers purchased their non-firm load at fixed, marginal cost-based prices, and the utility could call for curtailments for reliability and economic reasons. Facing the prospect of increased economic curtailment hours in the early 1990s, the utility developed its initial RTP pilot as an experimental rate design that would allow customers to continue purchasing a portion of their load at marginal cost based prices, but that would allow customers to buy-through economic curtailment periods at the utility's short-run avoided cost. As GPC’s RTP program has grown 
and matured, the utility has also recognized its value as a tool for load management, recruitment of new customer load, and economic development.

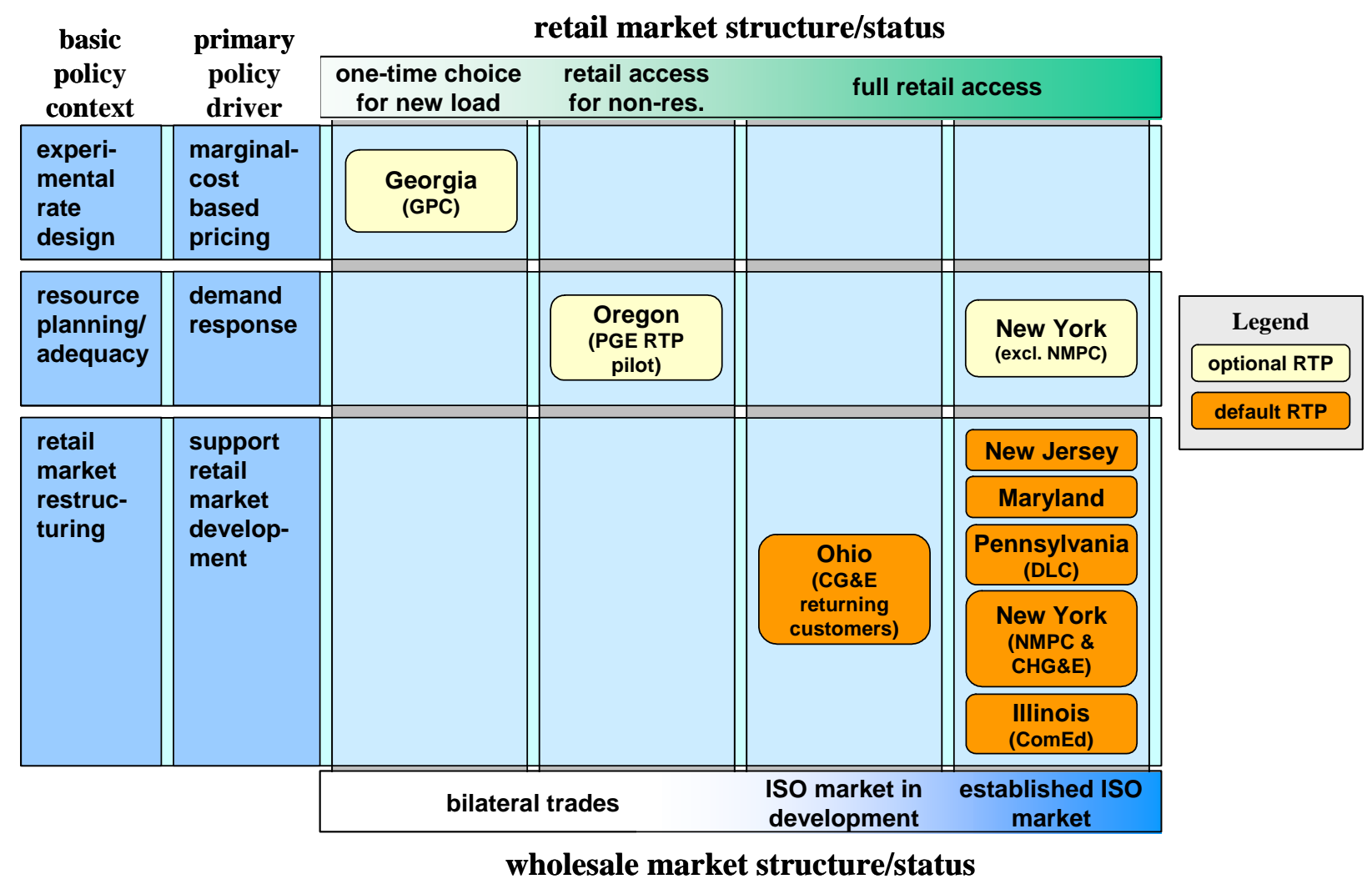

Figure ES-1. Regulatory and Market Context

\section{ES-2. RTP Tariff Design}

The eight case studies represent a range of RTP tariff designs. Most of the RTP tariffs have a one-part commodity charge, where customers face hourly prices for all of their hourly usage, with additional, unbundled billing components (i.e., demand charges or other volumetric charges) for non-commodity related costs. GPC and PGE are the only cases involving a twopart, CBL-based RTP tariff design. ${ }^{2}$ A key difference between these two tariffs is the procedure used to set and maintain each customer's baseline load (CBL). In PGE's case, each customer receives a CBL at the time of their enrollment that represents their typical hourly usage pattern, and the tariff specifies that the utility will review each customer's CBL every three years and may make adjustments. In GPC's case, all participants are allowed to maintain their CBL indefinitely over the term of their service, even if they permanently increase their load. Also, some customers are able to receive, at the time that they initially enroll in RTP, a CBL that is less than their typical usage level. First, customers that were previously on the utility's Supplemental Energy tariff were able to receive a CBL equal to their previous firm service level,

\footnotetext{
${ }^{2}$ With this type of tariff design, each participant is assigned an individual customer baseline load (CBL) profile, which consists of a set of hourly loads for a full year. The participant's monthly bill is calculated by applying the standard, non-RTP tariff billing components to the customer's CBL, and applying hourly prices to the difference between the customer's actual usage and its CBL in each hour.
} 
if they switched to RTP. Second, industrial customers with new load receive, by default, a CBL equal to $60 \%$ of their projected load if they enroll in RTP. Finally, all new customers (industrial and commercial) can receive a CBL below their default level if they can demonstrate an ability to shed their load by a proportional amount over a two hour period or if an another facility with the same footprint (e.g., another outlet of a particular retail chain) has already performed such a demonstration.

The hourly prices for each RTP tariff are typically derived from the most transparent of three different types of sources: the clearing price in a centralized spot market administered by an independent system operator or regional transmission organization (ISO/RTO); proprietary indices of bilateral bulk power transactions at regional trading hubs; or internal calculations by the utility of their marginal operating cost (the utility's "system lambda”). The RTP tariffs provide participating customers with different degrees of advance notice of hourly prices. The RTP tariffs adopted in New Jersey, Maryland, and Pennsylvania are all indexed to the PJM real time spot market, where hourly prices are determined after-the-fact; thus participating customers do not have any advance notice of firm hourly prices, although they could use day-ahead market prices as a proxy. Most of the other RTP tariffs provide day-ahead advance notice.

\section{ES-3. Key Findings: DR Impacts of RTP and Other DR Mechanisms}

Various mechanisms can be implemented at the retail level to induce DR from electricity consumers, including: RTP offered by utilities, spot market indexed pricing options offered by competitive retail suppliers, and DR programs offered by ISO/RTOs and/or utilities. The impact of each mechanism on the development of DR depends on, first, how much load is exposed to that particular mechanism and, second, how price responsive those customers are.

(1) With the exception of Georgia Power, optional RTP tariffs have generated limited levels of participation.

In five of the six optional RTP tariffs included in our case studies, less than $2 \%$ of the eligible customers have enrolled. In contrast, more than $40 \%$ of eligible customers have enrolled in GPC's RTP tariffs, comprising more than $80 \%$ of the eligible load (see Figure ES-2). The notable success of GPC can be attributed to a number of factors, namely: most customers on RTP can reasonably expect to achieve long-run bill savings, regardless of whether or not they are price responsive; GPC has aggressively marketed RTP for more than a decade to a broad group of C\&I customers; and their tariff design allows customers to hedge a portion of their load at a fixed price. 


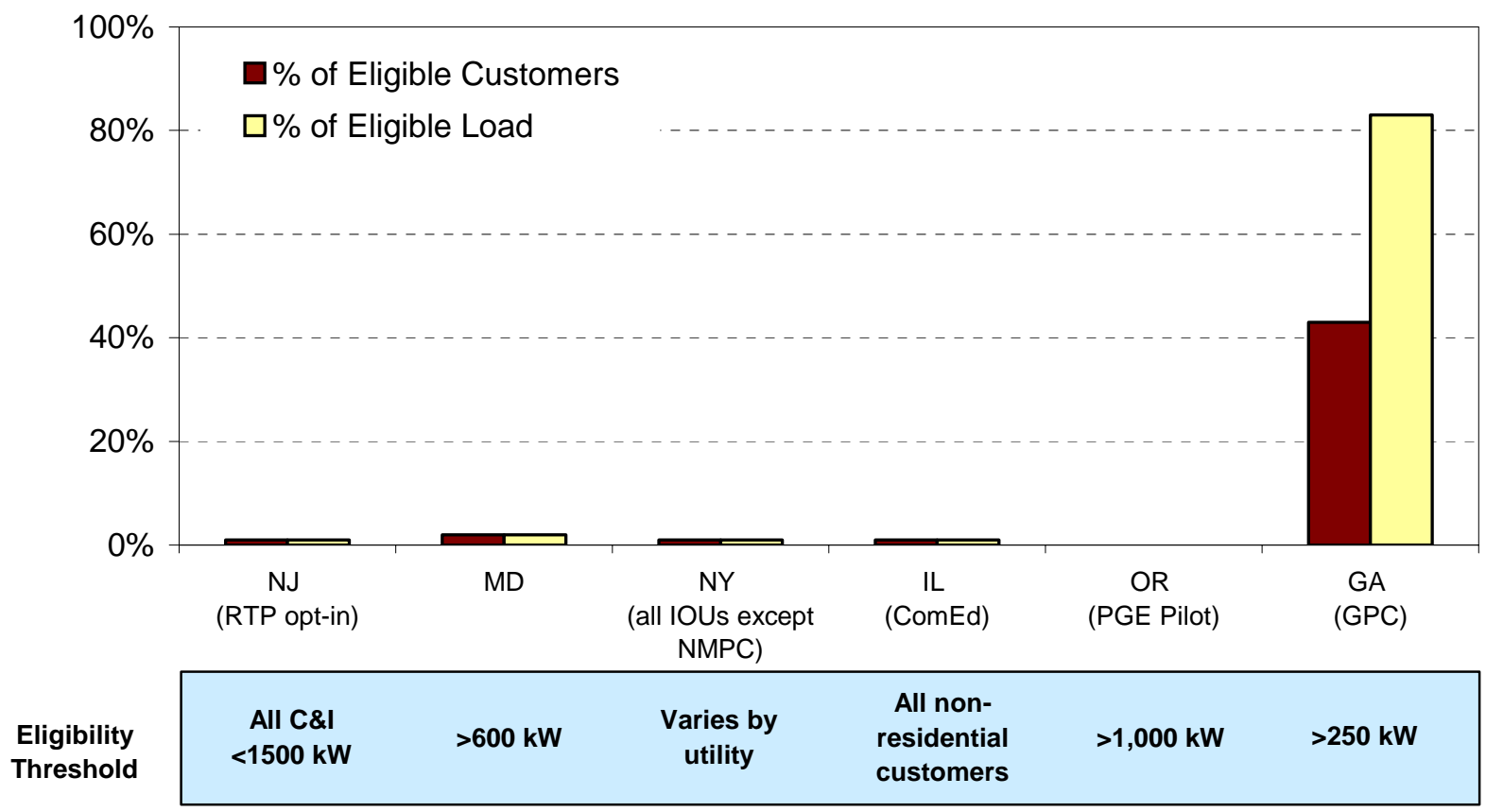

Figure ES-2. Enrollment in Optional RTP Tariffs in Late 2004/Early 2005

(2) In each of the three default RTP tariffs in place in early 2005, most of the load has switched to a different supply option, although the percentage remaining on RTP varies significantly.

In DLC's service territory, only 3\% of the load in the default RTP class is enrolled in RTP, while $34 \%$ and $16 \%$ of the load in the default RTP classes in NMPC's service territory and New Jersey, respectively, have remained on RTP (see Figure ES-3). Differences in participation rates among these three cases may reflect a number of factors related to tariff design and retail market development, such as: the amount of advance notice with which customers have knowledge of hourly prices (day-ahead for NMPC vs. after-the-fact for New Jersey and DLC); the availability of an alternative fixed price supply option with the utility (which only DLC offers); the size of the default RTP threshold (300 kW for DLC, compared to 1,500 kW and 2,000 kW for New Jersey and NMPC, respectively); and the availability of competitive retail supply offers. 


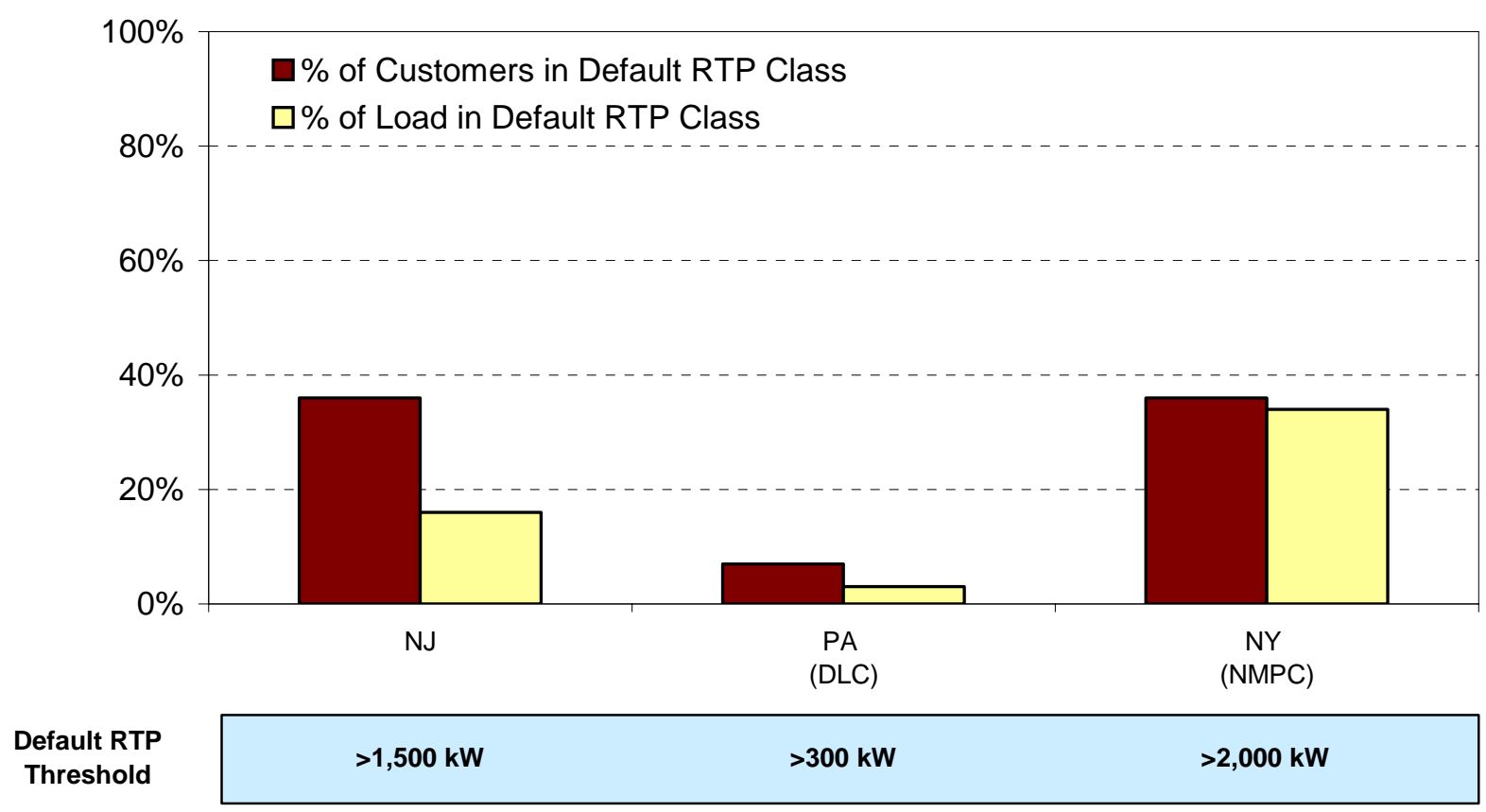

Figure ES-3. Enrollment in Default RTP Tariffs in Late 2004/Early 2005

(3) The case studies revealed several indirect impacts that default RTP might have on the development of DR in competitive retail markets; however more formal analysis is needed before firm conclusions can be drawn.

The case studies highlight three plausible (but untested) indirect positive impacts that default RTP might have on the development of DR in competitive retail markets. First, having RTP as the default service may create demand for spot market indexed pricing options offered by competitive suppliers that otherwise might not evolve, because customers use the default rate as a benchmark and seek out competitive supply contracts with a comparable pricing structure but lower prices. ${ }^{3}$ Second, customer demand for spot market indexed pricing may also be enhanced as a result of customer experience on default RTP and education/training activities conducted in concert with default RTP implementation. Third, several states have deployed interval meters across a wide population of C\&I customers as part of default RTP implementation, which facilitates customers being exposed to hourly prices.

(4) Competitive retail suppliers reported a wide range of values for the market penetration of spot market indexed pricing options, ranging from 5\% to $75 \%$ of their C\&I load in different regions.

The eight competitive retail suppliers interviewed for this project provided information on the penetration of spot market indexed pricing arrangements (i.e., a full pass through of spot market prices for all commodity requirements and block-and-index pricing arrangements) among large C\&I customers in various regions. The three suppliers that reported market penetration rates for New Jersey, specifically, indicated that a relatively large fraction (50-75\%) of their large C\&I

\footnotetext{
${ }^{3}$ In the case of default RTP service, competitive suppliers may be able to offer lower prices for ICAP or ancillary services charges, or a smaller mark-up on commodity charges than the default service retail adder.
} 
load in the state has opted for a spot market indexed supply contract. The values that suppliers reported for other regions varied between 5\% and 25\%. Several factors may account for the differences in reported market penetration rates, including: the customer size threshold used to define the large C\&I market in different regions (i.e., 1,500 kW in New Jersey vs. $600 \mathrm{~kW}$ in Maryland), the types of C\&I customers targeted by particular suppliers, regional differences in the mix of customers, and the availability of hedged utility supply options. Many of the suppliers we interviewed indicated their belief that much of the current interest in spot marketindexed products was temporary, due to low spot market volatility and mild weather, and that more customers would start locking-in fixed price contracts if price volatility increases.

(5) From one to ten percent (1-10\%) of the system load in several retail markets appears to be exposed to spot market prices, although there is significant uncertainty in these estimates.

Very little information is available in the public domain about the amount of load in competitive retail markets that faces hourly spot market prices through their retail supply contract. To fill this void, we developed lower and upper bound estimates of the amount of load that has switched to spot market indexed contracts with a competitive retail supplier in three large C\&I markets: the New Jersey CIEP class (all customers $>1,500 \mathrm{~kW}$ ), the Maryland Type III class (all customers $>600 \mathrm{~kW}$ ), and the NMPC SC-3A class (all customers $>2,000 \mathrm{~kW}$ ). We combined these estimates with data on enrollment in optional and/or default RTP tariffs offered by utilities in these states, in order to derive an estimate of the total load in each state exposed to hourly spot market prices. ${ }^{4}$

Based on this approach, we estimate that, as of early 2005, 1-4\% of the system peak load in Maryland, 6\% in NMPC's service territory, and 6-10\% in New Jersey was facing hourly spot market prices through either a utility RTP tariff or a retail supply contract with a competitive provider (see Figure ES-4). One key driver for the relatively low percentage of system peak load exposed to spot market prices in each of these markets is that the default RTP class only accounts for $10-20 \%$ of the total system load. The relatively low exposure to spot market pricing in Maryland primarily reflects the fact that, during the period for which these estimates were developed, RTP was an optional service for large C\&I customers in Maryland but was the default service for large C\&I customers in the other two regions.

\footnotetext{
${ }^{4}$ Note that we do not include in this analysis any estimate of the amount of load exposed to spot market indexed competitive supply contracts among customers smaller than the default RTP size threshold.
} 


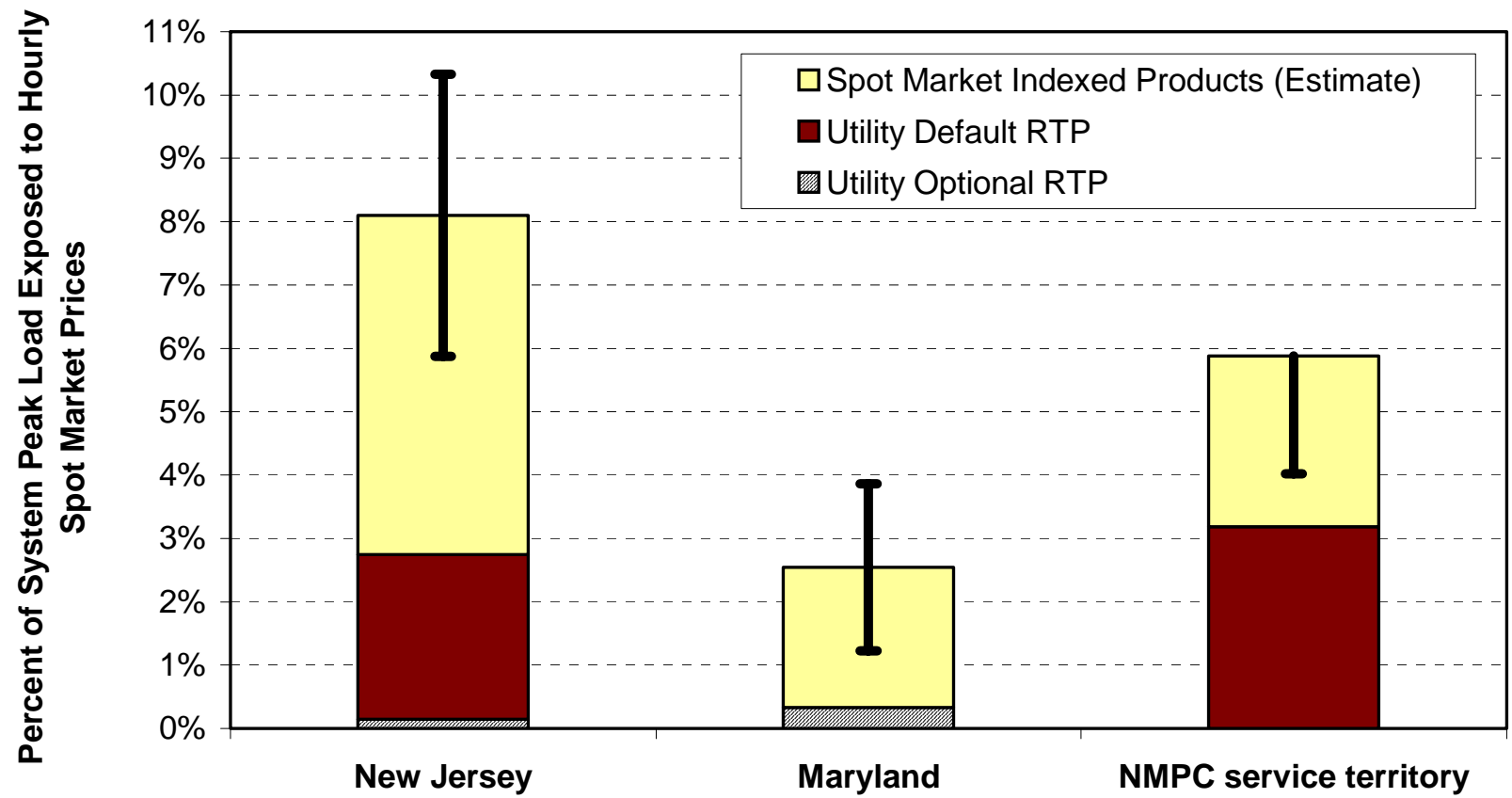

Figure ES-4. Percent of System Peak Load Exposed to Hourly Spot Market Prices in Three Regions ${ }^{5}$

(6) RTP tariffs that provide advance notice of prices have elicited load reductions in the range of $10-15 \%$ of participants' aggregate billing demand at very high prices.

Of the case studies examined in this report, formal analyses of customers' price responsiveness have been performed only for NMPC and GPC. Goldman et al. (2005) estimated the price elasticity of customers in NMPC's default RTP class using five years' of hourly billing data. NMPC customers are expected to reduce their load by an amount equal to approximately $10 \%$ of their combined billing demand, when peak period prices are five times greater than off-peak prices (e.g., a peak period price of $\$ 0.50 / \mathrm{kWh}$ and an off-peak price of $\$ 0.10 / \mathrm{kWh}$ ). Based on the amount of load remaining on NMPC's RTP tariff in 2004, this load reduction corresponds to approximately $0.3 \%$ of the utility's system peak.

Braithwait and O'Sheasy (2001) estimated the price elasticities of customers on GPC's RTP tariffs. RTP participants reduced their load by approximately $750 \mathrm{MW}$ in total when hourly prices were very high (i.e. maximum of $\$ 1.93 / \mathrm{kWh}$ for the day-ahead RTP rate and over $\$ 6.00 / \mathrm{kWh}$ for the hour-ahead RTP rate). This peak load reduction represents about $\sim 15 \%$ of the customer's aggregate billing demand and $~ 5 \%$ of the utility's system peak load.

(7) Little is currently known about the price responsiveness of customers participating in RTP tariffs that are indexed to real time spot markets.

\footnotetext{
${ }^{5}$ For New Jersey and Maryland, the vertical bars represent our upper and lower bound estimates for the amount of load exposed to spot market prices through a competitive supply contract, and the yellow bar represents the average of these two values. For NMPC, the yellow bar represents our best estimate of the amount of load exposed to spot market prices through a competitive supply contract, and the single vertical bar is our lower bound estimate. See Section 5.2.2 for further details.
} 
The RTP tariffs that have been recently implemented in New Jersey, Maryland, and DLC's service territory employ prices that are indexed to the PJM real time spot market, and these prices are not known until after the applicable hour has elapsed. To date, no formal evaluations have been conducted to assess the extent to which customers remaining on these default RTP tariffs respond to hourly prices. Thus, without any analysis, no definitive conclusions can be drawn at this point about the extent to which RTP tariffs of this type might induce price response. Utility and regulatory staff in New Jersey, Maryland, and Pennsylvania generally doubted whether customers on RTP in their state actively monitor or respond to hourly prices.

(8) Little is currently known about the price responsiveness of customers that purchase their supply through a spot market indexed contract with a competitive retail supplier.

Most of the competitive retail suppliers we interviewed stated their belief that the vast majority of customers on spot market indexed pricing options do not monitor or respond to hourly prices, although none of the suppliers had systematically examined the question. Accordingly, they indicated that, for the most part, they do not account for price response from customers facing hourly spot market prices in their scheduling and procurement activities. In general, competitive retail suppliers do not currently view spot market indexed pricing options in terms of an opportunity for customers to reduce their energy costs through responding to hourly prices. Suppliers typically do not focus on DR in marketing these service offerings, except perhaps to customers with onsite generation. And the suppliers offer few services to assist customers with responding to hourly prices. This lack of emphasis on DR in relation to spot market indexed pricing may partly reflect the relatively stable prices characteristic of current market conditions.

(9) A variety of DR programs offered by utilities and ISO/RTOs have demonstrated the ability to elicit load reductions in the range of $1-3 \%$ of the respective entities' system peak.

In all of the case studies, utilities or an ISO/RTO offers a variety of DR programs to C\&I customers. In 2004, participation in most of these DR programs (reported in terms of customers' contracted or nominated load reduction quantity) was in the range of $1-4 \%$ of the utility or statewide system peak load. ${ }^{6}$ Operational activity in many programs has been limited in recent years due to an absence of system reliability contingencies and/or low spot market prices. Those DR programs for which recent performance data are available have demonstrated load reductions in the range of $1-3 \%$ of the system peak.

\section{ES-4. Policy Implications for Competitive Retail Markets}

(1) Day-ahead default RTP can be an effective strategy for simultaneously meeting retail market development and DR-related goals.

RTP has been adopted as the default service in a number of states primarily to facilitate retail market development, because it always reflects current market conditions, does not require the use of class average load profiles for setting the commodity charge, and is does not require imposing switching restrictions. At the same time, default service RTP also has the potential to

\footnotetext{
${ }^{6}$ Note the difference in how participation is reported for DR program compared to RTP - i.e., customers' contracted or nominated load reduction as opposed to customers' combined billing demand or coincident peak demand.
} 
stimulate DR, both from customers that remain on the default service and from those that seek out a competitive supply arrangement with a similar pricing structure to the default service. Evidence to date suggests that default RTP tariffs that are indexed to the day-ahead energy market may be more effective at stimulating DR than default RTP tariffs that are indexed to the real-time spot market, because the former provides customers with a greater level of advance notice.

(2) State regulators and utilities should consider installing interval meters over a wider population of C\&I customers than just the default RTP class, and should also consider including features in the metering infrastructure that facilitate DR.

Large scale deployment of interval metering among C\&I customers has been conducted in several states to support implementation of default RTP. Such efforts represent another opportunity to leverage DR goals with retail market restructuring activities, in this case by installing interval meters across a wider customer population than the default RTP class, as was done in New Jersey, and by specifying metering systems with features that facilitate price response. ${ }^{7}$ Policymakers should consider whether these incremental measures are warranted, in light of the potential benefits they could yield in terms of the development of DR (e.g., by facilitating participation in ISO/RTO DR programs and/or bolstering the price responsiveness of customers facing hourly spot market prices through default RTP or a competitive supply contract).

(3) Rigorous collection and analysis of data related to customer exposure and response to spot market-indexed competitive supply contracts is needed.

A variety of policy and planning decisions (e.g., related to continuation of wholesale market price caps or certain types of DR programs) hinge upon assumptions about the price responsiveness of retail electricity consumers. Yet, little information is currently being collected in regulated or competitive markets to measure how and why customers respond to prices. Federal and state regulators and ISO/RTOs should consider undertaking efforts to regularly collect and analyze data on retail customers' supply arrangements and response to hourly pricing and other dynamic pricing options, to support policy and planning decisions that require knowledge about the price responsiveness of retail consumers. Given the sensitive nature of this information, appropriate measures would be required to ensure that data released to the public does not compromise the position of individual suppliers or customers.

(4) The development of DR in competitive retail markets may require addressing market barriers.

Competitive retail suppliers currently offer few services to help customers identify, analyze, or implement load response strategies and report a perceived lack of customer demand for these services. The potential for DR to develop in competitive retail markets will likely be limited in

\footnotetext{
${ }^{7}$ Advanced metering infrastructure features that could enhance DR capability include hardware or software that allow customers to directly access their metered usage data at frequent (e.g., hourly) intervals, meters with data ports that allow customers to directly download data from their meter for an EMCS, EIS, or load control device, and training on optimizing energy information systems (EIS) and energy management control systems for DR applications.
} 
the near-to-mid term without a concerted effort on the part of some entity to help customers develop their load response capabilities. Some set of policy interventions may therefore be warranted to enhance customers' capability and willingness to respond to dynamic prices. In many states that have implemented customer choice, the state regulatory commission and/or utilities have conducted general customer education activities to provide basic information about restructuring and/or default service. Policymakers should consider incorporating into these activities information to help customers better understand the potential cost savings and risk management benefits associated with load response to hourly spot market prices as well as technical information to help customers identify load response strategies. Additional programmatic efforts, such as facility DR audits and financial assistance with DR enabling technologies may also be warranted.

\section{ES-5. Policy Implications for Regulated Retail Markets}

(1) The implications of implementing default RTP in a regulated market, in terms of customer acceptance and DR impacts, depend on what types of hedging options are offered to customers in the default RTP class.

To implement RTP as the default service in regulated retail markets, political considerations are likely to require that customers in the default RTP class be afforded some opportunity to financially hedge their exposure to price risk. One option is to allow customers to opt out of RTP onto an alternative, fixed price rate. Experiences in competitive retail markets where customers have been offered a choice between an unhedged RTP tariff and a full-requirements, fixed price service have suggested that the large majority of customers will choose the fixed price service. Thus, if the goal is to stimulate DR, this approach does not seem particularly promising.

A second option is to structure the default RTP tariff as a traditional two-part RTP tariff, where each customer receives a CBL equal to their historical usage profile. The advantage of this approach is that customers' bills and the utility's revenues are affected only to the extent that customers' usage patterns change. However, the process of developing an hourly load profile for each individual customer to serve as their CBL can be quite time consuming, prone to contention, and, for new customers and others without an established history of interval load data, rather subjective.

A third option, which avoids some of the difficulties associated with the CBL-based tariff design, is to implement a default RTP tariff similar to the block and index type of arrangements available in competitive markets, where customers can nominate blocks of on-peak and off-peak load to purchase at a fixed price and face hourly prices for the remaining portion of their load. Little experience has been accumulated with such an approach in regulated, cost-of-service settings, although a host of potential issues can be identified, such as how to structure the load blocks and how to determine their price (i.e., based on embedded costs or some representation of a market-based risk premium).

(2) If RTP is to provide a significant source of $D R$ in regulated retail markets, the RTP tariff needs to offer, to a wide range of customers, substantial and/or fairly predictable financial benefits compared to fixed price tariff options available to the same customer class. 
A key lesson to emerge from GPC's experience is that, to attract a substantial fraction of the system load to an optional RTP tariff, it may be necessary for the tariff design to incorporate a fairly predictable financial benefit for a large population of customers. Customers benefit from participating in GPC's RTP tariffs in several ways. As with all RTP tariffs, customers can accrue bill savings by adjusting their usage in response to prevailing hourly prices (e.g., shedding load during high priced periods and/or rescheduling load from high to low priced periods). Customers in GPC's program also benefit by maintaining a CBL that is less their typical usage (see Section ES-2), thereby purchasing some portion of their usage (40\%, on average) at marginal cost based prices that, on average, are less than the utility's embedded cost based rates. As a result, many customers can expect bill savings over the long-run that are independent of their load response to high or volatile hourly prices. ${ }^{8}$

Can GPC's approach be directly translated to traditional, regulated retail settings? GPC's practice of offering new customers the option to receive a reduced CBL constitutes a departure from traditional, cost-of-service ratemaking practices by allowing some customers to make a smaller contribution to embedded costs in exchange for accepting greater price risk. ${ }^{9}$ The utility has successfully defended this practice on the grounds that it is necessary for the company to successfully recruit customer choice load, which benefits all ratepayers by spreading embedded costs over a larger amount of load. However, in most monopoly retail markets, where the utility already has the exclusive right to serve new customers, this particular line of reasoning would presumably be less compelling.

A fundamental question for regulators in traditional regulated markets that want to encourage the development of price response, then, is: Can some type of fairly predictable financial benefit for RTP participants be justified on the grounds that all ratepayers benefit from RTP participants' price response or that risk is transferred from other ratepayers to RTP participants? If so, how large of an incentive or discount is warranted (i.e., what is it worth to all ratepayers to have a significant subset of them be price-responsive)? And is that level of financial benefit likely to induce widespread participation in RTP? Finally, how best to structure the incentive? In GPC's case, the discount is provided implicitly by applying a different cost responsibility standard to incremental RTP load than to load billed under other rates. An alternative approach that policymakers may want to consider is to explicitly link the "incentives" offered to customers to enroll in RTP to their response during high price periods.

\footnotetext{
${ }^{8}$ So that customers can shield some of their exposed load from hourly price volatility, GPC also offers a variety of financial hedges ("Price Protection Products") and allows customers to temporarily adjust their CBL up or down, with a resulting charge or credit based on the utility's forecast of marginal costs over the applicable period.

${ }^{9}$ For the purpose of establishing retail rates, Georgia Power allocates embedded costs to RTP customers based on their CBL profile, not their actual load. However, the company determines their long term resource requirements based on RTP customers' total load.
} 



\section{Introduction}

Demand response (DR) has been broadly recognized to be an integral component of wellfunctioning electricity markets, although currently underdeveloped in most regions. Among the various initiatives undertaken to remedy this deficiency, public utility commissions (PUC) and utilities have considered implementing dynamic pricing tariffs, such as real-time pricing (RTP), and other retail pricing mechanisms that communicate an incentive for electricity consumers to reduce their usage during periods of high generation supply costs or system reliability contingencies.

Efforts to introduce DR into retail electricity markets confront a range of basic policy issues. First, a fundamental issue in any market context is how to organize the process for developing and implementing DR mechanisms in a manner that facilitates productive participation by affected stakeholder groups. Second, in regions with retail choice, policymakers and stakeholders face the threshold question of whether it is appropriate for utilities to offer a range of dynamic pricing tariffs and DR programs, or just "plain vanilla” default service. Although positions on this issue may be based primarily on principle, two empirical questions may have some bearing - namely, what level of price response can be expected through the competitive retail market, and whether establishing RTP as the default service is likely to result in an appreciable level of DR? Third, if utilities are to have a direct role in developing DR, what types of retail pricing mechanisms are most appropriate and likely to have the desired policy impact (e.g., RTP, other dynamic pricing options, DR programs, or some combination)? ${ }^{10}$

Given a decision to develop utility RTP tariffs, three basic implementation issues require attention. First, should it be a default or optional tariff, and for which customer classes? Second, what types of tariff design is most appropriate, given prevailing policy objectives, wholesale market structure, ratemaking practices and standards, and customer preferences? Third, if a primary goal for RTP implementation is to induce DR, what types of supplemental activities are warranted to support customer participation and price response (e.g., interval metering deployment, customer education, and technical assistance)?

\section{Project Description}

State agencies, utilities, and customer groups in California have been engaged in an ongoing process to develop retail mechanisms for DR, including consideration of utility RTP tariffs. To provide information to participants in this process, as well as to policymakers and stakeholders in other jurisdictions, Lawrence Berkeley National Laboratory (LBNL) and Neenan Associates conducted a comparative review of eight case study states, representing a cross-section of regulatory and market environments, where RTP has been implemented as a default and/or optional service for commercial and industrial (C\&I) customers (see Table 1-1).

\footnotetext{
${ }^{10}$ The viability of DR programs in the retail market may hinge on how load reductions are valued in the wholesale market, in particular, whether electricity consumers can bid load curtailments into centralized wholesale markets or only participate as price takers, responding to market prices.
} 
Table 1-1. Eight Case Studies of Default or Optional RTP

\begin{tabular}{|lllc|}
\hline \multicolumn{1}{|c}{ State } & \multicolumn{1}{c}{ Utilities } & Default RTP & Optional RTP \\
\hline New Jersey & All investor-owned utilities & Implemented (2003) & Implemented (2003) \\
\hline Maryland & All investor-owned utilities & Implemented (2005) & Implemented (2004) \\
\hline Pennsylvania & Duquesne Light Company (DLC) & Implemented (2005) & - \\
\hline \multirow{2}{*}{ New York } & Niagara Mohawk Power Company (NMPC) & Implemented (1998) & - \\
\cline { 2 - 4 } & All other investor-owned utilities & Considered (2003) & Implemented (2001) \\
\cline { 2 - 4 } & Central Hudson Gas \& Electric (CHG\&E) & Implemented (2005) & Implemented (2001) \\
\hline Illinois & Commonwealth Edison (ComEd) & Planned (2006) & Implemented (1998) \\
\hline Ohio & Cincinnati Gas \& Electric (CG\&E) & Implemented (2005) & Proposed (2003) \\
\hline Oregon & Portland General Electric (PGE) & - & Implemented (2004) \\
\hline Georgia & Georgia Power Company (GPC) & - & Implemented (1992) \\
\hline
\end{tabular}

Based on a detailed review of the regulatory history in these eight states and interviews with key stakeholders, we characterize and compare their experience in terms of the market and regulatory context, implementation process and stakeholder support, tariff design, and actual or anticipated impacts on the development of DR. Drawing from this synthesis, we identify key policy and technical issues and assess the potential role of RTP as a strategy for developing DR in different types of regulatory and market settings.

\section{$\underline{\text { Report Overview }}$}

The remainder of this report is organized as follows:

- Chapter 2 describes our research approach.

- Chapter 3 presents an overview of the key concepts and terminology related to default service and demand response used in this report.

- Chapter 4 presents a comparative summary of the eight case studies, which are included in the report as Appendix A.

- Chapter 5 presents the findings from our interviews with competitive retail suppliers.

- Chapter 6 contains a discussion of policy implications and recommendations.

- Appendix A consists of the eight in-depth case study summaries. 


\section{Approach}

Policymakers that are considering RTP can look to other jurisdictions where similar initiatives have been pursued, to better understand the relevant policy and implementation issues and to gauge their expectations about the likely impacts of RTP. However, the fundamental challenge in undertaking such a comparison is that each jurisdiction represents a unique and complex set of circumstances, which typically must be understood in some detail in order to draw lessons that are applicable more generally or to other specific contexts.

\section{Case Study Design}

We conducted a detailed examination of eight case study regions (i.e., states or utility service territories) where RTP has been implemented or considered as a default or optional service for C\&I customers. Our examination of each case study focused on a number of topical areas, including:

- The retail and wholesale market structure and its stage of development;

- The policy context and objectives underlying RTP implementation;

- The regulatory process used to design and implement RTP;

- The level of support and key positions of stakeholder groups participating in the RTP tariff design and implementation process;

- The RTP tariff structure;

- Interval metering and other enabling technology deployment;

- Customer education and other activities conducted to support participation in RTP and price response from participating customers;

- The impact of RTP on the development of DR (actual or anticipated); and

- The role of other DR mechanisms, including utility DR programs and interruptible tariffs, ISO/RTO DR programs, and dynamic pricing options offered by competitive retail suppliers.

\section{$\underline{\text { Literature Review and Stakeholder Interview Process }}$}

We obtained information on these topics through a detailed review of the public documents related to implementation of RTP and/or default service in each state, including regulatory filings, PUC orders and decisions, legislative documents, reports and studies by state agencies and regional transmission organizations (RTO), utility tariff sheets, trade press articles, and workshop presentations.

We then conducted telephone interviews with PUC staff, utilities, and competitive retail suppliers active in each state (see Table 2-1). The purpose of these interviews was to characterize their views on key policy and technical issues and to obtain information not available in the public domain. For our interviews with regulatory staff and utilities, we targeted those individuals that have been most closely involved in the process of developing and implementing RTP or default service in each state. For our interviews with competitive retail suppliers, we targeted individuals who are responsible, at either the managerial or executive level, for pricing and product design, and also, when possible, senior members of the regulatory affairs department. 
The interviews were conducted using a survey protocol developed for each type of stakeholder group, distributed to interview subjects in advance. The protocols included approximately 25-30 questions related to the case study topical areas listed above. Following each interview, respondents were given an opportunity to review our written interview notes and identify any incorrect or incomplete characterization of their responses.

Table 2-1. Stakeholders Interviewed

\begin{tabular}{|l|c|l|}
\hline \multicolumn{1}{|c|}{ Stakeholder Group } & $\begin{array}{c}\text { Number of } \\
\text { Organizations } \\
\text { Represented* }\end{array}$ & \multicolumn{1}{|c|}{ Description of Sample Frame } \\
\hline Regulatory Staff & 8 & $\begin{array}{l}\text { Interviewed senior staff at PUC in each of the } \\
\text { eight case study states }\end{array}$ \\
\hline Utilities & 10 & $\begin{array}{l}\text { Interviewed one or more utility in each case study } \\
\text { state }\end{array}$ \\
\hline Competitive Retail Suppliers & 8 & $\begin{array}{l}\text { Interviewed major competitive retail suppliers } \\
\text { active in one or more case study state }\end{array}$ \\
\hline
\end{tabular}

* We interviewed multiple individuals at many of these organizations, either jointly or separately, depending on scheduling availability. 


\section{Conceptual Background}

Policy discussions of default service and demand response do not always use consistent terminology or a common conceptual framework. Thus, in the interest of clarity, in this chapter we introduce and define the essential concepts and terminology used in this report.

\subsection{Default Service}

\section{Default vs. Optional Service}

We use the term default service to refer to any retail electricity service onto which customers are automatically placed if they do not affirmatively choose some other option. In other words, customers receive that service unless they opt out, provided that some other option is offered. Conversely, we use the term optional service to refer to any retail electricity service onto which customers are placed only if they affirmatively choose that option. In other words, customers must opt onto the service. This is different from the distinction between mandatory and voluntary service, as a default service is mandatory only in the limiting case where it is provided by a monopoly utility with no alternative rate options or competitive alternatives for the customer class.

\section{Default Service in Competitive Retail Markets}

Default service, as we define it, is applicable in both monopoly and competitive retail markets. However, it often has a more specific meaning in the context of competitive retail markets, referring to the retail supply service onto which customers are placed if they are not under contract with a competitive supplier. It is sometimes used in an even more restricted manner to refer to the retail supply service onto which customers are placed if they are not presently and have never been under contract with a competitive retail supplier. Other terminology, such as Standard Offer Service, Provider of Last Resort (POLR) service, and Basic Generation Service, is used in many of our case study states to refer to the retail supply service provided under either of these conditions. For simplicity, we use the term default service in these cases as well, even though, strictly speaking, they are special cases of the definition stipulated above.

\subsection{Typology of Retail Demand Response Mechanisms}

We use the term demand response (DR) in this report to refer to temporary customer load reductions induced in response to high market prices or system reliability conditions. ${ }^{11,12}$ In this section, we present a hierarchy of the retail mechanisms that can be used to induce customers to reduce their load during such periods. This is distinct from a description of wholesale mechanisms, which relate to the incentives faced by load serving entities (LSE) and other wholesale market participants, to facilitate and encourage demand response. ${ }^{13}$

\footnotetext{
${ }^{11}$ We include the operation of onsite generation in our definition of load reduction.

${ }^{12}$ Broader definitions of demand response have been used elsewhere, e.g., by the U.S. Demand Response Coordinating Council and the New England Demand Response Initiative (NEDRI 2003).

13 There are important interrelationships between wholesale and retail DR mechanisms (as there are between wholesale and retail market structures, more generally).
} 
At the highest level, we distinguish between financial and non-financial retail DR mechanisms. Financial mechanisms consist of a monetary incentive for DR. Non-financial mechanisms, which are not discussed further, include all other forms of inducement (e.g., public appeals or involuntary curtailments). Among financial DR mechanisms, we make a basic distinction between (a) those that communicate a monetary incentive for DR through dynamic pricing of one or more of the components of retail electricity service, and (b) those that communicate the incentive through a separate DR program that is "unbundled" from the provision of retail electricity services (see Figure 3-1).

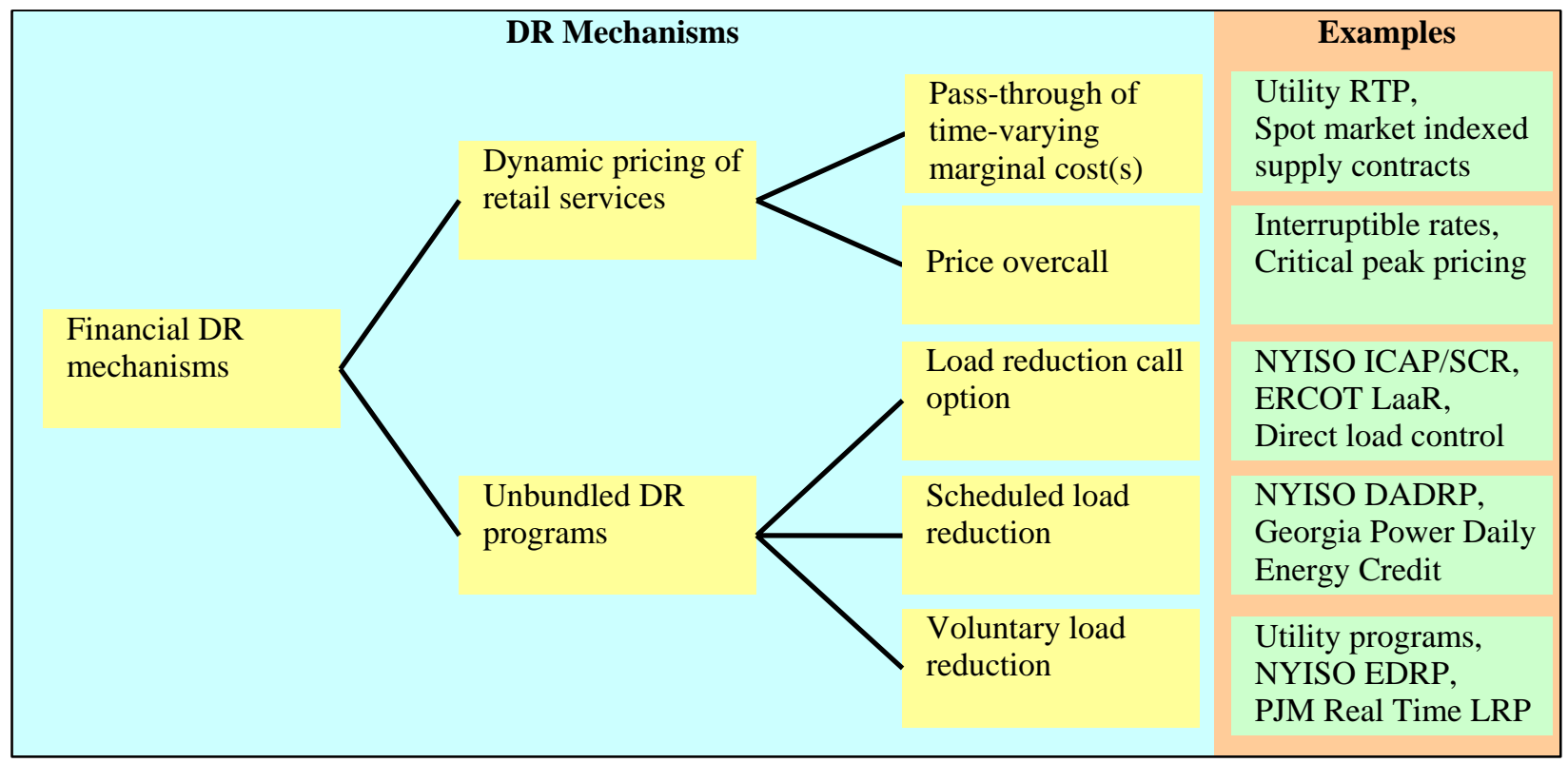

Figure 3-1. Typology of Retail DR Mechanisms ${ }^{14}$

\subsubsection{Dynamic pricing of retail services}

\footnotetext{
${ }^{14}$ Examples include: NYISO ICAP/SCR = Installed Capacity/Special Case Resources; ERCOT LAAR = Load Acting as a Resource; NYISO DADRP = Day-Ahead Demand Response Program; NYISO EDRP = Emergency Demand Response Program; and PJM Real-Time LRP = Real-time Load Reduction Program
} 
Retail electricity service consists of various components that the service provider must either provide directly with company-owned assets or procure. These include: generation supply (which may consist of distinct energy and capacity components), transmission, ancillary services, distribution, and metering and billing. In monopoly retail markets, all of these components are typically provided to the retail customer as a bundled service by the local utility. In competitive retail markets, these services are unbundled, with the local utility providing distribution services, and the other components provided by either a competitive supplier or by the designated default service provider (often the local distribution utility). Whatever type of market structure is in place, load reductions can be induced during periods of high market prices or system reliability contingencies by contemporaneous changes in the price charged to retail customers for one or more components of their retail electricity service - i.e., through dynamic pricing of retail services. Two basic types of dynamic retail pricing mechanisms have been used, which we describe below: a pass-through of time-varying marginal costs and price overcalls.

\section{$\underline{\text { Pass-through of time-varying marginal costs }}$}

Certain components of retail electricity service are characterized by short-run marginal costs that can vary significantly over small time scales (e.g., minutes or hours). Chief among these timevarying marginal costs is the operating cost of electricity generation in a vertically-integrated setting, or analogously, the spot market price of energy in a competitive wholesale environment. In addition, as demand for electricity approaches the limits of generation or T\&D capacity, changes in demand impose a marginal outage cost associated with the incremental increase in the risk of involuntary curtailments. ${ }^{15}$ Retail pricing arrangements that pass through time-varying marginal costs (or some proxy or projection thereof) in real time or near-real time impart a financial incentive for customers to reduce their load when these costs are high. The essential feature of this type of DR mechanism is that the customer faces marginal prices (i.e., the per $\mathrm{kWh}$ change in their bill for incremental changes in usage) that vary over short time intervals.

Real-time pricing (RTP) is the term typically used to describe this type of retail pricing arrangement when offered by a regulated utility. Traditionally, RTP rates offered by verticallyintegrated utilities have passed through the utility's marginal operating cost (fuel and variable O\&M), referred to as their "system lambda". Some utilities have also incorporated adders to capture the marginal outage cost and/or the marginal capacity cost of generation, transmission, or distribution facilities (Barbose et al. 2004). As centralized spot markets have become prevalent, utilities have increasingly offered RTP tariffs that pass through the day-ahead or realtime spot market price. Competitive retail suppliers also offer similar types of pricing options (as discussed in Chapter 5), whereby the customer purchases some or all of the commodity component of their retail supply service at a price that is indexed to the day-ahead or real-time spot market.

$\underline{\text { Price overcall }}$

\footnotetext{
15 The standard definition of the marginal outage cost is the change in Loss of Load Probability multiplied by the
} Value of Lost Load. 
Rather than exposing the customer to prices that change frequently (e.g., every hour), retail electricity services can be priced at a fixed rate with a price overcall option, which gives the service provider the right to temporarily increase the price applicable during a short period of time (e.g., several hours). The classic example of this type of pricing arrangement is an interruptible service tariff, whereby, during utility-specified interruption events, the customer faces a very high price (the non-compliance penalty) for usage above their firm load level. In markets where retail services are unbundled and where the ISO or RTO imposes installed capacity (ICAP) requirements, some LSEs may offer a limited variation of an interruptible service tariff consisting of non-firm pricing for the ICAP component of retail service. ${ }^{16}$ Although interruptible-type pricing options are typically used to respond to reliability events, price overcalls may also be exercised in response to high spot market prices. For example, some competitive retail suppliers offer customized structured contracts, whereby the customer can receive a discounted fixed price for their commodity charge in exchange for giving the supplier the option to overcall that price on some number of occasions (e.g., by passing through the spot market price). Regulated utilities may also offer standardized versions of this type of pricing arrangement, for example critical peak pricing, which is similar to a time-of-use (TOU) rate, except that the utility has the option to overcall the standard on-peak price with a higher “critical-peak” price during some limited number of hours per year.

\subsubsection{Unbundled DR programs}

Unbundled DR programs provide explicit payments for load reductions (or derivatives thereof), which are financially and contractually separate from the provision of any retail electricity service. DR programs can originate in the retail market in one of two ways.

First, ISOs or RTOs may develop and administer DR programs. Very large electricity consumers may be able to directly participate in these programs, however, end-users typically participate in these programs via an intermediary demand response service provider (DRSP) that acts as their agent for transactions with the ISO/RTO and that passes through (some portion of) the DR program payments. Depending on the ISO/RTO DR program rules and structure, different types of entities may be able to serve as a DRSP - not just an individual consumer's LSE, but other LSEs, distribution utilities, dedicated DR aggregators, energy service companies (ESCO), or DR technology vendors. ${ }^{17}$ In theory, the DR programs offered to electricity consumers by DRSPs could have a much different structure than the associated ISO/RTO program; however, in practice, this is usually not the case. ${ }^{18}$

Second, retail electricity service providers (i.e., vertically-integrated utilities, distribution utilities, default suppliers, or competitive retail suppliers) may develop and operate DR programs independent of any ISO program, which they offer exclusively to their customers. In markets where ISO/RTO DR programs are not offered, these are the only types of DR programs available in the retail market. However, even where ISO/RTO DR programs are offered, retail service

\footnotetext{
${ }^{16}$ A customer taking service on such an option is assessed ICAP charges only for their firm load, but is subject to a penalty charge for usage above their firm load level if the ISO/RTO recalls ICAP resources, which occurs during specified system reliability conditions.

${ }^{17}$ We use the term energy service company to refer to an entity that provides energy management related services to retail customers (e.g., energy efficiency improvements, energy management and information systems).

18 Thus, for simplicity, we often refer to individual ISO/RTO-administered DR programs as a proxy for the associated programs available to retail customers.
} 
providers may continue to independently develop and administer DR programs. For example, because ISO/RTO programs do not account for the distribution system benefits of peak period load reductions, a distribution utility might offer its own DR program to respond to distribution system contingencies.

Regardless of which of these two "paths” for retail DR program development are followed, most programs can be distinguished in terms of several basic program features related to the structure of the financial incentive faced by the retail customer - in particular, the nature of the customer's commitment to reduce their load, the form of the payment provided to customers for reducing their load, and whether a penalty is assessed if a customer fails to fully comply with their commitment (see Table 3-1). Based on these program features, we differentiate between three types of unbundled DR programs: load reduction call options, scheduled load reductions, and voluntary load reductions.

Table 3-1. Unbundled DR Program Features.

\begin{tabular}{|c|c|c|c|}
\hline \multirow{2}{*}{$\begin{array}{l}\text { Unbundled DR } \\
\text { Program Type }\end{array}$} & \multicolumn{3}{|c|}{ Key Program Features } \\
\hline & Customer Commitment & DR Payment Form & Penalty Provisions \\
\hline $\begin{array}{l}\text { Load reduction call } \\
\text { options }\end{array}$ & $\begin{array}{l}\text { Standing commitment over a } \\
\text { designated time period to } \\
\text { reduce load upon } \\
\text { notification, subject to } \\
\text { specified limitations }\end{array}$ & $\begin{array}{l}\text { Reservation payments based } \\
\text { on callable load reduction } \\
\text { (MW). Performance } \\
\text { payment may also be } \\
\text { provided based on actual } \\
\text { reductions in energy usage } \\
\text { or average demand (MWh or } \\
\text { MWa) }\end{array}$ & Non-compliance penalties \\
\hline $\begin{array}{l}\text { Scheduled load } \\
\text { reductions }\end{array}$ & $\begin{array}{l}\text { Commitment, made up to } \\
\text { several days in advance, to } \\
\text { reduce load during a specific } \\
\text { time period }\end{array}$ & $\begin{array}{l}\text { Payments for actual or } \\
\text { scheduled reduction in } \\
\text { energy usage (MWh) }\end{array}$ & $\begin{array}{l}\text { Non-compliance penalties } \\
\text { and/or imbalance charges }\end{array}$ \\
\hline $\begin{array}{l}\text { Voluntary load } \\
\text { reductions }\end{array}$ & None & $\begin{array}{l}\text { Performance payments } \\
\text { based on actual reduction in } \\
\text { energy usage or average } \\
\text { demand (MWh or MWa) }\end{array}$ & None \\
\hline
\end{tabular}

\section{Load reduction call option programs}

The distinguishing features of load reduction call option programs are that customers: make a standing commitment over some time period to reduce their load when notified; receive an upfront payment in exchange for this commitment and in some cases additional payments for actual load reductions; and are subject to penalties if they fail to fully comply with load reduction requests. In essence, the customer sells a call option on a particular load reduction quantity, which the entity offering the program can exercise, up to some number of pre-specified occasions, during a designated time frame.

Load reduction call option programs often serve as a capacity resource in the planning operations of the retail service provider or ISO/RTO and, as such, have an exercise period of at least several 
months (e.g., a summer season), if not a year or more. ${ }^{19}$ Both the NYISO and PJM offer programs of this type, as do a number of utilities, which typically have evolved out of their interruptible service tariffs. Many utility direct load control (DLC) programs could also be best categorized as a load reduction call option program, albeit with a number of caveats.

\section{$\underline{\text { Scheduled load reduction programs }}$}

The distinguishing features of scheduled load reduction programs are that customers: make a commitment, typically one day or less in advance, to reduce their load during a specific time period; receive a payment based on their scheduled commitment or actual performance; and are subject to penalties and/or imbalance charges if they do not fulfill their commitments.

NYISO and PJM both offer programs of this type, which allow customers or DRSPs to submit load reduction bids as a resource into the day-ahead energy market. If their bid clears the market, the load reduction is scheduled, and the customer is paid for their scheduled or actual load reduction amount based on the day-ahead locational market clearing price. If the customer (or DRSP) fails to fully deliver the scheduled load reduction, they are assessed imbalance-related charges for the deficient quantity (in NYISO, the higher of day-ahead or real-time spot market price, and in PJM, real time spot market prices and also possibly operating reserve balancing charges).

A few utilities have also offered scheduled load reduction DR programs. These programs generally differ from the NYISO and PJM programs in several ways. First, the transactions generally are initiated by the utility, which notifies participants of the price and/or the specific time period during which it is willing to pay for load reductions; and participants can then choose whether or not to affirmatively accept the offer. Second, customers that fail to perform as scheduled are typically assessed an administratively-determined penalty (similar to an interruptible service tariff), which may or may not reflect the actual cost or value of the replacement energy.

\section{$\underline{\text { Voluntary load reduction programs }}$}

The distinguishing features of voluntary load reduction programs are that customers: make no firm commitment to reduce their load, receive payment based on their actual performance, and are not subject to any penalties. In most programs of this type, the program administrator (e.g., utility or ISO/RTO) designates a "window" during which payments for load reductions are offered. $^{20}$ The "opening” of a load reduction window may be linked to either reliability or market conditions, and is typically designated one day or less in advance. The three eastern ISO/RTOs offer DR programs that provide payments for voluntary load reductions during emergency events declared by the ISO/RTO (typically triggered by inadequate operating reserves). ISO-NE also offers a program that provides payments, based on the prevailing real

\footnotetext{
19 The Electric Reliability Council of Texas (ERCOT) offers the Load Acting as a Resource (LaaR) program, which allows customers to submit load reduction bids into the spot markets for certain ancillary services. A unique feature of this program is that it is a call option load program, but the exercise period may be as short as one day.

${ }^{20}$ PJM's Economic Load Response Program - Real Time Option is a unique example of a voluntary load reduction program, as it has no designated payment window. Rather, participants can receive payments for load reductions occurring at any point in time, based on the prevailing real time spot market price.
} 
time spot market price, for voluntary load reductions occurring on days that the ISO-NE forecasts spot market prices to exceed \$100/MWh. Vertically-integrated utilities have also increasingly developed voluntary load reduction programs to avoid costly off-system purchases and/or to manage system reliability.

\subsection{Accounting for DR Resources}

The retail DR mechanisms described in the previous section represent distinct categories in terms of the structure of the financial incentive faced by the retail customer. However, an individual customer may be exposed to multiple mechanisms simultaneously. Thus, from the perspective of an entity responsible for system operations, planning, or oversight (e.g., utility, ISO/RTO, state or federal regulator), there may be a significant degree of overlap among the various DR mechanisms in terms of the quantity of demand response available in a given market. Naturally, the complexity of this overlap depends on key features of the wholesale and retail market structure. In this section, we describe the two boundary cases: a traditional industry structure with a single, vertically-integrated utility with a monopoly service franchise; and competitive market with competitive retail suppliers, a default service provider, distribution utilities, and an ISO or RTO that administers DR programs.

In a traditional electricity market with a single entity providing all components of the retail electricity service to all customers in a region, and no grid operator or wholesale market administrator to offer wholesale DR programs, accounting for DR resources is relatively straightforward (see Figure 3-2). In this case, the local utility may offer different dynamic pricing options for the bundled retail service as well as separate DR programs. Depending on eligibility rules, some customers may participate in a combination of dynamic pricing options and/or DR programs, for example, an interruptible service tariff and a voluntary load reduction program.

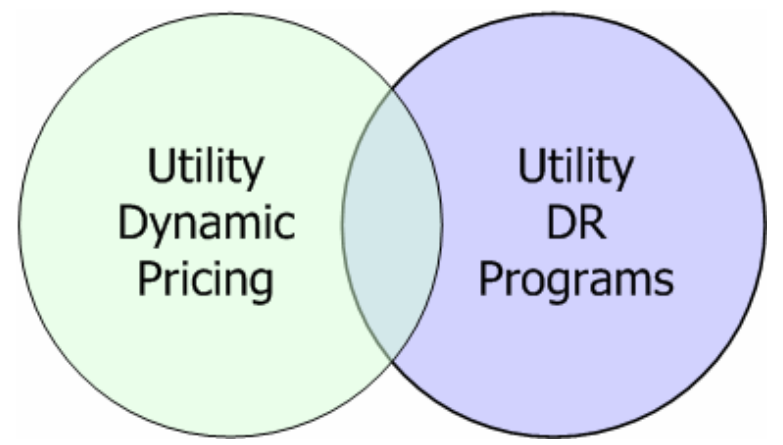

Figure 3-2. Customer populations exposed to price incentives for DR in vertically-integrated markets

In contrast, the picture is considerably more complex in a competitive retail market setting where an ISO or RTO also offers DR programs (see Figure 3-3). Just as in the traditional industry setting, a single customer may be exposed to financial incentives for DR through a combination of dynamic pricing options and unbundled DR programs. However, unlike the traditional industry setting, a multitude of different types of entities may each offer dynamic pricing options and/or unbundled DR programs. In particular:

- $\quad$ DRSPs may offer ISO/RTO DR programs to retail customers. 
- $\quad$ The default service provider may offer dynamic pricing for the commodity portion of default service (e.g., a pass-through of spot market prices). They could also potentially offer unbundled DR programs that are independent of any ISO DR program, for example, if state regulators required that the default service provider engage in a portfolio management process that includes demand-side strategies. ${ }^{21}$

- Competitive retail suppliers may offer various dynamic pricing options and independent unbundled DR programs.

- The distribution utility may also offer dynamic pricing for the distribution service (e.g., an interruptible service tariff) and/or independent unbundled DR programs aimed at maintaining distribution system reliability in a least-cost manner.

In principle, an individual customer could face price incentives for DR from up to three of these entities simultaneously: i.e., a DRSP, their distribution utility, and either the default service provider or a competitive retail supplier.

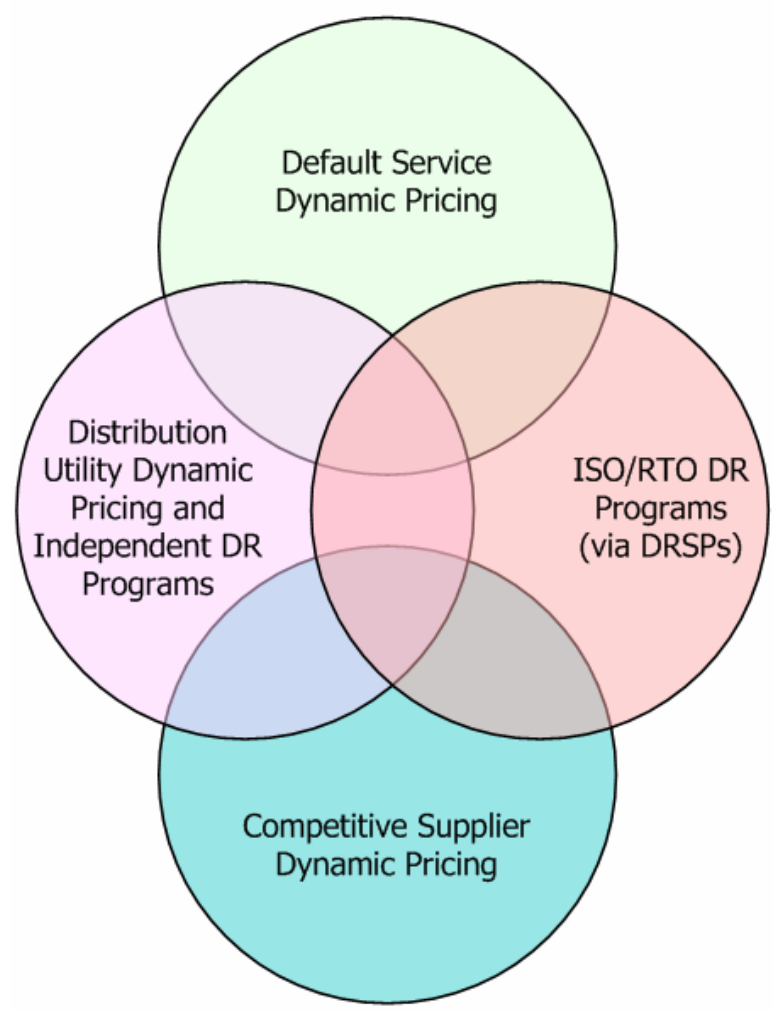

Figure 3-3. Customer populations exposed to price incentives for DR in competitive retail and wholesale markets

\footnotetext{
${ }^{21}$ In practice, the range of DR program options offered by the default service provider may be constrained if policymakers view such options as impeding the development of retail competition.
} 


\section{RTP as a Default or Optional Utility Service: Case Studies}

In this chapter, we examine the experience in eight states with some form of retail competition, where RTP has been implemented or considered for either the default service for large customers or an optional utility service. Drawing upon interviews with state regulatory staff and utilities, and a review of regulatory documents and other literature, we summarize and identify key trends related to:

- the regulatory and market contexts in which RTP was considered in each state;

- the process through which the decision was made to implement RTP and the tariff design was established;

- $\quad$ key positions of stakeholders participating in the RTP implementation process;

- key elements of tariff design and administration;

- customer enrollment in RTP;

- actual or anticipated load reductions from RTP; and

- customer enrollment in, and actual load reductions from, other utility and ISO/RTO DR programs in each state.

This summary is based on the set of case studies included in Appendix A, which contain more in-depth description and discussion of the topics summarized in this chapter. ${ }^{22}$

\subsection{Case Study Overview}

The case studies all share the common feature that they represent an effort in an individual state to implement RTP for C\&I customers taking their retail supply service from an investor-owned utility (IOU). However, they differ from one another in several important respects (see Table 4-1).

Statewide vs. utility-specific. In some case study states, efforts to implement RTP have been statewide, while in others, they have been limited to an individual utility or sub-set of the state's utilities.

Default (opt-out) vs. optional (opt-in). In some states, RTP has been designated or proposed as the default service for a particular customer class; i.e., the rate on which those customers are automatically placed if they do not choose a competitive supply arrangement or another utility rate (if offered). In other cases, RTP has been implemented or proposed as an optional tariff, on which customers are placed only if they affirmatively opt in.

Applicable customer class. Each RTP tariff is applicable to customers larger than some peak demand level, but the size of this threshold varies considerably across the case studies, from 100 $\mathrm{kW}$ to $3,000 \mathrm{~kW}$.

Non-RTP utility supply options. Customers for whom RTP is optional, by definition, have other utility supply options available; customers for whom RTP is the default tariff may also have alternative utility supply options, if only for a temporary period of time. Among the case studies

\footnotetext{
${ }^{22}$ The case study for New York describes the efforts to implement RTP by all of the state's utilities, except Niagara Mohawk Power Company (NMPC); for a detailed review of NMPC's experience with default RTP, refer to Goldman et al. (2005).
} 
where customers have a choice between RTP and other utility rates, the non-RTP options include capped or frozen rates, cost-of-service (COS) based rates, and market-based rates developed from an auction or that pass through the costs, on a class average basis, of direct market purchases over some intermediate time interval (e.g., monthly, seasonally, annually).

Implementation status. RTP has been fully implemented in several of these states, while in others, it has not yet been phased in, and in one case (Ohio), RTP was implemented, but for a much narrower class of customers than initially proposed.

Table 4-1. Overview of RTP Case Studies

\begin{tabular}{|c|c|c|c|c|c|}
\hline State & Utilities & Tariff Type & $\begin{array}{l}\text { Applicable } \\
\text { Customers }\end{array}$ & $\begin{array}{l}\text { Non-RTP Utility } \\
\text { Supply Options }\end{array}$ & History and Status \\
\hline New Jersey & Statewide & Default RTP & $>1250 \mathrm{~kW}$ & None & $\begin{array}{l}\text { Implemented in } 2003 \text { for } \\
\text { high voltage class; expanded } \\
\text { to all C\&I >1,250 kW in } \\
2005 \text {. }\end{array}$ \\
\hline Maryland & Statewide & Default RTP & $>600 \mathrm{~kW}$ & $\begin{array}{l}\text { Auction-based fixed- } \\
\text { price option } \\
\text { (temporary) }\end{array}$ & $\begin{array}{l}\text { Implemented for BGE } \\
\text { Schedule P customer class in } \\
\text { 2002. Implemented } \\
\text { statewide as optional service } \\
\text { in } 2004 \text { and default in } 2005 .\end{array}$ \\
\hline Pennsylvania & DLC & Default RTP & $>300 \mathrm{~kW}$ & $\begin{array}{l}\text { Auction-based fixed- } \\
\text { price option } \\
\text { (temporary) }\end{array}$ & $\begin{array}{l}\text { Implemented in } 2005 . \\
\text { Fixed-price option expires in } \\
2007\end{array}$ \\
\hline \multirow[t]{3}{*}{ New York } & NMPC & Default RTP & $>2000 \mathrm{~kW}$ & None & Implemented in 1998. \\
\hline & \begin{tabular}{|l|} 
All IOUs \\
other than \\
NMPC \\
\end{tabular} & Optional RTP & $\begin{array}{l}\text { Varies by } \\
\text { utility }\end{array}$ & Varies by utility & $\begin{array}{l}\text { Implemented in } 2001 . \\
\text { Proposal to make RTP } \\
\text { mandatory rejected in } 2003 .\end{array}$ \\
\hline & CHG\&E & Default RTP & $>1,000 \mathrm{~kW}$ & None & Implemented in 2005. \\
\hline Illinois & ComEd & Default RTP & $>3000 \mathrm{~kW}$ & None & $\begin{array}{l}\text { Implemented for new } \\
\text { customers in 2003. To be } \\
\text { implemented for existing } \\
\text { customers in } 2007 . \\
\end{array}$ \\
\hline \multirow[t]{2}{*}{ Ohio } & CG\&E & Default RTP & $\begin{array}{l}>100 \mathrm{~kW} \\
\text { returning } \\
\text { customers }\end{array}$ & \multirow[t]{2}{*}{ None } & \multirow[t]{2}{*}{ Implemented in 2005.} \\
\hline & & $\begin{array}{l}\text { Default Fixed } \\
\text { Price }\end{array}$ & $\begin{array}{l}>100 \mathrm{~kW} \\
\text { existing } \\
\text { customers } \\
\end{array}$ & & \\
\hline \multirow[t]{2}{*}{ Oregon } & \multirow[t]{2}{*}{ PGE } & $\begin{array}{l}\text { Optional RTP } \\
\text { pilot }\end{array}$ & $>1000 \mathrm{~kW}$ & \multirow{2}{*}{$\begin{array}{l}\text { COS-based, fixed } \\
\text { price and several } \\
\text { market-based options }\end{array}$} & Implemented in 2004. \\
\hline & & $\begin{array}{l}\text { Optional daily } \\
\text { TOU pricing }\end{array}$ & $\begin{array}{l}\text { All non- } \\
\text { residential }\end{array}$ & & Implemented in 2002. \\
\hline Georgia & GPC & Optional RTP & $>250 \mathrm{~kW}$ & $\begin{array}{l}\text { Multiple COS-based, } \\
\text { fixed-price options }\end{array}$ & Implemented in 1993. \\
\hline
\end{tabular}

In brief, the eight case studies profiled in this chapter are the following:

New Jersey: In 2003, RTP became the only supply option for customers in the high voltage classes that had not contracted with a competitive supplier. The class of applicable customers was expanded, in 2004, to all customers with a peak demand greater than 1,500 kW, and again in 
2005, to all customers larger than $1,250 \mathrm{~kW}$. All other C\&I customers, for whom the default service is an auction-based fixed-price rate, are allowed to voluntarily opt onto RTP.

Maryland: From July 2002 - June 2003, RTP was the only supply option for customers of Baltimore Gas \& Electric (BGE) with a peak demand greater than 1,500 kW (Schedule P) that had not contracted with a competitive supplier. This default service tariff was then supplanted by the statewide default service. From July 2004 - May 2005, RTP was an optional service for all customers in the state with a peak demand greater than $600 \mathrm{~kW}$. During this period, the default service for customers in this class that had not contracted with a competitive supplier was an auction-based, fixed-price service. In June 2005, RTP became the default and only supply option for customers $>600 \mathrm{~kW}$ that have not contracted with a competitive supplier.

Pennsylvania: In 2005, RTP became the default service for customers of Duquesne Light Company (DLC) with a peak demand greater than $300 \mathrm{~kW}$. An auction-based, fixed-price option is also available to this customer class, as an alternative to RTP, until mid-2007.

New York: RTP is currently the only utility supply option for Niagara Mohawk Power Company (NMPC) customers with a peak demand greater than 2,000 kW. RTP is also currently offered as an optional service by the state's other five IOUs, including Central Hudson Gas \& Electric (CHG\&E), Consolidated Edison (ConEd), New York State Electric and Gas (NYSEG), Orange \& Rockland (O\&R), and Rockland Gas \& Electric (RG\&E). In 2003, the New York Public Service Commission (NYPSC) considered a proposal to designate RTP as "mandatory" for certain customer classes of these utilities, but decided against doing so. In 2005, the NYPSC adopted a proposal by Central Hudson Gas \& Electric (CHG\&E) to make RTP the only utility supply option for its customers with a peak demand greater than $1,000 \mathrm{~kW}$.

Illinois: ComEd has offered RTP as an optional service for all non-residential customers since 1998. RTP is also currently the only utility supply option for new ComEd customers with a peak demand greater than $3,000 \mathrm{~kW}$. In 2007, RTP will become the only utility supply option for all ComEd customers with a peak demand greater than 3,000 kW (new and existing). The Illinois Commerce Commission (ICC) is also currently engaged in a process to develop uniform requirements for all of the utilities in the state, regarding the form and function of utility supply service to be offered following the state's statutory transitional period, which ends in 2006.

Ohio: Cincinnati Gas \& Electric (CG\&E), Cinergy’s utility in southern Ohio, proposed a set of optional RTP tariffs as part of a portfolio of utility supply options to be offered following the end of their rate cap period in 2004. This proposal ultimately was not adopted and, instead, a "market-based" fixed-price rate was adopted as the only utility supply option for customers with a peak demand greater than $100 \mathrm{~kW}$ that were taking their supply from the utility as of January 2, 2005. For customers that return to CG\&E from a competitive supplier after that date, RTP is the only utility supply option available.

Oregon: Portland General Electric (PGE) offers an optional RTP tariff for customers with a peak demand greater than $1,000 \mathrm{~kW}$. It is currently a pilot and is limited to a maximum of six customers. PGE also offers an optional, market-based service, similar to RTP, which has peak and off-peak prices that vary on a daily basis. This is one of several market-based options offered by the utility that have TOU prices fixed over different time intervals (daily, monthly, and quarterly). Customers that have provided notice during the annual open enrollment period 
that they plan to leave PGE's cost of service option but have not made an arrangement by year end must transfer to one of these market-based options, and are automatically transferred to the daily pricing option if they don’t specify otherwise.

Georgia: Georgia Power Company (GPC) offers two optional RTP tariffs with day-ahead and hour-ahead price notice, which are available to customers with a peak demand greater than 250 $\mathrm{kW}$ and 5,000 kW, respectively. Although not typically considered a customer choice state, Georgia has had a limited form of retail choice in place since 1973, and this market structure has played a critical role in GPC’s experience with RTP.

\subsection{Market and Regulatory Context}

The prevailing regulatory and market structure in each case study state provides important context for understanding the experience with RTP implementation (see Figure 4-1).

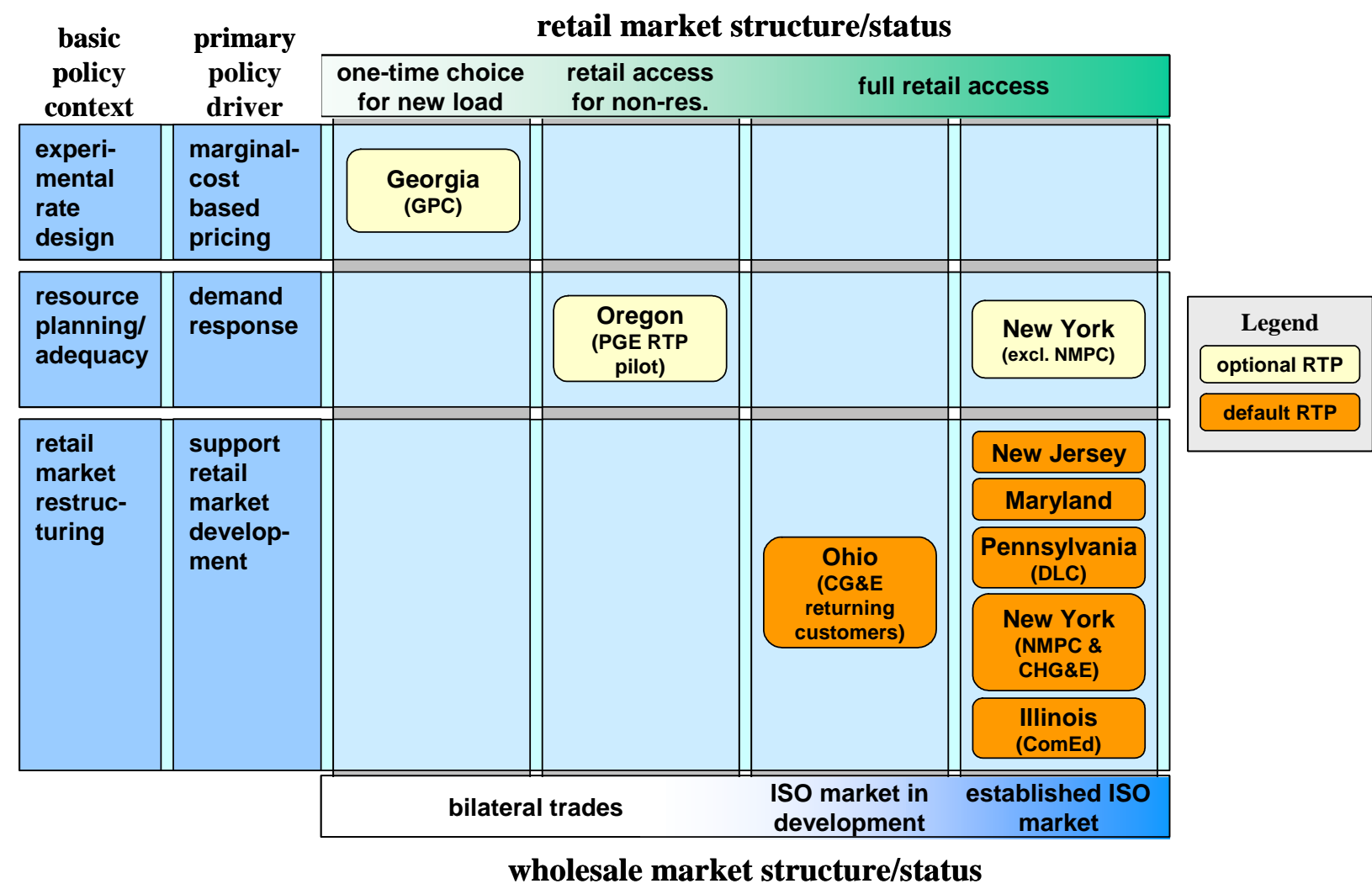

Figure 4-1. Regulatory and Market Context

\subsubsection{Retail market structure and development}

Full retail choice for all customers is currently in place in six of the eight case study states (New Jersey, Maryland, Pennsylvania, New York, Ohio, and Illinois), although the extent of retail market activity varies significantly across these six states. As of the end of 2004, the C\&I switching rates in these six states, in terms of percent of total C\&I load, was: $28 \%$ in New Jersey, 41\% in Maryland, 42\% in DLC's service territory, 36\%/65\% (C/I) in New York, 
38\%/62\% (C/I) in ComEd's service territory, and 18\% in CG\&E's service territory (Kema 2005). Utilities in most of these states are prohibited from directly competing for customer choice load, either by statute (e.g., New Jersey and Maryland) or by regulatory agreement (Pennsylvania, New York, Illinois).

Most of these states established a transition period during which the utilities offered administratively-priced (i.e., frozen, capped, or cost-of-service based) retail supply service to customers that have not switched to a competitive supplier. ${ }^{23}$ Utilities in New Jersey, Maryland, and Pennsylvania (DLC) have completed their transitional periods, and now offer only marketbased supply options to large C\&I customers that have not switched. In Ohio, the statutory "market development period" has expired, but the PUCO has effectively extended the transition period by requiring most utilities to offer fixed prices through $2008 .{ }^{24}$ In Illinois, the transitional period is not scheduled to expire until the end of 2006, although the supply service that ComEd will offer to customers $>3 \mathrm{MW}$ after that point has already been established.

The other two states, Oregon and Georgia, have a more limited form of retail competition. Oregon currently has retail choice only for non-residential customers, and a modest amount of switching has occurred. ${ }^{25}$ The IOUs in Oregon are required to continue offering cost-of-service based rates to all customers during the state's indefinite transitional period, which will end only when a broad set of conditions related to the development of the retail market are satisfied. In Georgia, a limited form of retail competition was established in 1973, whereby most new facilities with a connected load greater than $900 \mathrm{~kW}$ have a one-time choice of supplier. GPC is permitted to compete for this load, while continuing to operate under an obligation to serve all other customers in its service territory at cost-of-service based rates.

\subsubsection{Wholesale market structure and development}

The utilities in five of the case studies - New Jersey, Maryland, Pennsylvania (DLC), New York, and Illinois (ComEd) - operate in regions with an established, wholesale power exchange administered by an independent system operator (ISO) or regional transmission organization (RTO). These utilities have also divested most or all of their generating assets to merchant generating companies or transferred them to an affiliate or parent company. The utilities in the other three case studies - Ohio (CG\&E), Oregon (PGE), and Georgia (GPC) - are vertically integrated and operate in regions with no ISO/RTO power markets or, in the case of CG\&E, recently established RTO markets. ${ }^{26}$

\subsubsection{Policy context and impetus for RTP implementation}

\footnotetext{
${ }^{23}$ The end of the transitional period was defined by different types of conditions among the case studies. In New Jersey, Maryland, and Ohio, it was defined by statute. In Pennsylvania, the end of DLC's transitional period was defined by completion of the utility's stranded cost recovery and expiration of POLR service contracts. In Illinois, the end of the transition period for ComEd's customer class $>3 \mathrm{MW}$ was defined by demonstration that the retail market for these customers was sufficiently competitive.

${ }^{24}$ CG\&E's default RTP rate for returning customers is an exception.

${ }^{25}$ As of the end of 2004, 7\% of PGE's C\&I customers had switched (OPUC 2005).

${ }^{26}$ The Midwest Independent System Operator (MISO) launched their day-ahead and real-time energy markets on April 1, 2005.
} 
The eight case studies can be distinguished in terms of the policy context surrounding the efforts to implement RTP. In most of the states where default RTP was considered and/or adopted, the basic context was that the state's transition period had come (or was coming) to an end. This condition prompted some type of regulatory process to establish the terms of the supply service to be provided thereafter to customers not taking their supply from a competitive provider. In most of these states, this regulatory process encompassed a wide range of issues beyond just the development of RTP tariffs, and the general policy objective underlying these initiatives was to facilitate the development of the competitive retail market. Many of these efforts were guided by broad statutory mandates related to the character of the post-transition default service (e.g., that it be "market-based"). The policy context of the default RTP tariffs implemented by NMPC and recently proposed by CHG\&E was similar in the sense that both utilities proposed default RTP in the context of efforts to support the development of the retail market. However, these proposals were not prompted specifically in response to the end of a formal transition period; but rather, in the case of NMPC, as part of their initial restructuring settlement process, and in the case of CHG\&E, in response to a policy directive issued by the NYPSC requiring the state's utilities to develop plans to promote retail choice.

PGE's RTP pilot and the statewide optional RTP tariffs in New York were developed in what might be broadly characterized as a resource planning or resource adequacy context, with the primary policy objective being to stimulate demand response. In Oregon, interest in RTP and DR more generally intensified in the aftermath of the Western electricity crisis in 2000/2001. In 2003, OPUC staff issued a white paper on DR recommending, among other things, that the state's IOUs develop optional RTP tariffs, and the OPUC adopted this recommendation. In New York, the NYPSC was engaged in a broad set of initiatives to identify and implement strategies to mitigate projected supply shortfalls, and as part of these efforts, they issued an order requiring that all of the utilities in the state develop optional RTP tariffs (with the exception of NMPC, which already had implemented default RTP).

The context within which GPC developed their RTP tariffs was unique among the case studies. GPC previously offered a curtailable (i.e., interruptible) rate option for large C\&I customers that incorporated marginal cost based pricing for non-firm load. Some of the customers on that rate expressed interest in an alternative rate option that would also incorporate marginal cost based pricing, but without a non-firm provision. Responding to this customer interest, as well as to the general nationwide trend towards retail competition and market-based retail pricing, the utility developed their initial RTP pilot as an experimental rate design intended to test an alternative (more refined) approach to marginal cost based pricing.

\subsubsection{State regulatory policies on demand response}

Policymakers and regulatory agencies in many of the case study states have adopted policies or engaged in processes to develop DR, even if RTP was not implemented for this particular purpose (see Table 4-2). ${ }^{27}$ In New Jersey, Maryland, and Pennsylvania, much of the policy activities for DR programs targeted to large C\&I customers have migrated from the state public utility commissions to PJM, which conducts planning and evaluation associated with its DR programs. However, regulators in these states have continued to support the development of DR at the regional level, through participation in the Mid-Atlantic Distributed Resources Initiative

\footnotetext{
${ }^{27}$ We focus specifically on activities targeted or policies that impact large C\&I customers.
} 
(MADRI), a collaborative between state public utility commissions, PJM, and DOE to coordinate DR policies and markets in the Mid-Atlantic region. In New York, the NYISO conducts planning and evaluation of DR programs, while New York State Energy Research and Development Authority (NYSERDA) conducts a corresponding set of activities for DR enabling technology programs funded through the state's system benefits charge. The NYPSC has continued to maintain an active role in the development of DR in New York by requiring the state's investor-owned utilities to offer retail tariffs that facilitate DR (i.e., optional RTP and the NYISO DR programs) and to perform associated marketing and customer education activities.

In Illinois, the utilities have historically assumed primary responsibility for developing DR programs, based on their own financial motivation. However, in early 2005, the governor issued a Sustainable Energy Plan, outlining a number of policies intended to spur the development of renewable energy, energy efficiency, and demand response in the state. The ICC has subsequently initiated a process for implementing this plan, including the formation of an Energy Efficiency and Demand Response working group to solicit guidance from stakeholders and industry experts. Policy issues related to DR were also taken up, albeit secondarily, in the course of the post-2006 initiative, a series of workshops where stakeholders discussed a broad range of issues related to the end of the state's statutory transition period.

In Ohio, the state regulatory commission has not recently engaged in any efforts explicitly for the purpose of developing DR. Staff at the Public Utility Commission of Ohio (PUCO) expressed the view that DR is a value-added service best provided by the competitive market, not by state regulations or programmatic activity (PUCO, 2004c).

In Oregon and Georgia, investor-owned utilities are required to conduct integrated resource planning and to include cost effective DSM measures in their resource strategies. In 2003, the Oregon Public Utilities Commission (OPUC) required that "the utilities Integrated Resource Plans should evaluate demand response programs on par with other options for meeting energy and capacity needs," following the recommendations in OPUC staff's DR white paper earlier that year (OPUC 2003). The utilities in Georgia are not subject to any similar requirement related to DR specifically, and historically, GPC has not included DR programs for large customers as an explicit resource option in their IRP. ${ }^{28}$ Rather, evaluation of DR programs has generally occurred within separate proceedings of more limited scope, such as when GPC restructured their interruptible/curtailable program in 2001.

\footnotetext{
${ }^{28}$ GPC accounts for their existing DR programs for large customers in their IRP in terms of a stipulated reduction in their peak demand forecast. The utility has included a direct load control program for residential customers as a DSM measure in their IRP.
} 
Table 4-2. DR-related policy activities in case study states

\begin{tabular}{|c|c|}
\hline State & DR-related Policy Activities \\
\hline New Jersey & \multirow{3}{*}{$\begin{array}{l}\text { - PJM conducts ongoing planning for and evaluation of DR programs } \\
\text { - State utility regulatory agencies are participating in the Mid-Atlantic Distributed } \\
\text { Resources Initiative } \\
\text { - The Pennsylvania Renewable Portfolio Standard (currently under development) } \\
\text { includes DR among the resources that can be used to meet the standard. }\end{array}$} \\
\hline Maryland & \\
\hline $\begin{array}{l}\text { Pennsylvania } \\
\text { (DLC) }\end{array}$ & \\
\hline New York & $\begin{array}{l}\text { - NYISO conducts ongoing planning for and evaluation of DR programs } \\
\text { - The NYPSC ordered utilities to participate in NYISO DR programs and offer optional } \\
\text { RTP tariffs, and later investigated modifications to optional RTP tariffs to increase } \\
\text { participation, ordering the utilities to enhance marketing/customer assistance } \\
\text { - NYSERDA provides financial incentives (\$6-10M/year) for DR enabling technologies } \\
\text { and conducts ongoing planning for and evaluation of DR enabling technology } \\
\text { programs }\end{array}$ \\
\hline Illinois (ComEd) & $\begin{array}{l}\text { - The ICC is in the early stages of implementing the governor's Sustainable Energy Plan, } \\
\text { issued in early 2005, which calls for the development of renewables, energy efficiency, } \\
\text { and DR. } \\
\text { - DR was discussed (albeit secondarily) within the post-2006 initiative, a series of } \\
\text { workshops in which stakeholders discussed a broad set of issues associated with the } \\
\text { end of the state's transition period in } 2006 \text {. }\end{array}$ \\
\hline Ohio (CG\&E) & - None (recently) \\
\hline Oregon (PGE) & $\begin{array}{l}\text { - PGE conducts IRP and has historically included DSM. Following recommendations by } \\
\text { OPUC staff, the OPUC recently directed the utilities to include DR in their IRP and to } \\
\text { file an RTP or critical peak pricing tariff for non-residential customers. } \\
\text { - The OPUC is investigating policies to facilitate advanced metering infrastructure to } \\
\text { support DR efforts }\end{array}$ \\
\hline Georgia (GPC) & $\begin{array}{l}\text { - GPC conducts IRP and is required to evaluate DSM. However, DR programs for large } \\
\text { C\&I customers have historically been evaluated outside of the IRP process. }\end{array}$ \\
\hline
\end{tabular}

\subsection{RTP Implementation Process and Stakeholder Support}

In each case study, the decision to implement RTP was made and the RTP tariff design was established within some process or combination of processes involving a number of different stakeholder groups. In several cases, substantive issues related to RTP were also addressed within regulatory proceedings following the initial implementation phase. In this section, we compare the implementation process undertaken in each state in terms of the structure of the process and the support and positions of major stakeholders.

\subsubsection{Process structure}

In all of the case study states, the decision whether or not to implement RTP and the initial adoption of a particular rate design were codified through a regulatory order. However, the structure of the process culminating in that regulatory order varied in several basic ways (see Table 4-3). 
Table 4-3. Regulatory Process for RTP Implementation

\begin{tabular}{|c|c|c|c|c|c|}
\hline \multirow[t]{2}{*}{ State } & \multirow[t]{2}{*}{ Tariff } & \multicolumn{4}{|c|}{ Regulatory Process } \\
\hline & & Type & Scope & Key Components & Duration \\
\hline New Jersey & $\begin{array}{l}\text { Statewide } \\
\text { default } \\
\text { RTP }\end{array}$ & $\begin{array}{l}\text { OII/OIR } \\
\text { (recurring } \\
\text { annually) }\end{array}$ & $\begin{array}{l}\text { Establish default service rates } \\
\text { and procurement process for all } \\
\text { customers in the state, for the } \\
\text { following year }\end{array}$ & $\begin{array}{l}\text { Public hearings } \\
\text { Joint utility rate } \\
\text { proposal } \\
\text { Public comment } \\
\text { period }\end{array}$ & 6 months \\
\hline Maryland & $\begin{array}{l}\text { Statewide } \\
\text { default } \\
\text { RTP }\end{array}$ & OII/OIR & $\begin{array}{l}\text { Establish post-transition period } \\
\text { default service rates and } \\
\text { procurement process for all } \\
\text { customers in the state }\end{array}$ & $\begin{array}{l}\text { Negotiated settlements } \\
\text { (Phase I and II) }\end{array}$ & $\begin{array}{l}16 \\
\text { months }\end{array}$ \\
\hline Pennsylvania & $\begin{array}{l}\text { DLC } \\
\text { default } \\
\text { RTP }\end{array}$ & Rate Case & $\begin{array}{l}\text { Establish post-transition period } \\
\text { default service rates and } \\
\text { procurement process for all DLC } \\
\text { customers }\end{array}$ & $\begin{array}{l}\text { Technical conferences } \\
\text { Litigated hearings and } \\
\text { public comment } \\
\text { period } \\
\text { Negotiation between } \\
\text { DLC and customer } \\
\text { groups }\end{array}$ & 9 months \\
\hline \multirow[t]{3}{*}{ New York } & $\begin{array}{l}\text { NMPC } \\
\text { default } \\
\text { RTP }\end{array}$ & Rate case & $\begin{array}{l}\text { Establish utility rate options } \\
\text { (incl. default service) for NMPC } \\
\text { customers for the transition and } \\
\text { post-transition periods }\end{array}$ & $\begin{array}{l}\text { Settlement agreement } \\
\text { between industrial } \\
\text { customers and utility }\end{array}$ & $\sim 1 \mathrm{yr}$ \\
\hline & $\begin{array}{l}\text { Statewide } \\
\text { optional } \\
\text { RTP }\end{array}$ & OII/OIR & $\begin{array}{l}\text { Implement statewide optional } \\
\text { RTP }\end{array}$ & $\begin{array}{l}\text { Public comment } \\
\text { period }\end{array}$ & 5 months \\
\hline & $\begin{array}{l}\text { CHG\&E } \\
\text { default } \\
\text { RTP }\end{array}$ & $\begin{array}{l}\text { Utility } \\
\text { application }\end{array}$ & $\begin{array}{l}\text { Implement RTP as the only } \\
\text { utility supply option for large } \\
\text { customers }\end{array}$ & Utility filings & 6 months \\
\hline Illinois & $\begin{array}{l}\text { ComEd } \\
\text { default } \\
\text { RTP }\end{array}$ & Rate case & $\begin{array}{l}\text { Establish whether retail market } \\
\text { for ComEd customers }>3 \mathrm{MW} \\
\text { should be "declared } \\
\text { competitive" and if so, establish } \\
\text { post-transition period utility } \\
\text { supply service for this customer } \\
\text { class }\end{array}$ & $\begin{array}{l}\text { Litigated hearings and } \\
\text { public comment } \\
\text { period } \\
\text { Negotiated stipulation } \\
\text { between ComEd and } \\
\text { competitive suppliers }\end{array}$ & 9 months \\
\hline Ohio & $\begin{array}{l}\text { CG\&E } \\
\text { default } \\
\text { RTP }\end{array}$ & $\begin{array}{l}\text { Utility } \\
\text { application }\end{array}$ & $\begin{array}{l}\text { Establish post-transition period } \\
\text { utility supply service for all } \\
\text { CG\&E customers }>100 \mathrm{~kW}\end{array}$ & $\begin{array}{l}\text { Rate proposal } \\
\text { Negotiated stipulation } \\
\text { between CG\&E and } \\
\text { stakeholder groups }\end{array}$ & $\begin{array}{l}27 \\
\text { months }\end{array}$ \\
\hline \multirow[t]{2}{*}{ Oregon } & $\begin{array}{l}\text { PGE } \\
\text { optional } \\
\text { RTP }\end{array}$ & $\begin{array}{l}\text { Advice } \\
\text { filing }\end{array}$ & Consider RTP pilot proposal & $\begin{array}{l}\text { Utility advice filing } \\
\text { Public comment } \\
\text { period } \\
\text { Negotiation between } \\
\text { PGE and PUC staff }\end{array}$ & 2 months \\
\hline & $\begin{array}{l}\text { PGE } \\
\text { optional } \\
\text { daily TOU } \\
\text { pricing }\end{array}$ & Rate case & $\begin{array}{l}\text { Establish transition period utility } \\
\text { supply options for all PGE non- } \\
\text { residential customers }\end{array}$ & No data & No data \\
\hline Georgia & $\begin{array}{l}\text { GPC } \\
\text { optional } \\
\text { RTP }\end{array}$ & $\begin{array}{l}\text { Advice } \\
\text { filings }\end{array}$ & $\begin{array}{l}\text { Consider pilot/permanent RTP } \\
\text { tariff proposals }\end{array}$ & $\begin{array}{l}\text { Public comment } \\
\text { period }\end{array}$ & $<1 \mathrm{yr}^{\mathrm{a}}$ \\
\hline
\end{tabular}

a. Duration of the advice filing process for implementing permanent RTP tariffs 


\section{$\underline{\text { Process Scope }}$}

The scope of the RTP implementation processes differed in terms of the range of issues addressed and whether the process was statewide or utility-specific. Where RTP has been proposed in the context of developing the post-transition period default supply service, a wide range of both policy and technical issues have typically been addressed, extending beyond simply the development of RTP tariffs for large C\&I customers. ${ }^{29}$ In some of these states (New Jersey and Maryland), all issues were addressed at a statewide level, while in others (Pennsylvania, Illinois, Ohio, and, to a lesser extent, New York), broad policy issues were addressed at a statewide level, but tariff designs were developed within utility-specific regulatory processes. In contrast to the aforementioned cases, where the context was not the development of the post-transition period default supply service (i.e., optional RTP in New York, Oregon, and Georgia), the process scope has been much narrower, focusing primarily on issues related to RTP tariff design and administration.

\section{Process Type}

The type of regulatory process conducted in each state to initially implement RTP reflects the scope (statewide or utility-specific) and the type (default or optional) of RTP tariff under consideration. ${ }^{30}$ The statewide RTP tariffs, both default and optional, were implemented through Order Instituting Investigation or Order Instituting Rulemaking (OII/OIR) type processes. The utility-specific default RTP tariffs were implemented through either rate cases or utility applications. Finally, the utility-specific optional RTP tariffs were initially implemented through advice filings.

\section{$\underline{\text { Process Components }}$}

In most of the cases involving the development of the post-transition period default service, the core process consisted of an initial proposal issued by the utility, followed by a public comment period and, in the two rate cases, litigated hearings. One variant on this basic process (e.g., New Jersey and Pennsylvania) involved technical conferences or public hearings held prior to the formal regulatory proceeding, so that the utility could receive preliminary feedback on its forthcoming proposal. Another variant (e.g., Pennsylvania, Ohio, and Illinois) involved negotiations between the utility and a small number of stakeholder groups following the utility's initial proposal, resulting in a jointly-issued, revised proposal for the commission's consideration.

\footnotetext{
${ }^{29}$ For example: what entity is to provide default service, what types of default service are to be offered to different customer classes, and how to procure generation supply for default service customers.

${ }^{30}$ We categorize the process in each state according to the categories used by the California Public Utilities Commission. Orders Instituting Investigation or Orders Instituting Rulemaking (OII/OIR) are commission-initiated processes to set basic policy rules (OIR) or to conduct preliminary information gathering (OII). Rate cases are conducted to address major changes to capital expenditures, rates, and/or revenue requirements, and can be initiated either at the utility's request, by a third party, or, in some states, automatically every few years. Utility applications involve requests by the utility for approval of a specific activity (e.g., an IRP filing) and are similar to rate cases, except that they can be initiated only utilities. Advice letters and advice filings are also utility-initiated processes but generally involve minor activities that do not significantly impact rates or revenue requirements.
} 
Maryland is unique among those cases involving the development of post-transition period default service. All of the details of the default service implementation, including the rate structure for various customer classes and the procurement process, were developed and agreed upon through a negotiated settlement process involving approximately 25 stakeholder groups, representing a diverse set of interests. The settlement was then submitted to the MDPSC for approval, with a limited public comment period consisting of a set of briefs filed by the various parties to the settlement.

In the cases involving optional RTP, the initial implementation process was comparatively less structured. In all of these cases, the utility submitted an initial tariff proposal, followed by a limited amount of public comment or, in the case of PGE's RTP pilot, negotiations with PUC staff regarding several specific tariff provisions. GPC’s RTP tariffs were also initially implemented in this manner, but have received a great deal of substantive attention in a variety of subsequent rate cases and other litigated proceedings.

\section{Duration}

Most of the case studies had a relatively brief ( $<1$ year) implementation phase, even where a broad range of issues were considered. The principal exception is Ohio, where CG\&E's default service application was pending before the commission for more than two years. In part, the process was delayed because the separate rulemaking to define the broad statewide terms for default service had not yet concluded. However, the length of the process could perhaps also be attributed to the divergent objectives of its key participants: CG\&E sought to continue providing retail supply and maintain its market share, while competitive suppliers sought to promote the development of a competitive retail market.

\subsubsection{Stakeholder views on default and optional RTP service}

In general, one or more identifiable party in each case study was chiefly responsible for initially recommending or proposing that RTP be implemented as a default or optional tariff, and in the course of the ensuing regulatory process, other stakeholders expressed their overall support for or opposition to the proposal, distinct from their position on specific, technical details (see Table 4-4). ${ }^{31}$

\footnotetext{
${ }^{31}$ Thus, we distinguish between positions on whether optional or default RTP should be implemented from positions on how it should be implemented (e.g., related to tariff design and administration), discussed in Section 4.4.
} 
Table 4-4. Stakeholder Positions on RTP

\begin{tabular}{|c|c|c|c|c|c|}
\hline \multirow[t]{2}{*}{ State } & \multirow{2}{*}{$\begin{array}{c}\text { RTP } \\
\text { Proposal }\end{array}$} & \multicolumn{4}{|c|}{ Stakeholder Group } \\
\hline & & Utilities & $\begin{array}{l}\text { Regulatory } \\
\text { Staff }\end{array}$ & $\begin{array}{c}\text { Large Customer } \\
\text { Groups }\end{array}$ & $\begin{array}{c}\text { Competitive } \\
\text { Retail Suppliers }\end{array}$ \\
\hline New Jersey & $\begin{array}{l}\text { Statewide } \\
\text { default RTP }\end{array}$ & Proposed & Supported & Supported & Supported \\
\hline Maryland & $\begin{array}{l}\text { Statewide } \\
\text { default RTP }\end{array}$ & Supported & Supported & Supported & Supported \\
\hline Pennsylvania & $\begin{array}{l}\text { DLC default } \\
\text { RTP }\end{array}$ & $\begin{array}{l}\text { Supported } \\
\text { optional RTP; } \\
\text { opposed default } \\
\text { RTP }\end{array}$ & $\begin{array}{l}\text { Supported default } \\
\text { RTP }\end{array}$ & $\begin{array}{l}\text { Encouraged utility } \\
\text { to propose } \\
\text { optional RTP; } \\
\text { opposed default } \\
\text { RTP }\end{array}$ & $\begin{array}{l}\text { Proposed default } \\
\text { RTP, instead of } \\
\text { optional RTP }\end{array}$ \\
\hline \multirow[t]{3}{*}{ New York } & $\begin{array}{l}\text { NMPC } \\
\text { default RTP }\end{array}$ & Proposed & Supported & $\begin{array}{l}\text { Supported; } \\
\text { proposed fixed } \\
\text { price alternative }\end{array}$ & $\begin{array}{l}\text { Not actively } \\
\text { involved in } 1998\end{array}$ \\
\hline & $\begin{array}{l}\text { Statewide } \\
\text { optional RTP }\end{array}$ & $\begin{array}{l}\text { Mixed support for } \\
\text { default RTP }\end{array}$ & $\begin{array}{l}\text { Proposed optional } \\
\text { RTP and initiated } \\
\text { investigation of } \\
\text { default RTP } \\
\end{array}$ & $\begin{array}{l}\text { Opposed default } \\
\text { RTP proposal }\end{array}$ & $\begin{array}{l}\text { Supported default } \\
\text { RTP proposal }\end{array}$ \\
\hline & $\begin{array}{l}\text { CHG\&E } \\
\text { default RTP }\end{array}$ & Proposed & No data & No data & No data \\
\hline Illinois & $\begin{array}{l}\text { ComEd } \\
\text { default RTP }\end{array}$ & Proposed & Opposed & Opposed & Supported \\
\hline Ohio & $\begin{array}{l}\text { CG\&E } \\
\text { options for } \\
\text { existing } \\
\text { customers }^{\mathrm{a}}\end{array}$ & $\begin{array}{l}\text { Proposed optional } \\
\text { RTP and opposed } \\
\text { default "variable } \\
\text { rate" }\end{array}$ & $\begin{array}{l}\text { Opposed optional } \\
\text { and default RTP }\end{array}$ & $\begin{array}{l}\text { Opposed default } \\
\text { "variable rate" }\end{array}$ & $\begin{array}{l}\text { Opposed default } \\
\text { “variable rate” }\end{array}$ \\
\hline \multirow[t]{2}{*}{ Oregon } & $\begin{array}{l}\text { PGE optional } \\
\text { RTP }\end{array}$ & $\begin{array}{l}\text { Jointly proposed } \\
\text { optional RTP with } \\
\text { PUC staff }\end{array}$ & $\begin{array}{l}\text { Jointly proposed } \\
\text { optional RTP with } \\
\text { utility }\end{array}$ & $\begin{array}{l}\text { No public } \\
\text { comment }\end{array}$ & $\begin{array}{l}\text { No public } \\
\text { comment }\end{array}$ \\
\hline & $\begin{array}{l}\text { PGE optional } \\
\text { daily TOU } \\
\text { pricing }\end{array}$ & $\begin{array}{l}\text { Proposed market- } \\
\text { based options } \\
\text { (incl. daily TOU } \\
\text { pricing) }\end{array}$ & Supported & Supported & $\begin{array}{l}\text { Concerned that set } \\
\text { of market-based } \\
\text { options replicates } \\
\text { competitive offers }\end{array}$ \\
\hline Georgia & $\begin{array}{l}\text { GPC optional } \\
\text { RTP }\end{array}$ & Proposed & Supported & Supported & $\begin{array}{l}\text { No public } \\
\text { comment }\end{array}$ \\
\hline
\end{tabular}

a. For Ohio, we focus on stakeholder support related to RTP for existing utility customers. Ultimately, a fixedprice default service was approved for these customers, and RTP was implemented as the default service for returning customers only.

\section{$\underline{\text { Utilities }}$}

Utilities have generally supported default RTP proposals in cases where they have divested their generation assets and where established state regulatory policies have clearly prohibited their participation in the competitive retail market. Their support for default RTP stems from a number of considerations, perhaps the most important of which is that, by passing through spot market prices to default service customers, utilities can avoid many of the risks and costs that they would bear if they were to provide fixed price default service. ${ }^{32}$ Some utilities may also have a strategic interest in encouraging customers to switch to a competitive supplier (which

\footnotetext{
${ }^{32}$ A provider of fixed price default service faces risks associated with balancing and load migration, and administrative costs associated with procuring long term supply resources.
} 
default RTP is presumed to stimulate), depending on the particular regulatory incentives that the utility faces as a default service provider and whether the company has an affiliated competitive retail supplier operating in the same market.

Utilities in several states (Pennsylvania, New York, and Ohio) have opposed default RTP proposals, even though all have supported optional RTP. In general, their opposition to default RTP derives from some level of interest in continuing to supply retail load, expressed in terms of "maintaining a level playing field" with competitive suppliers and/or "not limiting customer choice.” For example, in its opposition to the PUCO draft order mandating a variable rate default service, CG\&E asserted that it should be able to adjust its retail service offerings as necessary to maintain market share.

Utilities have supported optional RTP proposals in all cases where it has been considered. Their support rests upon two fundamental categories of benefits that optional RTP can potentially yield for utilities. The first set of benefits derives from the value of RTP as a tool for load management and risk management. Specifically, by encouraging load shifting, load growth, and peak shaving, RTP can improve the utility's system load factor, utilize excess generation capacity, and/or reduce reliance upon spot market purchases during peak periods, all of which help to reduce and/or stabilize the utility's average costs. The second set of benefits derives from the value of RTP as a tool for customer retention and retail competition. Some customers prefer RTP, particularly when it can be combined with flexible hedging options, and utilities that are seeking to maintain a long run presence in the retail market recognize that, by making such options available, they can better retain existing customers and attract new ones. Both CG\&E and DLC included RTP as an option in their default service proposals for similar reasons, and GPC has maintained strong support for RTP because of its indispensable role in helping the utility compete for customer choice load in Georgia.

\section{$\underline{\text { Regulatory Staff }}$}

Support for default RTP by regulatory staff has generally been founded on a broader interest in facilitating retail market development and successfully implementing the post-transitional phase in the state's restructuring process In particular, they have supported default RTP because: it is market-based (often a statutory requirement), eliminates the need for class-average load profiles for commodity pricing (and the associated cross-subsidies and cost shifting that are presumed to distort the retail market), mitigates administrative complications associated with managing and accounting for load migration (e.g., switching restrictions), and is generally deemed to encourage switching and attract retailers to the region (on the presumption that most customers want greater price certainty).

Support for optional RTP by regulatory staff has generally been driven by policy goals related to resource adequacy and cost-effective resource acquisition (e.g., in Oregon and New York). In Georgia, economic development has also been a key factor underlying GPSC staffs' support for GPC's RTP tariffs; the state's industrial sector has been contracting, and RTP is considerably 
less costly for many industrial customers, compared to the utility's standard, embedded cost based rates. $^{33}$

In several states, regulatory staff opposed or had reservations about instituting RTP. In Illinois, regulatory staff did not consider the marketplace for ComEd's large customers sufficiently competitive to subject these customers to default RTP. In Ohio, regulatory staff opposed RTP for existing utility customers (default or optional) on the grounds that it would inhibit the development of retail competition. In their view, RTP and interval metering are value-added services and, as such, are to be provided by competitive retail entities. Furthermore, if RTP is designated as the default service, it erodes the opportunity for competitive suppliers to "cherry pick" customers with inexpensive load profiles who would otherwise cross-subsidize other customers in their rate class if the default service were instead based on a class average load profile. Finally, in New York, regulatory staff supported implementation of the statewide optional RTP tariffs, but ultimately opposed making the tariffs mandatory for certain customer classes given the ardent opposition to default RTP by many customer groups. NYPSC staff concluded that forcing customers onto RTP was premature at that point in time, and that a more effective strategy for developing demand response would be to first focus on educating customers about the benefits and risks associated with RTP.

\section{Large Customers}

Support for default RTP by large customer groups has been mixed, and tends to reflect the maturity of the competitive retail market and/or the availability of alternative fixed-price utility supply options. For example, large customer groups in New Jersey, Maryland, and NMPC's service territory have supported the default RTP proposals. In Maryland and DLC's service territory, the C\&I retail market had already reached a relatively mature state at the time that the default service proceedings were underway, with approximately $30 \%$ of all C\&I load already switched to a competitive supplier. The Maryland and NMPC default RTP proposals also incorporated temporary fixed-price utility supply options (in NMPC's case, at the behest of customer groups), which presumably allayed concerns about the immediate availability of competitive hedged supply options. In contrast, customers in Pennsylvania (DLC), Illinois (ComEd), Ohio, and New York (statewide RTP) voiced strong opposition to default RTP, citing various interrelated concerns, such as the lack of a robust retail market, undue risk exposure, potential negative bill impacts, and the need for greater customer education and time to adapt.

In cases where optional RTP has been proposed, large customers groups have generally come out in support, and in several cases, they have been instrumental in initiating the proposal. In Georgia, particularly, large customer groups have been avid supporters of RTP, notwithstanding various technical issues they have raised with respect to specific tariff provisions or administrative procedures. In Pennsylvania, large customers were active in encouraging DLC to include RTP as an option in its default service proposal, although, as mentioned above, they opposed default RTP.

\footnotetext{
${ }^{33}$ As described more fully in the Georgia Power case study, most industrial customers have a CBL that is equal to approximately $60 \%$ of their typical load. Because RTP prices are, on average, well below standard, embedded cost based rates, the customer is able to save significantly on the remaining $40 \%$ of their load.
} 


\section{Competitive Retail Suppliers}

Competitive retail suppliers have consistently supported default RTP, identifying several ways in which it serves to promote retail competition. First, provided that the default RTP tariff is a full pass-through of spot market prices with no hedge, it creates an opportunity for competitive suppliers to offer supply products that incorporate risk management options. Second, because RTP always reflects the current state of the market (unlike default service options developed through an auction or RFP mechanism), suppliers have greater assurance that they will continue to have enough headroom, even if wholesale market costs rise.

Given their strong support for default RTP, competitive suppliers have generally expressed reservations about utilities offering RTP as an optional service (since the two are mutually exclusive). Furthermore, many competitive suppliers are categorically opposed to any optional utility service for customers with retail choice. In their opinion, utilities should offer only one basic default service, and alternatives to that service should be offered only by competitive retail suppliers.

\subsection{Tariff Design and Implementation Details}

Once the threshold decision is made to implement RTP, a number of basic tariff design and implementation details remain to be addressed. ${ }^{34}$ First, what customers will be eligible for and, in the case of default service, automatically placed on RTP? Second, what additional metering or other infrastructure will be required for RTP implementation, and how will the incremental cost be recovered? Third, what pricing structure and terms will be adopted? And finally, what, if any, supplemental activities to support customer participation and price response will be conducted, and by whom?

\subsubsection{Customer size threshold}

Two different customer groups are relevant to a description of RTP tariffs: (1) those customers that, in the case of default RTP, are automatically placed onto the tariff; and (2) those customers that, for either default or optional RTP, are allowed to voluntarily select the tariff. Typically, these groups are defined in terms of a minimum peak demand level. As a convention, we will refer to the minimum peak demand level defining these two groups as the default threshold and the eligibility threshold, respectively. For default RTP, the two thresholds may be one and the same; that is, the only customers that are allowed on the rate are those that are automatically transferred onto it. Or, the eligibility threshold may be lower than the default threshold, in which case some customers that are not automatically transferred can voluntarily enroll (e.g., as in New Jersey and Illinois). Although the particular peak demand level chosen for the default threshold arguably has greater political ramifications than that for the eligibility threshold, both have potential implications for cost recovery (e.g., related to infrastructure deployment), demand response, and a variety of other important policy and ratemaking issues.

\footnotetext{
${ }^{34}$ This distinction between the threshold decision to implement RTP and specific tariff design and implementation details is a heuristic device. In practice, proposals to implement RTP typically specify or assume various tariff design and implementation details.
} 
The eligibility and default thresholds adopted in the case studies vary across a wide range, from all non-residential customers to $5,000 \mathrm{~kW}$ (eligibility thresholds), and from $100 \mathrm{~kW}$ to $3,000 \mathrm{~kW}$ (default thresholds) [see Table 4-5]. In many cases, the threshold has been reduced over time, or there is some likelihood that it may be reduced in the future. For example, the eligibility thresholds for Georgia Power's optional day-ahead and hour-ahead RTP programs were reduced from initial levels of 1,000 kW and 10,000 $\mathrm{kW}$ to $250 \mathrm{~kW}$ and 5,000 kW, respectively. In New Jersey, the class of default RTP customers has been expanded on several occasions: first, from the highest voltage classes to all customers $>1,500 \mathrm{~kW}$, and in 2005, it will be expanded to all customers $>1,250 \mathrm{~kW}$. BPU staff indicated that, at some time in the future, the threshold might be reduced further, to as low as $750 \mathrm{~kW}$ (NJBPU 2004). In Maryland, the default threshold was reduced from 1,500 kW, when initially implemented for BGE's Schedule P customer class, to the current level of $600 \mathrm{~kW}$.

Different factors have been relevant to the choice of a particular threshold in the various case studies. In many cases, the initial choice was largely determined by pre-existing tariff classifications and/or pre-existing interval metering installations (e.g., NMPC, CHG\&E's proposal, the initial New Jersey default RTP tariff, BGE Schedule P customers in Maryland). In some cases, though, particularly those involving default RTP, the specific threshold chosen reflects some assessment about how large a customer should be for RTP to be appropriate. These assessments were typically based on some evaluation of the range of competitive alternatives available, customers' sophistication, and/or the cost of additional metering or other infrastructure.

In regions with retail choice, larger customers are often deemed more likely to receive attractive offers from competitive suppliers, and therefore establishing RTP as the default service for these customers is less likely to impose an undue risk by "forcing" these customers onto RTP. A fundamental complication involved in making this kind of judgment is that the degree of competition in the retail market for large customers is, itself, potentially affected by the decision to make RTP the default service (i.e., a "chicken and egg" problem). Perhaps because of this complication, in most cases where the issue was considered, it was done informally. Illinois was unique in this regard, as the particular default threshold for ComEd's RTP tariff (3,000 kW) was linked to a formal process to establish whether or not the retail market for these customers could be "declared competitive."”5

Larger customers are also often judged to have a greater level of sophistication in terms of: their familiarity with energy markets and with technologies and strategies to manage their load (perhaps because the organization has a dedicated energy manager or purchaser); their ability to assess rate and contract alternatives and negotiate with retailers; and their financial wherewithal to invest in enabling technologies or other load response strategies. These various dimensions of a customer's sophistication are relevant both to demand response related goals and, in the case of default RTP, to issues of fairness. Typical practice has been to use customer size as a proxy for

\footnotetext{
${ }^{35}$ The Illinois Public Utilities Act established the following criteria by which the ICC determines whether a tariffed utility service has become a competitive service: 1 ) the service or a reasonably equivalent substitute service is reasonably available at a comparable price from one or more providers other than the electric utility or an affiliate of the electric utility, 2) the electric utility has lost or there is a reasonable likelihood that the electric utility will lose business for the service to the other provider or providers, and 3) there is adequate transmission capacity into the service area to make electric power and energy reasonably available to the customer segment or group from one or more providers other than the electric utility or an affiliate of the electric utility (ILCS, 2005).
} 
sophistication; however, when the NYPSC considered statewide mandatory RTP, some customers objected to the use of a specific peak demand threshold, arguing that industry classifications would be a much better indicator of customers' ability to adjust their load in response to time varying prices. ${ }^{36}$

The third issue often considered in assessing the appropriateness of RTP for different customer groups has to do with the incremental cost of deploying the necessary metering infrastructure. Large customers are fewer in number and have larger loads than smaller customers, so the cost of installing advanced meters for these customers is lower, both in aggregate and on a per-kW basis. In states where interval meters have already been upgraded for large customers prior to RTP being considered, the incremental costs are limited to changes required in customer information and billing systems.

Table 4-5. Customer Size Threshold and Interval Metering Deployment

\begin{tabular}{|c|c|c|c|c|}
\hline State & RTP Tariff & $\begin{array}{c}\text { Default } \\
\text { Threshold }\end{array}$ & $\begin{array}{l}\text { Eligibility } \\
\text { Threshold }\end{array}$ & Interval Metering Deployment \\
\hline New Jersey & $\begin{array}{l}\text { Statewide default } \\
\text { RTP }\end{array}$ & $1500 \mathrm{~kW}$ & $\begin{array}{l}\text { all non- } \\
\text { residential }\end{array}$ & $\begin{array}{l}\text { Utilities directed to install metering for all } \\
\text { customers }>750 \mathrm{~kW} \text {; cost recovery to be } \\
\text { determined in future rate cases. }\end{array}$ \\
\hline Maryland & $\begin{array}{l}\text { Statewide default } \\
\text { RTP }\end{array}$ & $600 \mathrm{~kW}$ & $600 \mathrm{~kW}$ & $\begin{array}{l}\text { Utilities directed to install metering for all } \\
\text { customers }>600 \mathrm{~kW} \text {; customers billed for costs } \\
\text { through pre-existing metering tariff. }\end{array}$ \\
\hline $\begin{array}{l}\text { Pennsylvani } \\
\text { a }\end{array}$ & DLC default RTP & $300 \mathrm{~kW}$ & $300 \mathrm{~kW}$ & Default customers already have interval meters \\
\hline \multirow[t]{3}{*}{ New York } & NMPC default RTP & $2000 \mathrm{~kW}$ & $2000 \mathrm{~kW}$ & $\begin{array}{l}\text { Default/eligible customers already have interval } \\
\text { meters }\end{array}$ \\
\hline & $\begin{array}{l}\text { Statewide optional } \\
\text { RTP }\end{array}$ & $\mathrm{n} / \mathrm{a}$ & $\begin{array}{l}\text { varies by } \\
\text { utility }^{\text {a }}\end{array}$ & $\begin{array}{l}\text { Meters installed on an as-needed basis. } \\
\text { NYSERDA offers SBC-funded rebates. }\end{array}$ \\
\hline & $\begin{array}{l}\text { CHG\&E default } \\
\text { RTP }\end{array}$ & $1000 \mathrm{~kW}$ & $\begin{array}{l}\text { all non- } \\
\text { residential }\end{array}$ & Default customers already have interval meters. \\
\hline Illinois & $\begin{array}{l}\text { ComEd default } \\
\text { RTP }\end{array}$ & $3000 \mathrm{~kW}$ & $\begin{array}{l}\text { all non- } \\
\text { residential }\end{array}$ & $\begin{array}{l}\text { Meters installed on an as-needed basis. All RTP } \\
\text { customers pay an itemized metering charge. }\end{array}$ \\
\hline Ohio & $\begin{array}{l}\text { CG\&E default RTP } \\
\text { for returning } \\
\text { customers }\end{array}$ & $100 \mathrm{~kW}$ & $100 \mathrm{~kW}$ & $\begin{array}{l}\text { Meters installed on an as-needed basis; only } \\
\text { customers }<500 \mathrm{~kW} \text { charged for installation cost }\end{array}$ \\
\hline \multirow[t]{2}{*}{ Oregon } & PGE optional RTP & $\mathrm{n} / \mathrm{a}$ & $1000 \mathrm{~kW}$ & Eligible customers already have interval meters. \\
\hline & $\begin{array}{l}\text { PGE optional daily } \\
\text { TOU pricing }\end{array}$ & $\mathrm{n} / \mathrm{a}$ & $\begin{array}{l}\text { all non- } \\
\text { residential }\end{array}$ & Meters installed on an as-needed basis. ${ }^{b}$ \\
\hline Georgia & GPC optional RTP & $\mathrm{n} / \mathrm{a}$ & $\begin{array}{l}250 \mathrm{~kW} \\
(\mathrm{DA}) \\
5000 \mathrm{~kW} \\
(\mathrm{HA})\end{array}$ & $\begin{array}{l}\text { Meters installed on an as-needed basis. All RTP } \\
\text { customers pay an administrative charge, which } \\
\text { covers metering costs. }\end{array}$ \\
\hline
\end{tabular}

a. CHG\&E, NYSEG, and O\&R permit any non-residential customer to enroll in RTP, while ConEd and RGE have eligibility thresholds of $100 \mathrm{~kW}$ and $300 \mathrm{~kW}$, respectively.

b. The OPUC is also investigating policies to facilitate advanced metering infrastructure to support DR efforts.

\footnotetext{
${ }^{36}$ That being said, some large customer groups further argued that, regardless of their "sophistication,” many customers would incur excessive costs to respond or other negative impacts on their business.
} 


\subsubsection{Interval metering deployment}

Interval meters capable of recording electricity usage in hourly or sub-hourly increments are required for RTP, yet, often, some or all of the eligible customers lack the necessary metering. Whether to install interval meters across a broad customer population (e.g., all eligible customers) or only on an as-needed basis, and how the associated costs should be recovered, are important issues in the RTP implementation process, with implications for demand response, ratemaking, and the development of competitive retail markets for commodity services and metering.

Our case studies fall into four categories with respect to interval metering deployment and cost recovery (see Table 4-5). First, for PGE (RTP pilot), NMPC, and DLC, interval meters had already been installed for the eligible customer classes prior to RTP implementation, thus no further deployment activities were required. CHG\&E's default RTP proposal also applies only to customers already equipped with interval meters. Second, in Georgia and Illinois, interval metering is installed on an as-needed basis, and costs are recovered through monthly administrative or metering charges assessed on all RTP customers. In New York, meters are also installed on an as-needed basis for customers that enroll in the optional RTP tariffs, and customers are charged individually; however, NYSERDA offers rebates, funded through the state System Benefit Charge, to defray a significant portion of these costs. ${ }^{37}$ Third, in Maryland, utilities were directed to install interval meters for the entire class of customers that default to RTP (i.e., all customers $>600 \mathrm{~kW}$ ), and to seek cost recovery in their rate cases. Smaller customers are also eligible for RTP, but must pay individually for their meters. Finally, in New Jersey, utilities were directed to install meters for all default customers as well as all for other eligible customers $>750 \mathrm{~kW}$ and to seek cost recovery in their upcoming general rate cases. According to BPU staff, the decision to install meters for customers below the default threshold at that time (i.e., with a peak demand of $750-1,500 \mathrm{~kW}$ ) was, in part, based on the rationale that the meters would facilitate peak demand reductions and thus benefit all ratepayers (NJBPU 2004). Doing so would also facilitate reducing the default threshold further in the future, as entertained in recent regulatory proceedings.

\subsubsection{Pricing structure and terms}

RTP tariffs can be characterized by a number of basic pricing-related provisions (see Figure 4-2). The pricing structure of RTP tariffs is defined by two distinctions (see Text Box 1): whether the various cost elements are bundled or unbundled, and whether all of the customer's load is subject to time-varying prices or only deviations from their customer baseline load (CBL). Other key pricing-related tariff provisions include: the source of, or method for deriving, time-varying prices; the amount of advance notice with which firm prices are quoted; and whether retail adders are applied to the time-varying price, and if so, at what level the adder is set.

\footnotetext{
${ }^{37}$ Rebates for up to $65 \%$ of the total installation meter cost are offered through NYSERDA's Peak Load Reduction Program. A total of $\$ 7.5$ million in funding for various peak load reduction measures is offered through this program in 2005.
} 


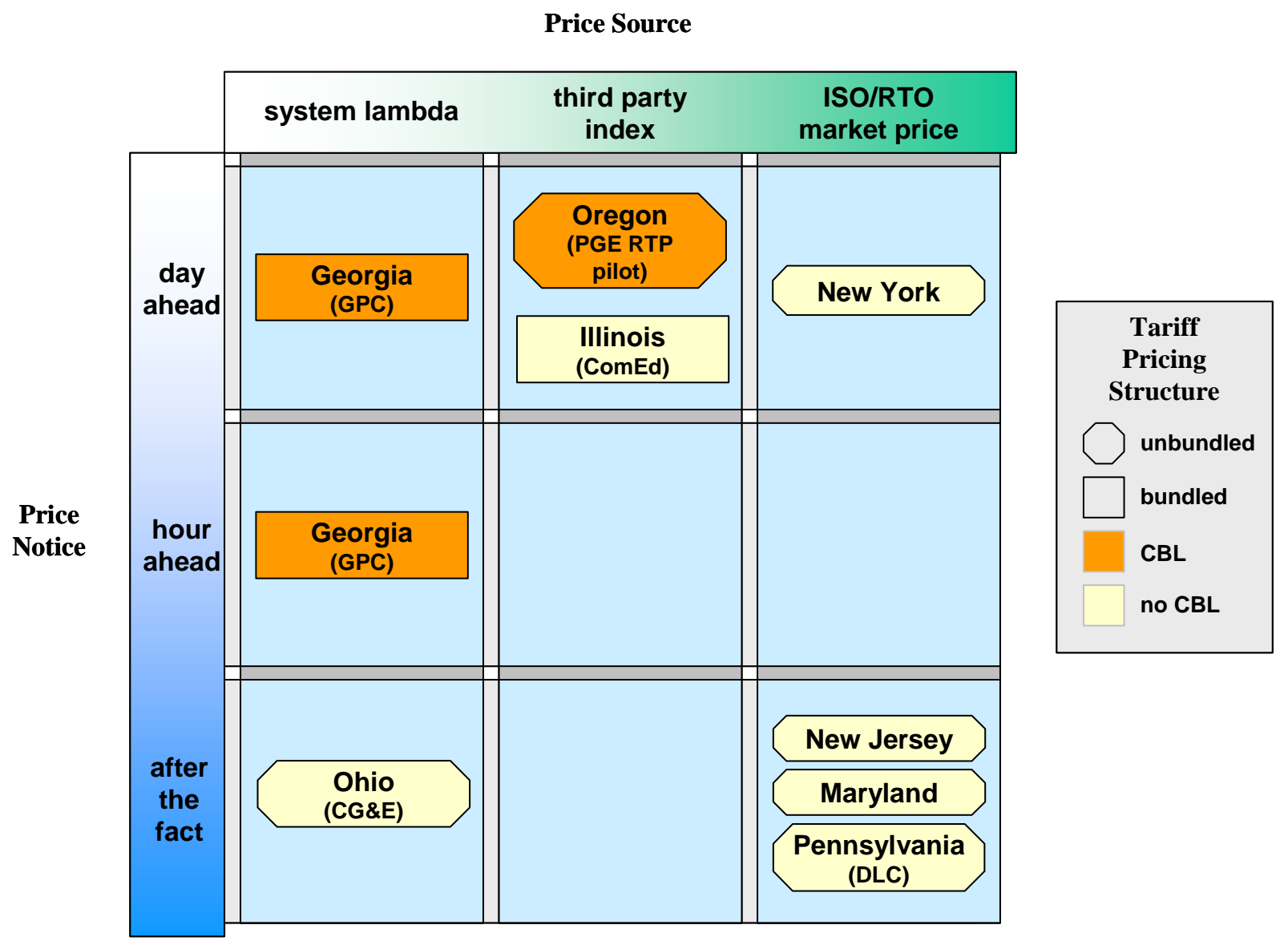

Figure 4-2. RTP Tariff Design Features

\section{Pricing Structure}

Almost all of the case study RTP tariffs are unbundled, a consequence of the broader unbundling process undertaken in most of these states, usually prior to the opening of the retail market. In these cases, RTP participants are billed for generation service under the RTP tariff, and for the utility delivery service under a separate, delivery services tariff, which typically consists of some combination of billing demand, volumetric, and customer charges. ComEd has not formally unbundled; however, their RTP tariff does contain distinct, itemized charges for energy and the various delivery service components (transmission, distribution, metering, etc.). Only Georgia has a fully bundled tariff, where delivery service charges are embedded in the billing components of the non-RTP tariff applied to RTP customer's CBL.

Most of the RTP tariffs have no CBL component; that is, participants are assessed time-varying prices for all of their usage. All of these tariffs, with the exception of the optional RTP tariffs in New York, were implemented in the context of developing the post-transition period default service (see Section 4.2.3). Although a CBL-based design was never explicitly considered in most of these cases, there are several reasons why RTP with a CBL is an unlikely candidate in this particular policy context. Perhaps the most fundamental reason is that making the rate more attractive to customers - in this case, by allowing them to hedge part of their load through their CBL - is contrary to one of the primary objectives of these default service tariffs, which is to 
encourage (or at least to not discourage) customer switching. Moreover, utility-supplied hedges of any type are likely to be viewed by many stakeholders as contrary to the model of a competitive retail market in which risk management is one of the key services to be supplied by competitive entities. $^{38}$

The only RTP tariffs with a CBL among the case studies are those offered by GPC and PGE, as well as the optional RTP rate included in CG\&E's initial default service proposal (but later superseded by the approved default rates). ${ }^{39}$ The underlying rationale for the CBLbased design in all of these cases is that the parties responsible for developing the tariff design had an interest in promoting customer acceptance of RTP, either for load management and/or customer retention and recruitment. The optional RTP tariffs in New York were also developed with an interest in promoting customer acceptance; however the utilities and PSC staff opted against implementing a CBL-based tariff design in light of difficulties encountered with the CBL-based tariff offered by NMPC in the late 1980s and early 1990s (NYPSC 2004). ${ }^{40}$

CBL-related issues have come up in a number of other case studies as well and, to some extent, are endemic to this type of tariff design, particularly when implemented in a cost-of-service

\footnotetext{
${ }^{38}$ A number of other reasons why these tariffs do not incorporate a CBL can also be identified. First, CBL-based tariffs are more difficult for customers to understand and to compare to competitive offers, and therefore less appropriate for a default service tariff. Second, they are more complicated to administer: for example, some process would be required to set the CBL for each customer transferred to the tariff, and in cases where the utility has divested its generation, some process would need to be developed to procure the fixed price generation supply for the CBL portion of customer's load. Third, one of the primary motivations for the CBL design - utility revenue stability - is accomplished much more directly by unbundling the distribution costs and passing through wholesale commodity and transmission costs, thus obviating this particular rationale for a CBL.

${ }^{39}$ PGE's tariff was explicitly modeled after GPC's. Although PGE has unbundled, the RTP tariff specifies that delivery service charges are assessed on the customer's CBL, not on their actual usage. Thus, incremental load above the CBL is not subject to T\&D related charges.

${ }^{40}$ The utilities in New York are also subject to many of the same policy and administrative feasibility issues discussed above in connection with the default RTP tariffs included in the case studies.
} 
regulatory environment. PGE staff have expressed concern that, because RTP prices are expected to be higher than the cost-of-service (CBL) prices in 2005, customers that are already planning on reducing their load would be able to receive payments for these load reductions by switching to RTP, in effect, "free-riding”. In Georgia, customer groups and PSC staff have also raised several issues related to the utility's process for setting and adjusting the CBL. GPC allows new customers to receive a CBL below their projected load, and does not require that any RTP customer's CBL be updated if the customer permanently increases their load. The net effect of these two factors is that approximately $40 \%$ of RTP customers' combined load is "incremental" load above their individual CBLs, and is therefore billed at marginal cost based rates not subject to the same embedded cost allocation as the utility's standard tariffs. PSC staff raised concern in the company's recent rate case that this condition has led to a significant revenue deficiency for the RTP tariff class and a corresponding disparity between the contribution of RTP customers and non-RTP customers to the company's embedded cost recovery and profits. ${ }^{41}$ At the same time, however, the company's approach to setting and maintaining CBLs is what makes the average price paid by customers on RTP much less than what they would pay under a standard tariff, and is thus a significant reason for the large number of customers enrolled in RTP (see Appendix A).

\section{Source of Hourly Prices}

Three sources of hourly prices are used among the case studies (see Figure 4-2): the locational market clearing price in an energy market administered by a regional transmission organizations (RTO) or independent system operators (ISO); indices of bilateral bulk power transactions at regional trading hubs published by third parties (e.g., ICE, Dow Jones, Platts, etc.); and internal calculations by the utility of their marginal operating cost, referred to as their system lambda. These alternative approaches differ from one another in several significant respects, including their transparency and efficiency. ${ }^{42}$ However, not all options are feasible in each case, depending on whether the RTP tariff is offered in a region with an ISO/RTO or a liquid bilateral trading hub, and whether the utility offering the tariff is vertically integrated (since only those utilities calculate a system lambda).

In general, the most transparent source of prices available is used among the case studies. Thus, in regions with an ISO or RTO, the RTP price is indexed to the ISO/RTO locational market clearing price (e.g., New York, Pennsylvania, New Jersey, Maryland). ComEd is an exception, although only temporarily. Their RTP tariff was designed before the utility joined PJM and uses a different approach to derive hourly RTP prices, which involves shaping peak and off-peak bilateral index prices into hourly prices using PJM historical hourly price profiles. However, now that ComEd has been integrated into PJM, the company is planning to revise its RTP tariff so that the hourly prices are indexed directly to the PJM locational market clearing price.

\footnotetext{
${ }^{41}$ The CBL-related issue that has received more attention, but which is peculiar to GPC and not inherent in CBLbased designs, is that some customers have objected that the company's practice of allowing only new customers to receive a reduced CBL constitutes unjust discrimination.

${ }^{42}$ ISO/RTO market clearing prices are public available and therefore highly transparent. Third-party indices are proprietary and therefore less transparent. The system lambda approach is the least transparent of the three, as utilities generally do not publicly disclose their procurement and dispatch decisions.
} 
PGE and Georgia Power, neither of which are a part of an ISO/RTO, also use the most transparent methods available. For their RTP pilot, PGE uses a combination of third-party indices of bilateral trades in the region, in order to derive distinct hourly prices that are provided to customers with day-ahead notice. They start with peak and off-peak prices published each day by the Intercontinental Exchange (ICE) for firm delivery on the following day at the MidColumbia (Mid-C) trading hub. ${ }^{43}$ The company then shapes these into hourly prices using Dow Jones indices for hourly spot market transactions at Mid-C on the previous day.

There are no published indices of bilateral trades in Georgia; thus GPC uses the system lambda approach. According to GPC staff, customers have generally found this approach acceptable, in part because the CBL-based design essentially requires that the utility be willing to "buy back" power at the RTP price if a customer reduces their load below their CBL (GPC 2004b). Several large customer groups have raised a number of specific concerns, particularly with respect to the treatment of off-system spot market purchases (see Appendix A). Prior to 2000, the hourly RTP price was based on the cost of the most expensive unit of energy produced or purchased. Large industrial and manufacturing customer groups objected that this method did not communicate a strong enough incentive for the utility to minimize the cost of off-system purchases, and they asked the PSC to require GPC to modify their approach (e.g., by excluding off-system purchases from their system lambda calculation) and also to disclose their procurement practices so that customers could verify that the utility minimized its supply costs (GMTA and GIG 1999, Pollack 2000). In response, the GPSC required that GPC modify their price calculation method by averaging the cost of all purchased power above system generation in their resource stack, but they did not require that the utility disclose their procurement practices.

CG\&E is the only example among our case studies where the most transparent source of prices was not used. The Midwestern ISO (MISO), of which CG\&E is a part, began operating dayahead and real-time energy markets in 2005; and various third-party indices are also published for bilateral transactions at the Cinergy hub. However, CG\&E uses the system lambda approach for their default RTP tariff for returning customers, with a price floor equal to the fixed-price rate of the default tariff for existing customers (see Appendix A).

\section{$\underline{\text { Advance Notice of Hourly Prices }}$}

The amount of advance notice with which firm RTP prices are quoted has significance for a number of important issues, and involves several tradeoffs. With more advance notice, customers have more time to plan and execute their load response strategy. ${ }^{44}$ However, the more advance notice, the less the price will reflect actual real time conditions (e.g., price spikes and reliability constraints). The amount of advance notice also affects the distribution of risk between RTP participants and the utility, with the utility bearing an increasing amount of forecasting risk, the more advance notice of RTP prices they provide. ${ }^{45}$

\footnotetext{
${ }^{43}$ ICE publishes their price indices at 1:30 PM CST on the day that the transaction occurred. Thus, prices for dayahead transactions are published the day prior to delivery. In contrast, Dow Jones publishes their index prices for day-ahead transactions on the day after the transaction - i.e., on the same day as delivery.

${ }^{44}$ Evidence from several studies also suggests that many customers require knowledge that prices will remain high for several hours at a time to make responding worthwhile (Goldman et al. 2004, Neenan et al. 2003).

${ }^{45}$ It should be noted that, relative to traditional embedded-cost ratemaking, even day-ahead RTP constitutes a substantial transfer of risk away from load-serving entities onto customers.
} 
The case study RTP tariffs include three different levels of advance notice: day-ahead, hourahead, and after-the-fact (see Figure 4-2). GPC, PGE, ComEd, and all of the New York utilities offer RTP with day-ahead price notice. CG\&E also included an optional RTP rate with dayahead notice in its initial default service proposal (not shown in Figure 4-2). The use of dayahead pricing reflects several considerations. In several cases (GPC, PGE, and CG\&E, particularly), the parties responsible for developing RTP had an interest, for load management and/or customer retention and recruitment purposes, in offering a tariff that customers would find attractive and that would provide them with enough advance notice of high prices to respond. In New York, the utilities procure a significant share of their power in the day-ahead market, thus using day-ahead market prices for RTP customers (rather than real time market prices) is more compatible with their existing scheduling and procurement processes. Finally, for ComEd, the adoption of day-ahead pricing was partially driven by the fact that the indices used to derive RTP prices, which track bilateral transactions for day-ahead delivery, are published either at the end of the trading day or the beginning of the following day.

One complication with quoting firm prices on a day-ahead or hour-ahead basis is that it potentially exposes the utility to costs and risks associated with balancing RTP customers' load in real time. This issue takes on added significance in customer choice settings, since retail suppliers and other stakeholders may have an interest in ensuring that utility RTP rates reflect the full market costs, including any risk premium associated with providing firm price quotes a day in advance. This issue recently arose in New York, and in response, CHG\&E has proposed passing through their actual balancing costs for their entire retail load through a uniform, per kWh charge assessed on all of their retail customers (CHG\&E 2005). ${ }^{46}$ GPC and PGE, which operate in regions with no transparent balancing market, incorporate a rather arbitrary "risk adder" into their hourly prices. In Georgia, the size of the risk adder has been the subject of some dispute in rate cases and other proceedings, with customers periodically arguing for a smaller adder, and utilities arguing for a larger one. ${ }^{47}$

The remaining case study RTP tariffs all provide price notification after-the-fact, that is, after the applicable time period has elapsed. The default RTP tariffs offered in New Jersey, Maryland, and Pennsylvania (DLC) are all indexed to the average hourly locational market-clearing price in the PJM real time spot market, which is not determined until after the hour has elapsed. This tariff design reflects several specific design objectives, all of which derive from the basic policy context of implementing the post-transition period default service in a manner that supports the development of the competitive retail market. Indexing to the real-time market, rather than to the day-ahead market, is simpler to administer, since it avoids any separate balancing process and corresponding mechanism for distributing balancing costs. It also encourages customer switching, to the extent that it exposes customers to greater risk. Given that customers on these default RTP tariffs do not know the prices until after their consumption has occurred, they have a limited ability to provide demand response. To the extent that other indicators, such as weather

\footnotetext{
${ }^{46}$ Competitive retail suppliers wanted the charge to be determined on a customer-specific basis, rather than on a class average basis, as CHG\&E has proposed (CHG\&E 2005).

${ }^{47}$ GPC's risk adder was originally intended to compensate the utility for forecasting risk and to contribute to fixed cost recovery; however, GPC staff indicated that currently it serves to recover certain marginal operating costs not included in the system lambda calculation.
} 
or day-ahead market prices, are correlated to real-time market prices, customers may be able to deduce when real-time market prices are high and respond accordingly. ${ }^{48}$

\section{$\underline{\text { Retail Adders }}$}

RTP tariffs include a variety of charges in addition to commodity-related charges, including those for transmission, ancillary services, distribution, metering, etc. One special type of charge that is unique to utility tariffs implemented in customer choice markets is the retail adder. Unlike other charges, which are intended to recover actual costs born by the utility, the retail adder is intended to represent the hypothetical retailing costs (e.g., marketing, administrative expenses, profit margin, etc.) that a competitive supplier would incur to provide a similar product. ${ }^{49}$ Retail adders are not specific to RTP, but rather, they are an artifact of any default service tariff that directly passes through wholesale market costs, whether on an hourly basis or over some longer time interval (e.g., monthly). Their purpose is to provide a level playing field between the default tariff and similarly-structured competitive products.

The default RTP tariffs offered by New Jersey and Maryland utilities and by DLC in Pennsylvania all incorporate retail adders ranging from 2.25 to 5 mills. In New York, customers that switch receive a shopping credit that varies among utilities (e.g., 2 mills for NMPC), which serves to provide headroom for competitive retailer suppliers. ComEd's default RTP tariff does not, strictly speaking, have a retail adder, but it does include a 10\% “adder” for fixed cost recovery, which also serves to provide headroom for competitive suppliers, even if not intended for that purpose.

\subsection{Customer Education and Assistance to Support RTP Participation and Price Response}

A variety of programmatic and administrative activities can be conducted in concert with offering an RTP tariff, to encourage customers to participate and to facilitate price response from participating customers. Such activities include: (1) marketing efforts to inform customers about RTP and explain tariff provisions; (2) customer education about the fundamentals of electricity markets; (3) technical assistance to help customers identify, analyze, and implement load response strategies; and (4) financial assistance with the purchase and installation of enabling technologies for load response. Some of these types of activities may be provided in the marketplace by competitive retail suppliers, ESCOs, technology vendors, and other private entities. However, we focus here on public or ratepayer-funded activities, which are typically conducted by utilities or state agencies (see Table 4-6).

\footnotetext{
${ }^{48}$ LBNL calculated a correlation coefficient of 0.744 between the PJM day-ahead and real-time spot market prices (PSEG pricing zone) during summer peak periods in 2001-2003.

${ }^{49}$ In some cases, a portion of the revenues from the retail adder does also serve to compensate the utility for actual administrative costs that they bear as the default service provider.
} 
Table 4-6. Publicly- and Ratepayer-Funded Activities Conducted in Support of RTP

\begin{tabular}{|c|c|c|c|c|c|}
\hline State & RTP Tariff & $\begin{array}{c}\text { Marketing of } \\
\text { RTP }\end{array}$ & $\begin{array}{c}\text { Education } \\
\text { about } \\
\text { Electricity } \\
\text { Markets }\end{array}$ & $\begin{array}{c}\text { Technical } \\
\text { Assistance } \\
\text { with Load } \\
\text { Response }\end{array}$ & $\begin{array}{c}\text { Financial } \\
\text { Assistance } \\
\text { with End-Use } \\
\text { Technology }\end{array}$ \\
\hline New Jersey & Statewide default RTP & - & Utilities \& BPU & - & - \\
\hline Maryland & Statewide default RTP & - & Utilities \& PSC & - & - \\
\hline Pennsylvania & DLC default RTP & - & - & - & - \\
\hline \multirow[t]{3}{*}{ New York } & NMPC default RTP & - & \multirow{3}{*}{$\begin{array}{r}\text { Utilities \& } \\
\text { NYSERDA }\end{array}$} & \multirow[t]{3}{*}{ NYSERDA } & \multirow[t]{3}{*}{ NYSERDA } \\
\hline & Statewide optional RTP & Utilities & & & \\
\hline & CHG\&E default RTP & - & & & \\
\hline Illinois & ComEd default RTP & - & - & - & - \\
\hline Ohio & CG\&E default RTP & - & - & - & - \\
\hline \multirow[t]{2}{*}{ Oregon } & PGE optional RTP & Utility & $\begin{array}{c}\text { Utility and } \\
\text { OPUC }\end{array}$ & Utility & - \\
\hline & $\begin{array}{l}\text { PGE optional daily } \\
\text { TOU pricing }\end{array}$ & - & - & - & - \\
\hline Georgia & GPC optional RTP & Utility & Utility & - & - \\
\hline
\end{tabular}

The optional RTP tariffs have been marketed to varying degrees. (For obvious reasons, RTP tariffs offered only as a default service do not require any marketing.) GPC has made RTP a central element in their efforts to recruit new C\&I customers, most of which have a choice of supplier, by constructing offers for these customers based on RTP with different CBL levels. The company also markets RTP to existing customers that are expanding their operations, but does not formally market RTP to other existing customers (most of whom are presumed to already be familiar with the RTP rates given their considerable notoriety). PGE marketed their RTP pilot through customer account representatives for several months in 2004, after the program was first launched. The company has since discontinued any active marketing for the program, having reevaluated its viability and appropriateness in light of current market conditions (PGE 2004). ${ }^{50}$ In New York, the utilities were recently ordered by the NYPSC to step up customer education and marketing activities for their optional RTP tariffs, in order to boost participation. ComEd, whose RTP tariff has been offered on an optional basis since 1998, has conducted no marketing for RTP. The state's restructuring law requires utilities to choose whether or not they will compete for retail load; and if they choose not to compete (i.e., to become an Integrated Distribution Company), as ComEd has done, they are prohibited from actively seeking to recruit or retain customers, which effectively limits any marketing for RTP.

Among the case studies with optional RTP, customer education about electricity markets (e.g., market structure, price trends, fundamentals, hedging options, etc.) is typically integrated to some extent into the marketing process. GPC also provides a high level of ongoing customer support and education for its RTP participants. Once per year, the utility invites all RTP customers to an "RTP Forum", where GPC staff provide training on the rate and talk about expected conditions and pricing for the next year. Each RTP customer is also assigned a client

\footnotetext{
${ }^{50}$ RTP prices are expected to be higher, on average, than the cost-of-service (CBL) rate in 2005, thus diminishing much of the potential load building benefits that customers could obtain and raising potential free-rider problems associated with customers that are planning to reduce load regardless of pricing enrolling in the tariff and thereby receiving payments for load reductions they were already planning on making. Also, in response to the Western electricity crisis in 2000/2001 and the subsequent rate hikes, PGE is emphasizing a commitment to providing stable and predictable electricity prices, with which RTP is potentially at odds.
} 
manager, who serves as their point of contact for questions about RTP and can provide some help with developing strategies for managing exposure to price risk. Finally, GPC sends out information and warnings to RTP customers if a big change in prices has occurred or is anticipated. In several of the default RTP cases, utilities or the PSC have held workshops to inform affected customers about the default rate, market prices, and alternative supply options available. However, the emphasis of these activities typically has been to make sure that customers have enough information to make informed decisions about their supplier, rather than to help them develop effective risk management strategies that might facilitate continued enrollment in default RTP.

The only examples among the case studies where any type of technical or financial assistance has been offered are New York and Oregon. In New York, NYSERDA offers several programs, funded through the System Benefits Charge, that provide technical assistance and financial incentives for enabling technologies (e.g., interval meters, EMS, load controls, EIS, and DG). These programs were developed to facilitate demand response in the state and are targeted not only to customers on RTP, but also to participants in the NYISO demand response programs. In Oregon, PGE offers a limited form of technical assistance, incorporated into their marketing efforts, by helping prospective participants analyze the potential bill impacts of different scenarios. ${ }^{51}$

The lack of technical and financial assistance in the other states reflects several factors. In cases involving default RTP, demand response has generally not been a primary goal, and therefore there hasn't been a compelling motivation for offering such programs. Several of these states also lack some of the infrastructure necessary for delivering technical or financial assistance, for example, if utilities are prohibited or discouraged from offering DSM programs or other "behind-the-meter" services, and no independent program administrator (such as NYSERDA) has been designated.

\subsection{Customer Participation in RTP}

In an environment where customers have a choice between RTP and alternative supply options, the amount of load participating in RTP is one of the key determinants, along with customers' price elasticity, driving the overall magnitude of load response to spot market price volatility. In any given market, RTP participants might include: customers that have voluntarily opted onto a utility RTP tariff; customers that were automatically transferred to a default RTP tariff and have not switched to a competitive supplier or transferred to an alternative utility option; and customers that have switched to a competitive supplier under an arrangement where the price for some or all of their usage is indexed to the spot market. The first two groups are the subjects of this section; the third group is addressed in Chapter 5.

For each case study, we obtained data on RTP participation, in terms of the number of customers enrolled (as of some recent date) and their combined peak demand, as well as corresponding data on the population of eligible and/or default customers (see Table 4-7).

\footnotetext{
51 The Energy Trust of Oregon, the independent administrator of ratepayer-funded energy efficiency and renewable energy programs in Oregon, does not currently offer programs targeting DR enabling technology adoption.
} 
Table 4-7. Optional and Default RTP Customer Population and Participation in Early 2005

\begin{tabular}{|c|c|c|c|c|c|c|}
\hline \multirow[b]{2}{*}{ State } & \multirow[b]{2}{*}{ RTP Tariff } & \multirow[b]{2}{*}{$\begin{array}{l}\text { Start } \\
\text { Date }\end{array}$} & \multicolumn{2}{|c|}{ Default/Eligible Customers } & \multicolumn{2}{|c|}{ Participating Customers } \\
\hline & & & $\begin{array}{c}\text { No. of } \\
\text { Customers } \\
\text { or Accounts }\end{array}$ & $\begin{array}{l}\text { Peak Load } \\
\text { (MW) }\end{array}$ & $\begin{array}{c}\text { No. of } \\
\text { Customers } \\
\text { or Accounts }\end{array}$ & $\begin{array}{l}\text { Peak Load } \\
\text { (MW) }\end{array}$ \\
\hline NJ & $\begin{array}{l}\text { Statewide Default RTP }^{\mathrm{a}} \\
\text { Eligible to opt-in }\end{array}$ & $\begin{array}{l}8 / 03 \\
8 / 03\end{array}$ & $\begin{array}{c}1,877 \\
482,000\end{array}$ & $\begin{array}{l}2,920 \\
9,500\end{array}$ & $\begin{array}{c}677 \\
61\end{array}$ & $\begin{array}{c}461 \\
25\end{array}$ \\
\hline MD & $\begin{array}{l}\text { Statewide Default RTP } \\
\text { Eligible to opt-in }^{\text {b }}\end{array}$ & $\begin{array}{l}6 / 05 \\
7 / 04 \\
\end{array}$ & $\begin{array}{l}1,539 \\
1,539 \\
\end{array}$ & $\begin{array}{l}2,383 \\
2,383 \\
\end{array}$ & $\begin{array}{l}\text { NI } \\
27 \\
\end{array}$ & $\begin{array}{l}\mathrm{NI} \\
42 \\
\end{array}$ \\
\hline $\mathrm{PA}$ & DLC Default RTP $^{\mathrm{C}}$ & $1 / 05$ & 860 & 1,050 & 59 & 35 \\
\hline \multirow[t]{3}{*}{$\mathrm{NY}$} & NMPC Default RTP $^{\mathrm{d}}$ & $11 / 98$ & 149 & 545 & 49 & 183 \\
\hline & Statewide Optional RTP ${ }^{\mathrm{e}}$ & $5 / 01$ & No data & 5,000 & 32 & No data \\
\hline & CHG\&E Default RTP & $4 / 05$ & 62 & 340 & $\mathrm{NI}$ & NI \\
\hline IL & $\begin{array}{l}\text { ComEd Default RTP }^{\mathrm{f}} \\
\text { Eligible to opt-in }\end{array}$ & $\begin{array}{c}1 / 07 \\
10 / 98 \\
\end{array}$ & $\begin{array}{c}350 \\
347,000 \\
\end{array}$ & $\begin{array}{c}2,500 \\
12,500 \\
\end{array}$ & $\begin{array}{l}\mathrm{NI} \\
40 \\
\end{array}$ & $\begin{array}{c}\text { NI } \\
\text { No data }\end{array}$ \\
\hline $\mathrm{OH}$ & CG\&E Default RTP & $1 / 05$ & NA & NA & No data & No data \\
\hline \multirow[t]{2}{*}{ OR } & PGE Optional RTP Pilot $^{g}$ & $1 / 04$ & 150 & 400 & 0 & 0 \\
\hline & PGE Daily TOU Option ${ }^{\mathrm{g}}$ & $3 / 02$ & 14,384 & 1,887 & 20 & 25 \\
\hline GA & GPC Optional RTP $^{\mathrm{h}}$ & 1993 & 3,880 & 6,100 & 1,664 & 5,050 \\
\hline
\end{tabular}

Notes: NI = not yet implemented in early 2005, NA = not applicable

a. Switching statistics for CIEP class dated February 28, 2005 (NJBPU, 2005). Optional participation by eligible customers dated January 19, 2005 (BGS Auction 2005).

b. Optional participation by eligible customers dated February 2005 (MDPSC 2005).

c. Switching statistics dated March 2005 (DLC 2005).

d. Switching statistics dated August 2004 (Goldman et al. 2005)

e. Participation as of September 2004 (NYPSC 2004b)

f. Participation as of January 2005 (ComEd 2005)

g. Participation as of December 2004 (PGE 2004)

h. Participation as of November 2004 (GPC 2004)

\subsubsection{Eligible/Default customer population}

Each RTP tariff (default and optional) has an eligibility threshold that defines the population of customers eligible for the tariff, and each default RTP tariff has a default threshold that defines the population of customers for which RTP is the default service (which may be the same as, or a sub-set of, the eligible customer population). Understanding the size of these populations gives some measure of the technical potential for RTP participation and provides context for interpreting market penetration rates.

The largest eligible customer populations (on the order of $10 \mathrm{GW}$ each) are in New Jersey and ComEd's service territory, where all non-residential customers are eligible for RTP, and in New York, where all utilities except NMPC offer optional RTP with relatively low eligibility thresholds. GPC, which has a low eligibility threshold and a large system load, has an eligible customer population of approximately $6 \mathrm{GW}$. PGE is a much smaller utility and has an eligible customer population of $1.6 \mathrm{GW}$ for their daily TOU pricing option and just $700 \mathrm{MW}$ for their RTP pilot (although the tariff currently has a enrollment cap of six customers).

In 2004, the combined peak demand of the default customer populations was 4,500 MW, across the three case studies with default RTP in place: New Jersey, Pennsylvania (DLC), and New York (NMPC). This total will reach 6,900 MW after RTP becomes the default service in 
Maryland in 2005, and 9,700 MW when and if RTP becomes the default service for customers of CHG\&E and ComEd, as currently planned. The largest default customer populations are in New Jersey, Maryland, and ComEd, reflecting the relatively large size of the total system load in these cases. $^{52}$

\subsubsection{RTP participation}

Among the three default RTP tariffs in place in the U.S. in early 2005 (New Jersey, DLC, and NMPC), approximately $700 \mathrm{MW}$ remained on the rate, equal to about $15 \%$ of the total load (27\% of customers) in the default RTP customer classes. ${ }^{53}$ The remaining $73 \%$ of customers in these default customer classes has either switched to a competitive supplier or, in the case of DLC, has opted onto another utility rate. Of these three cases, New Jersey and NMPC have relatively high participation levels, each with $>30 \%$ of customers in the default RTP class remaining on RTP (see Figure 4-3). In comparison, within only months after implementation, only $7 \%$ of the applicable customers in DLC's service territory have remained on default RTP.

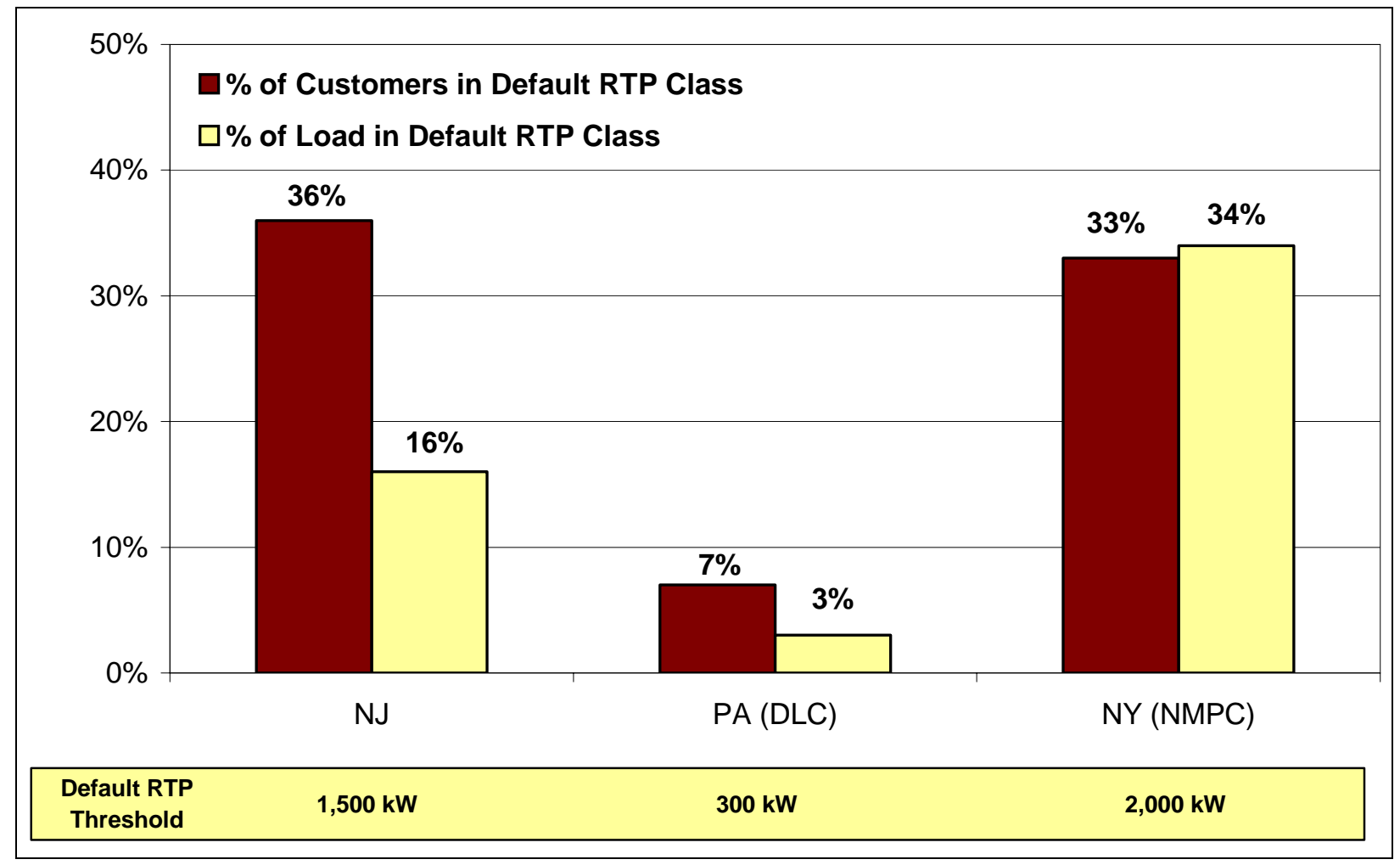

Figure 4-3. Customer Participation Rates in Default RTP in Early 2005

Several tariff design issues may contribute to these differences. First, DLC is temporarily offering an alternative, fixed price utility supply option for customers in the default RTP class that are unable to procure a competitive supply contract and do not want to remain on the default

\footnotetext{
${ }^{52}$ System peak demand is approximately $18 \mathrm{GW}$ in New Jersey, 15 GW in Maryland, and 22 GW in ComEd's service territory.

${ }^{53}$ In comparison, Barbose et al. (2004) reports that, in 2003, a total of approximately 11,000 MW was enrolled in optional RTP tariffs in the U.S.
} 
rate. As of early $2005,88 \%$ of the load in the default RTP class that had not switched to a competitive supplier had opted onto the fixed price alternative. Second, the DLC default threshold is much lower than in New Jersey and for NMPC (300 kW, compared to 1,500 kW and $2,000 \mathrm{~kW}$, respectively). If, as many suppose, smaller customers are less predisposed than larger customers to RTP, then, all other things equal, one would expect lower participation rates among DLC customers. ${ }^{54}$ Third, NMPC's RTP tariff provides price notification on a day-ahead, rather than after-the-fact, basis; survey results reported in Goldman et al. (2005) indicate that NMPC customers are more willing to remain on RTP with this greater advance notice.

The differences in participation rates among RTP tariffs offered on an optional basis are quite stark. GPC has the largest amount of load on RTP of any optional or default RTP tariff in the country (Barbose et al. 2004). Several factors have contributed to their success: the tariffs have been available for more than a decade; the utility aggressively markets RTP and provides a high level of ongoing customer support; and, perhaps most importantly, GPC's procedure for establishing customers' CBL enables participants to obtain significant bill savings relative to their other tariffs, by purchasing a substantial portion of their total energy usage at marginal cost based rates, not subject to the same embedded cost responsibility as the standard, non-RTP tariff rate. $^{55}$

In comparison, the other RTP tariffs offered on an optional basis have generated quite limited participation (see Figure 4-4). Only a handful of customers have enrolled on the optional RTP tariffs in New York, despite being having been available to the vast majority of non-residential customers for more than four years. ${ }^{56}$ NYPSC staff attributes the low participation to a lack of customer understanding of RTP (in particular, an overstated sense of the associated risk) and also to the limited potential bill savings, citing analyses performed by utilities showing that only a small percentage of eligible customers would have lower bills on RTP, absent load shifting (NYPSC 2004b). In Oregon, no customers have enrolled in PGE's RTP pilot. Market prices in the region are currently higher than the utility's cost-of-service rate, thus dampening customers' potential benefits from building load at marginal cost-based market prices. ComEd's RTP tariff, which has been offered on an optional basis to all non-residential customers since 1998, currently has about 40 customers enrolled, comprising less than 1\% of the eligible customer population. As discussed in Section 4.5, ComEd is prohibited from actively seeking to retain or recruit customers, which constrains the extent to which it can conduct any overt marketing for RTP. Utility staff suggested that, of those customers that have enrolled, some may have done so to take advantage of the lower average prices on RTP compared to the utility's standard tariff, or to accrue bill savings by running onsite generation during high price periods. Other participants

\footnotetext{
${ }^{54}$ One might argue that, at the same time, smaller customers are likely to face more difficulty attracting competitive alternatives, which would tend to have a countervailing effect. However, the high switching rates for Maryland and DLC C\&I customers, across all size ranges, suggests that this has not been a dominant issue.

${ }^{55}$ Three specific aspects of the CBL provisions are important in this regard. First, new industrial customers receive, by default, a CBL equal to $60 \%$ of their projected load. Second, all new customers (industrial and commercial) are able to receive a CBL below the default level if they can satisfy the demonstration requirements. Third, all RTP participants (new and existing) can maintain their initial CBL indefinitely over the term of their enrollment.

${ }^{56}$ In fact, the vast majority of those that have enrolled are on NYSEG's tariff, which provides only a shadow bill based on RTP prices, but continues to bill customers based on standard tariff rates.
} 
are among the limited class of customers that are currently ineligible for any of the utility's other rates. $^{57}$

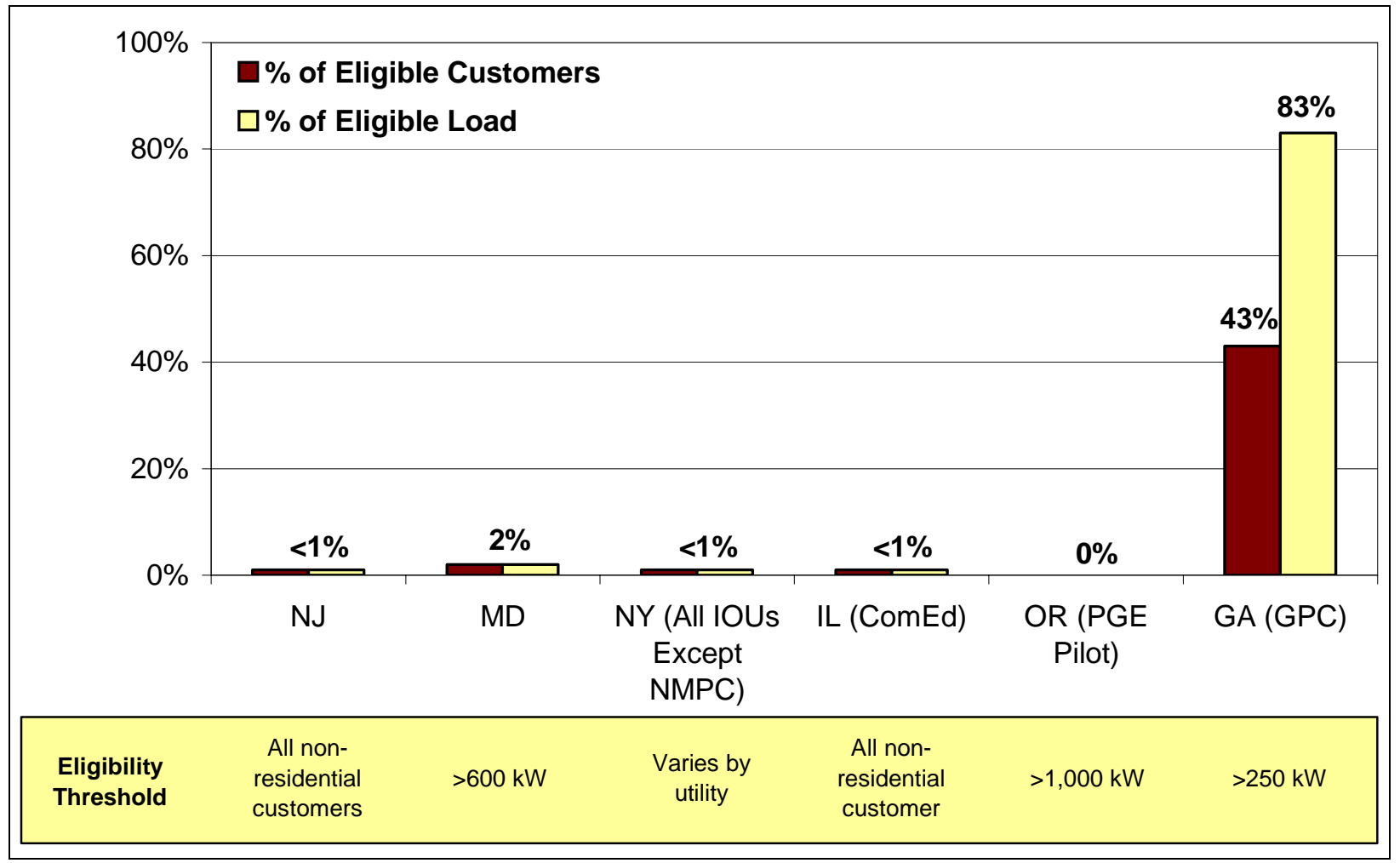

Figure 4-4. Customer Participation in Optional RTP in Early 2005

\subsection{Price Response from RTP Participants}

For six of the case studies (NJ, MD, PA, IL, OH, and OR), the price responsiveness of, or load reductions from, RTP participants has not yet been analyzed, according to the regulatory staff and utilities interviewed. Many of these tariffs have only recently been implemented and/or few customers have participated; thus there may not yet have been enough experience to warrant analysis. However, based on our discussions with regulatory staff in many of the states with default RTP, it is not clear that there is a perceived need for analyzing the DR impacts of default RTP tariffs or who should bear that responsibility.

GPC has commissioned several studies to estimate the price response of customers on their dayahead and hour-ahead RTP tariffs. An analysis of summer 1999 experience estimated that the combined load reduction across participants in both tariffs was 750-800 MW when hourly prices reached \$1.93/kWh for RTP-DA and \$6.43/kWh for RTP-HA. ${ }^{58}$ Approximately two-thirds of this load reduction was associated with RTP-DA participants, and the remaining third was from RTP-HA participants. An analysis of summer 2000, when prices were less extreme than summer

\footnotetext{
57 Currently, new customers $>3$ MW and customers that returned to ComEd from a competitive supplier and opted for a fixed multi-year Customer Transition Charge are eligible only for RTP.

58 These were the maximum hourly prices on the day that this load reduction occurred. The average peak period prices on this day were approximately \$1.50/kWh for RTP-DA and \$2.00/kWh for RTP-HA.
} 
1999, found that the RTP customers produced a maximum load reduction of 482 MW (GPC 2004c). This is approximately the peak load reduction that the utility attributes to their RTP tariffs in their IRP load forecasts, assuming typical summer conditions. GPC reports that most RTP customers require a price of at least $\$ 0.20-0.30 / \mathrm{kWh}$ before they respond, although some customers, particularly those with onsite generation, respond to lower prices (GPC 2004b). ${ }^{59}$

In addition to temporary load reductions, there is anecdotal evidence to suggest that some of GPC’s RTP customers have also undertaken various permanent load modifications.

Representatives of four large retail and department store chains (BJ's, Kohl's, Lowe's, and WalMart) testified in GPC's 2004 rate case that, as a result of taking service on RTP, their companies have installed a range of permanent measures to reduce peak electricity demand and to take advantage of low off-peak prices, including: high efficiency air-conditioning and building envelope components; fuel switching (e.g., gas-driven desiccant cooling systems); and electric heating (Civic et al. 2004).

Notwithstanding the substantial load response that customers enrolled in GPC's RTP tariffs have demonstrated, GPSC staff has raised several issues regarding the value of RTP as a load management tool. One concern is that, despite the sizable aggregate load response, many RTP customers appear to not respond to hourly prices. PSC staff suggested that the fact that many customers can reduce their energy costs on RTP compared to the standard tariff without responding to hourly prices "may induce customers to simply 'ride through' limited hours of higher prices” (Best et al. 2004). As a result, additional generation capacity may be required, reducing hourly prices and further dampening the incentive for RTP customers to reduce their peak demand (GPSC 2004a). PSC staff also raised the concern that, "since it appears that RTP is being used to compete for new loads, the Company's claims of peak load reduction benefits to its system really do not exist," or in other words, that the overall load growth facilitated by RTP may offset the temporary load reductions induced by high RTP prices (Best et al. 2004). Despite these concerns, staff acknowledged that the RTP tariffs serve a variety of purposes other than peak load management, such as allowing the utility to compete for new loads and promoting economic development (Cearfoss and Wilson 2004).

The price responsiveness of customers on NMPC's default RTP tariff was analyzed by Goldman et al. (2005). This evaluation included an analysis of hourly usage and price data for five summers (2000-2004), supplemented by customer surveys and interviews that provided information about customer characteristics and circumstances, load response strategies, and their supply arrangements with ESCOs (e.g. whether they had hedged contracts). Major findings of this study related to the price responsiveness of the default RTP customer class are as follows:

- The load-weighted average elasticity of substitution of the class is estimated to be 0.11 (e.g. a doubling of the peak price relative to the off-peak price that day would result in an $11 \%$ reduction in peak electricity usage). This price response is associated with both those customers that have remained on the default service RTP rate as well as from those that have switched to a competitive supplier and signed a contract that exposes them to hourly spot market prices.

\footnotetext{
${ }^{59}$ Load reductions associated with onsite generation account for approximately 100-200 MW of the total RTP load response (GPC 2004b). Much of the current RTP response from onsite generation is associated with pulp and paper mills that increase electricity production from their cogeneration units during high price periods, to displace purchases from the utility.
} 
- At the highest peak to off-peak price ratio observed during the five summers (5:1), the 119 accounts are estimated to reduce their usage on peak by about $50 \mathrm{MW}$, an $11 \%$ reduction from their typical usage.

- The $20 \%$ of customers that are most price responsive (i.e. with an elasticity of substitution greater than 0.10 ) account for $75-80 \%$ of the estimated aggregate load response of the class.

\subsection{Other DR Mechanisms for Large C \&I Customers}

Default and optional RTP tariffs are but one type of mechanism that can be incorporated into retail electricity markets to induce DR (see Chapter 3). Understanding what other DR mechanisms are available in the case study states, and how they have performed, provides important context and a useful point of comparison for understanding the role of RTP as a strategy for developing DR. In this section, we describe the DR mechanisms other than RTP that were offered by utilities and ISO/RTOs in the case study states in 2004; DR mechanisms offered by competitive retail suppliers are the subject of Chapter 5.

\subsubsection{DR programs and interruptible service rates}

In each of the case study states, multiple DR programs were available to large C\&I customers in 2004 (see Table 4-8). In all of the regions that were part of an ISO/RTO market in 2004 (New Jersey, Maryland, New York, and ComEd's service territory in Illinois), C\&I customers could participate in various ISO/RTO DR programs (see Text Box 4-2). ${ }^{60,61}$ Most of these programs have been introduced during the past 4-5 years in an effort to improve wholesale market performance and system reliability, consistent with FERC's policy directives for RTOs to integrate DR into wholesale market design. Most utilities in these states have registered with the ISO/RTO as a DRSP, and offer the programs to their customers under nearly identical terms as the ISO/RTO program, perhaps retaining a portion of the incentive payment to cover administrative costs and/or offering the program with expanded curtailment hours to respond to T\&D system contingencies. ${ }^{62}$ Various unregulated entities, including competitive retail suppliers and dedicated DR aggregators, also participate in the ISO/RTO DR programs, although the terms and conditions under which they offer programs to retail customers are not public.

\footnotetext{
${ }^{60}$ DLC joined PJM at the start of 2005.

${ }^{61}$ PJM's ALM program is not exclusively for large C\&I customers; it includes a large number of utility direct load control programs for residential and small C\&I customers as well.

${ }^{62}$ The NYPSC issued an order in 2000 requiring that all of the state's investor-owned utilities offer tariffs that allow retail customers to participate in NYISO's DR programs.
} 
Table 4-8. Utility and ISO/RTO DR Programs Applicable to C\&I Customers in 2004

\begin{tabular}{|c|c|c|c|}
\hline \multirow[t]{2}{*}{ State (Utility) } & \multicolumn{3}{|c|}{ DR Mechanism Type } \\
\hline & $\begin{array}{c}\text { Call Option Load } \\
\text { Reduction Programs and } \\
\text { Interruptible Tariffs } \\
\end{array}$ & $\begin{array}{c}\text { Scheduled Load } \\
\text { Reduction Programs }\end{array}$ & $\begin{array}{c}\text { Voluntary Load } \\
\text { Reduction Programs }\end{array}$ \\
\hline $\begin{array}{l}\text { New Jersey (statewide) } \\
\text { Maryland (statewide) }\end{array}$ & PJM ALM Program & $\begin{array}{l}\text { PJM Economic LRP - Day- } \\
\text { Ahead Option }\end{array}$ & $\begin{array}{l}\text { PJM Economic LRP - Real } \\
\text { Time Option, } \\
\text { PJM Emergency LRP }\end{array}$ \\
\hline \begin{tabular}{|l} 
Pennsylvania (DLC) \\
\end{tabular} & Interruptible service $^{\text {a }}$ & - & Energy Exchange \\
\hline New York (statewide) & NYISO ICAP/SCR Program & NYISO DADRP & NYISO EDRP \\
\hline Illinois (ComEd) & $\begin{array}{l}\text { ComEd Rider } 26 \\
\text { (Interruptible Service) } \\
\text { ComEd Rider } 27 \\
\text { (Displacement of Self } \\
\text { Generation) } \\
\text { ComEd Rider } 30 \text { (The } \\
\text { Alliance) } \\
\text { PJM ALM Program } \\
\end{array}$ & $\begin{array}{l}\text { PJM Economic LRP - Day- } \\
\text { Ahead Option }\end{array}$ & $\begin{array}{l}\text { ComEd Early Advantage } \\
\text { ComEd Rider } 32 \text { (Energy } \\
\text { Cooperative) } \\
\text { ComEd Voluntary Load } \\
\text { Response Program } \\
\text { PJM Emergency LRP } \\
\text { PJM Economic LRP - Real } \\
\text { Time Option }\end{array}$ \\
\hline Ohio (CG\&E) & $\begin{array}{l}\text { PowerShare - CallOption, } \\
\text { Interruptible contracts }\end{array}$ & - & PowerShare - QuoteOption \\
\hline Oregon (PGE) & \begin{tabular}{|l} 
Dispatchable Standby \\
Generation Program
\end{tabular} & - & Demand Buy Back Program \\
\hline Georgia (GPC) & $\begin{array}{l}\text { Demand Plus Energy Credit } \\
\text { Rider }\end{array}$ & $\begin{array}{l}\text { (Day-Ahead) Daily Energy } \\
\text { Credit Rider }\end{array}$ & - \\
\hline
\end{tabular}

a. DLC cancelled their interruptible service tariffs in 2005.

Utilities in New Jersey, Maryland, and New York have phased out their legacy load management programs for C\&I customers or integrated them into the ISO/RTO DR programs. In contrast, ComEd, which has built up a broad portfolio of DR programs over the past decade, is in the process of integrating these programs into the PJM market framework. According to utility staff, the company is planning a transition and partial exit from DR program responsibilities over the next three years - phasing out some of their legacy load management programs, aligning customer incentives for the remaining programs with the PJM framework, and possibly seeking cost recovery for DR programs that are not self-funding. As part of this transitional process, ComEd modified its Voluntary Load Response (VLR) Program in 2004 so that it would become the vehicle through which customers could participate in PJM's Emergency Load Response Program. VLR participants are now called for curtailments by PJM during Emergency LRP program events, and the full PJM incentive payments are passed through to the customer. ComEd has also retained the capability to call for load curtailments through the VLR program independent of PJM, to mitigate reliability conditions in their T\&D system and provide a separate T\&D-related incentive payment.

The four utilities in the remaining case studies (DLC, CG\&E, PGE, and GPC), have all introduced new DR programs or substantially revised existing programs in the past five or so years (in some cases also continuing their legacy interruptible service rates). All four utilities have recently launched “economic” DR programs that provide performance-based payments for load reductions during periods when marginal supply costs or spot market prices are projected to be high. GPC's program (Daily Energy Credit rider) requires that customers commit on an event-by-event basis; the other three (DLC’s Energy Exchange, CG\&E’s PowerShare QuoteOption, and PGE’s Demand Buy Back) require no commitment. Most of these new programs were introduced during or immediately following periods of unprecedented volatility 
in the spot market in each region, and were motivated by an enhanced recognition of the potential role for DR to displace short-term market purchases (in addition to the established role of DR as a long-term capacity resource). ${ }^{63}$

CG\&E and GPC have both also introduced programs during the last five years that represent a new generation of interruptible service (PowerShare - CallOption and Demand Plus Energy Credit, respectively). Unlike traditional interruptible rates, which provide payments entirely based on a customer's contracted load response capability and have rigid commitment terms, these new programs provide both capacity and energy payments, and offer participants several options with respect to the number of curtailment hours and the frequency of curtailment calls.

\section{Text Box 4-2. PJM and NYISO DR Programs}

\section{PJM DR Programs}

- $\quad$ Active Load Management (ALM) Program. The program provides LSEs with a credit against their capacity obligation for committing to provide load reductions during emergency events declared by PJM. Participants that fail to comply with their load reduction commitment are assessed a deficiency penalty.

- Economic Load Response Program - Day-Ahead Option. The program offers participants the option to submit load reduction bids into the day-ahead energy market. If their bid is accepted, they are paid for their accepted bid, based on the day-ahead market clearing price. If a participant's load reduction is less than their accepted bid, they are charged for the difference at the real-time market clearing price and are assessed charges for balancing operating reserves.

- Economic Load Response Program - Real-Time Option. Program participants can choose to provide load reductions at any time or be dispatched by PJM in the real time market, and are paid for their measured load reduction at the real-time market clearing price.

- Emergency Load Response Program. Program participants are paid for load reductions during emergency events declared by PJM. Payments are based on participants' measured load reduction and the greater of the real time market clearing price or \$500/MWh. No penalties are assessed if participants do not respond.

\section{NYISO DR Programs}

- Installed Capacity/Special Case Resources (ICAP/SCR) Program. Program participants receive an up-front reservation payment for committing to provide load reductions during emergency events declared by NYISO. Participants receive additional payments for actual load reductions, based on the amount curtailed and the greater of the prevailing real time market clearing price or the participant's designated strike price. Participants that fail to comply with their load reduction commitment are de-rated for future reservation payments and may be assessed a deficiency penalty.

- Day-Ahead Demand Response Program (DADRP). The program offers participants the option to submit load reduction bids into the day-ahead energy market. If their bid is accepted, they are paid for their accepted load reduction bid based on the day-ahead market clearing price. Any imbalance between a participant's actual load reduction and their accepted bid is settled at the higher of the day-ahead and real-time market clearing prices.

- $\quad$ Emergency Demand Response Program (EDRP). Program participants are paid for load reductions during emergency events declared by NYISO, at a price equal to the greater of the real time market clearing price or \$500/MWh. No penalties are assessed if participants do not respond.

\footnotetext{
${ }^{63}$ In GPC's case, the connection with spot market volatility was indirect. In 1999, hourly prices reached unprecedented levels of $\$ 6.43 / \mathrm{kWh}$ for RTP-HA and $\$ 1.93 / \mathrm{kWh}$ for RTP-DA. In the course of a proceeding in the following year, GPC indicated that RTP prices could be substantially reduced if interruptible customers were called in response to economic conditions (Hinson et al 2000). In response, the PSC ordered GPC to introduce a new set of interruptible service options that would allow for load curtailments to be dispatched on an economic basis.
} 


\subsubsection{DR program participation and demonstrated load reductions}

Several DR programs offered by utilities and ISO/RTOs in the case studies had substantial levels of participation in 2004 (see Figure 4-5 and

Table 4-9). ${ }^{64}$ NYISO has built up a large base of participants in its programs. Its two reliability programs, ICAP/SCR and EDRP, together constitute a contracted or nominated load reduction capability equal to about 5\% of the system peak demand, while customers enrolled in NYISO's economic program, DADRP, have nominated a combined load reduction capability equal to about $1 \%$ of the statewide system peak. ComEd also has a sizable base of C\&I load (a subscribed load reduction potential of approximately 1,200 MW) across its portfolio of DR programs. Their largest program, VLR, doubled in size from 2001-2004, to approximately 800 MW. Finally, two utilities, DLC and Georgia Power, had relatively sizable interruptible/curtailable rates in 2004, which constituted a contracted interruptible load equal to $3-4 \%$ of each utility's total system peak demand. ${ }^{65}$

Other utility DR programs among the case studies have attracted more modest levels of participation (e.g., DLC's Energy Exchange program and GPC's Daily Energy Credit rider) or have experienced a significant decline in participation over the past several years (e.g., CG\&E's PowerShare programs and PGE's Demand Buy Back program). Utility staff attributed this to several factors, including low spot market prices and correspondingly low incentives over the past several years, as well as competition from other suppliers or other utility DR programs. For example, GPC staff indicated that, since their Daily Energy Credit (DEC) program was introduced in 2001, the incentives offered for load reductions have generally remained below a level of $\$ 0.15-\$ 0.25 / \mathrm{kWh}$ deemed necessary for customers to respond. Perhaps more fundamentally, GPC staff also suggested that most of the company's price responsive customers are already enrolled on RTP and the DEC program rules are such that RTP customers would have little financial incentive to participate in the DEC program. ${ }^{66}$

In addition to participation data, we collected a limited amount of information about the actual load reductions achieved by some of these DR programs over the past 3-4 years (see Figure 4-6 and

Table 4-9). Many of the programs have had little operational experience in recent years, because spot market prices have been low and system operators have had few occasions where load reductions were required for reliability purposes. In general, the largest load reductions have occurred among those programs that have had the largest participation levels. In terms of programs' actual load reductions relative to participants' subscribed load reduction amount, call option programs have generally performed best, because of participants' incentive to avoid noncompliance penalties. Voluntary load reduction programs have also generated significant load reductions when incentive payments have been large enough (e.g., NYISO's EDRP, which offers

\footnotetext{
${ }^{64} \mathrm{DR}$ program participation is denominated in terms of customers' contracted or nominated load reduction (i.e., the load reduction amount that, upon enrolling in the program, customers indicate they are willing to provide), and is therefore not directly comparable to the RTP participation statistics presented in Section 4.6, which are denominated in terms of customers' combined peak or billing demand.

${ }^{65}$ DLC cancelled their interruptible tariff in 2005, upon joining PJM.

${ }^{66}$ Specifically, customers cannot receive a bill credit for the same load reduction quantity under both the DEC rider and RTP.
} 
${ }^{g}$ In 2001, enrollment in the PowerShare - QuoteOption program was 274 MW, throughout all three of Cinergy's utility service territories (CG\&E, PSI, and UHL\&P); enrollment in the PSI service territory (Indiana) declined from 148 MW to 38 MW between 2001 and 2003 (Rogers 2001 and Rogers 2003).

${ }^{\mathrm{h}}$ Cinergy reports that this program produced a load reduction of $50 \mathrm{MW}$ in their PSI service territory (Indiana) during the first program event in February 2003 (Rogers 2003). ${ }^{\mathrm{i}}$

I As of September 2001, the program had 26 participants with $175 \mathrm{MW}$ of potential curtailable load (Goldman et al. 2002).

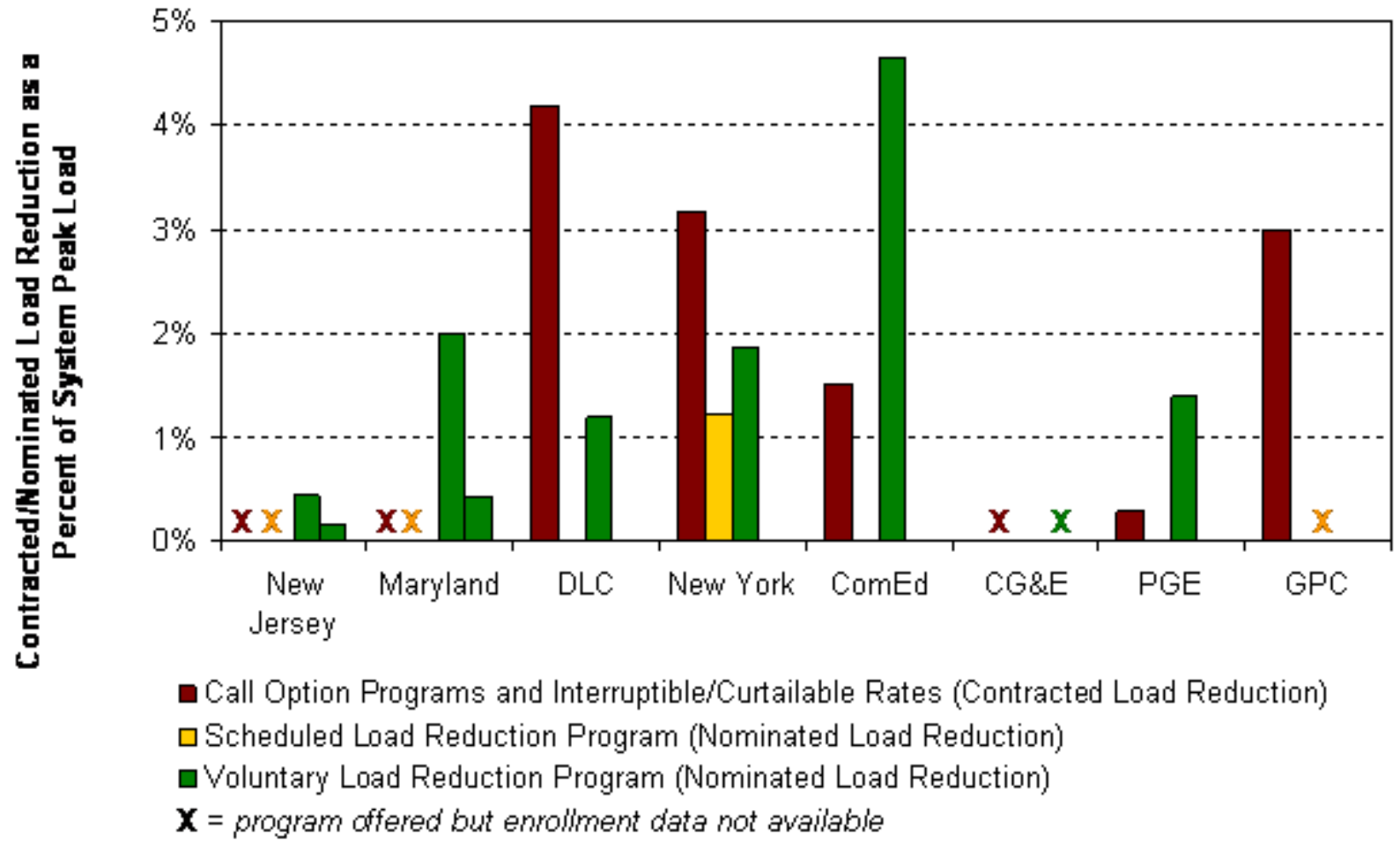

Figure 4-5. DR Program Enrollment in 2004 as a Percent of System Peak Load 
Real Time Pricing as a Default or Optional Service for C\&I Customers

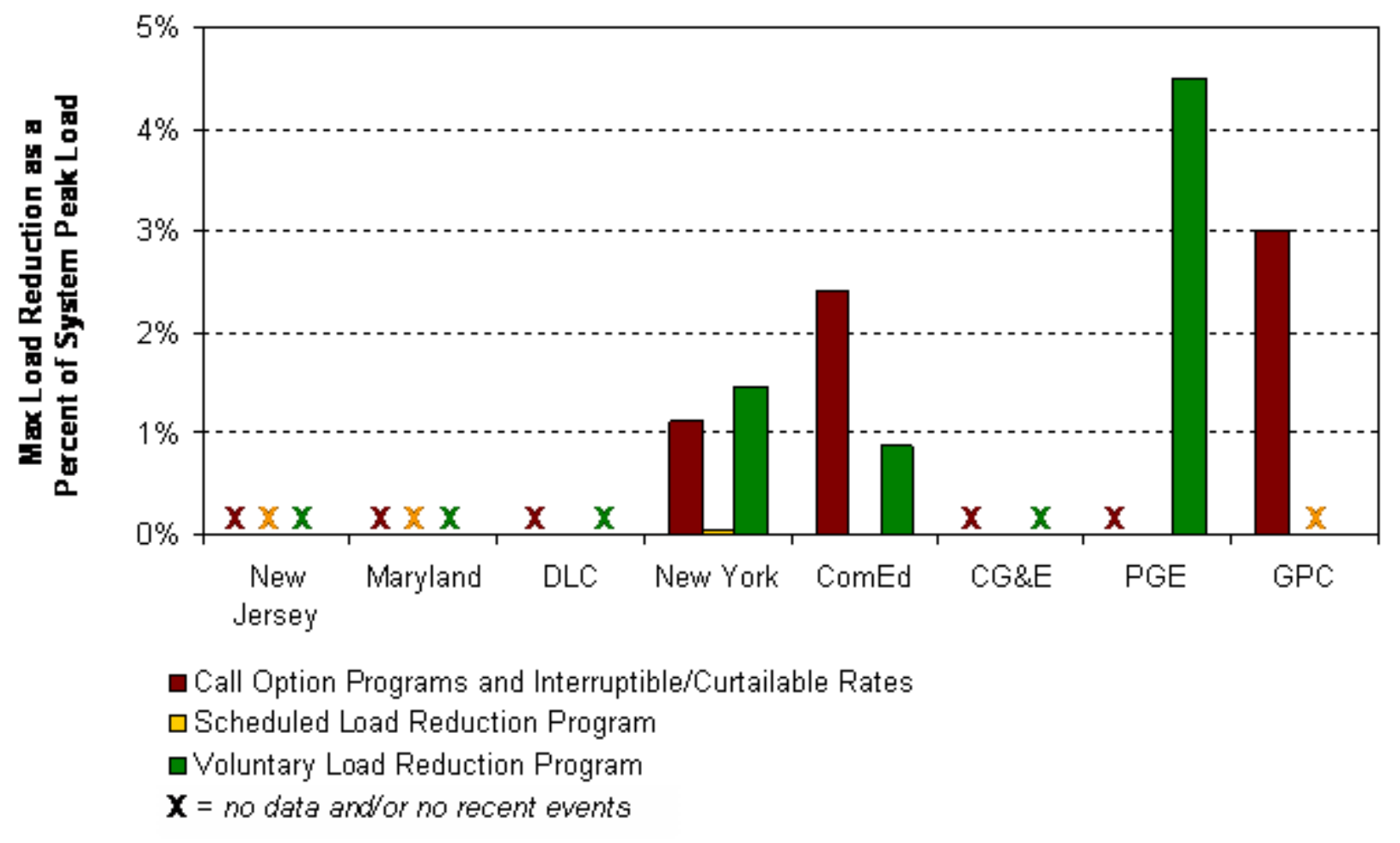

Figure 4-6. DR Program Maximum Load Reductions as a Percent of System Peak Load 


\section{Demand Response from Competitive Retail Supplier Product Offerings}

In this chapter, we present the findings from interviews conducted with competitive retail suppliers that serve C\&I customers in the case study states (see Table 5-1) and that have participated in regulatory proceedings associated with default service implementation. ${ }^{67}$ The eight retail suppliers in our interview sample include both national and regional suppliers, which, together, represented about 60-65\% of competitive C\&I sales in the U.S. in 2004.

In this chapter, we summarize findings from the interviews related to:

- The types of pricing options and DR-related products and services offered by competitive retail suppliers;

- The market penetration rates among C\&I customers for pricing options and other competitive retail services that potentially facilitate DR; and

- General market and policy issues affecting the development of DR in competitive retail markets.

Our interviews with competitive retail suppliers also included questions related to default service design; findings from these questions are incorporated into Section 4.3.2.

Table 5-1. C\&I Market Share of Competitive Suppliers in Sample (2003)

\begin{tabular}{|l|c|}
\hline \multicolumn{1}{|c|}{ State } & $\begin{array}{c}\text { Percent of Total Competitive C\&I Sales } \\
\text { (2003 }^{\mathrm{a}}\end{array}$ \\
\hline New Jersey & $53 \%$ \\
\hline Maryland & $54 \%^{\mathrm{b}}$ \\
\hline Pennsylvania & $56 \%$ \\
\hline New York & $47 \%$ \\
\hline Illinois & $28 \%$ \\
\hline Ohio & $19 \%$ \\
\hline Oregon & Not Available $^{\mathrm{c}}$ \\
\hline Georgia & $0 \%^{\mathrm{d}}$ \\
\hline
\end{tabular}

Data source: EIA (2005), Tables C2 and C3

b Based on data reported by KEMA (2004c), these suppliers' share of the C\&I market in Maryland rose to 74\% by May 2004.

c EIA (2005) does not include data on competitive retail sales in Oregon. One of the suppliers interviewed indicated that they are active in Oregon, but we have no information about their market share.

d None of the suppliers indicated that they are active in Georgia. The limited customer choice market in Georgia is dominated by the investor owned utilities, municipal utilities, and co-operatives.

\footnotetext{
${ }^{67}$ See Appendix B for a copy of the questionnaire.
} 


\subsection{DR-Related Products and Services Offered by Competitive Retail Suppliers}

Competitive retail suppliers can facilitate DR through three general types of product or service offerings:

(1) Dynamic retail supply pricing arrangements that communicate a price incentive for DR (e.g., by passing-through spot market prices or by incorporating a price overcall feature);

(2) DR programs that provide payments for load reductions that are financially and contractually unbundled from the provision of retail supply; and

(3) Products and services that enhance customers' ability to modify their load on short notice in response to price signals (e.g., technical assistance).

In this section, we describe the products and services in each of these three categories offered by our sample of competitive retail suppliers.

\subsubsection{Pricing options for retail supply}

We asked competitive suppliers to describe the pricing options that they offer to C\&I customers, and organized their responses into six types of pricing options (see Table 5-2). We counted a supplier as offering a particular product only if it is one of their "standard" product offerings and/or if they have customers that are currently taking their supply under such an arrangement. ${ }^{68}$

Table 5-2. Retail Supply Pricing Options Offered by Retail Suppliers Interviewed

\begin{tabular}{|l|c|}
\hline \multicolumn{1}{|c|}{$\begin{array}{c}\text { Pricing Options } \\
\text { Fixed price }\end{array}$} & $\begin{array}{c}\text { Number of Suppliers that Offer This } \\
\text { Type of Pricing Option } \\
\text { (n=8) }\end{array}$ \\
\hline Indexed to fixed-price default service rate & 8 \\
\hline Indexed to spot market & 3 \\
\hline Block and index (a.k.a. "block and swing”) & 8 \\
\hline Indexed to spot market with price cap or collar & 8 \\
\hline Price overcall for energy and/or capacity component & $3^{\text {a }}$ \\
\hline
\end{tabular}

a. Only seven of the eight suppliers would confirm whether or not their company offered such an option.

\section{Fixed price}

All of the competitive suppliers interviewed offer a fixed-price retail supply option. For large C\&I customers with interval metering, fixed price offers are typically developed for each customer based on their specific load profile. ${ }^{69}$ Fixed-price offers may be structured as a single, flat price applicable in all hours over the contract term, or they may be structured as a schedule of fixed prices differentiated by time of use (TOU) or season. All suppliers in our sample offer the first of these two (i.e., flat price arrangements). This flat price may constitute a single charge for all components of full-requirements service (e.g., energy, capacity, transmission, ancillary services, etc.); although in other cases, separate demand or customer charges are included to

\footnotetext{
${ }^{68}$ Thus, we did not count a supplier as offering a particular product if they indicated that they would provide such a product if a customer asked, but that it is not a standard product and that none of their current customers have such an arrangement.

${ }^{69}$ This contrasts with regulated utilities' rates, which are designed around a class average load profile and thereby incorporate intra-class cross-subsidies.
} 
cover one or more of the non-energy components. Three suppliers also offer fixed-price options with a TOU-based price schedule. One supplier indicated that they offer this product primarily so that customers with a TOU-based utility tariff can easily compare pricing terms. ${ }^{70}$

Several suppliers incorporate a volume band into their fixed price contracts. With this type of arrangement, the customer pays a pre-specified contract price so long as their usage over a prespecified period falls within the agreed upon volume range. Usage in excess of the upper limit is settled at a market indexed price. If the customer's usage is less than the lower limit of the volume band, the customer purchases the minimum volume at the contract price, and is credited for the difference between that volume and their actual usage at a market indexed price. The suppliers offer varying degrees of flexibility with respect to the width of the band and the length of the period over which imbalances are accrued. For example, one supplier offers balancing on either a monthly or annual basis, and any imbalance above or below the volume band is settled at the average spot market price during that period. Another supplier offers balancing on an hourly interval; customers on this type of contract are therefore directly exposed to hourly spot market prices for their marginal usage outside of their volume band.

\section{Indexed to fixed default service rate}

Three suppliers offer retail supply contracts with a price that is indexed to the default service rate, with some fixed discount (i.e., either a lower price or a percentage discount off of that rate). These types of products are often marketed as a "Guaranteed Savings" option, because they provide customers with a guaranteed level of savings off of the default rate. All of the suppliers that offer this type of product do so in markets where the default service rate is fixed for onemonth periods or longer (e.g., most utility service territories in New York). Thus, the price of the Guaranteed Savings options offered by competitive retail suppliers in these regions is fixed over the same period and adjusted in unison with the default rate.

\section{$\underline{\text { Indexed to spot market }}$}

All suppliers offer a retail supply option that "passes through" the spot market price of energy for all of the customer's hourly energy usage (i.e., "real time pricing”), although several offer it only in specific markets. ${ }^{71}$ For example, one supplier offers spot market indexed pricing only as the version of its Guaranteed Savings product offered to customers for whom the default service is a spot market-indexed rate (e.g., customers in the CIEP class in New Jersey). Two other suppliers do not offer spot market indexed products in several regions where they are active, because they are not in close proximity to a liquid trading hub.

Most of the spot market indexed products described by the suppliers in our sample are indexed to the locational market clearing price in the regional ISO/RTO day-ahead or real-time energy market. Only one interviewee described spot market indexed products outside of an ISO region;

\footnotetext{
${ }^{70}$ Because flat, fixed-price offers are developed based on the customer's individual load profile, customers with relatively flat load profiles don't have the same opportunity as they would in regulated settings to arbitrage between the flat price and the TOU-based pricing option.

${ }^{71}$ Other components of the retail service, such as capacity and ancillary services, may continue to be offered at a hedged price.
} 
prices for this product are indexed to published market data (e.g., Dow Jones or ICE price indices) for bilateral spot market transactions at nearby trading hubs. ${ }^{72}$

All suppliers offer spot market pricing indexed to the ISO/RTO real-time spot market. Although less common, a number of suppliers also offer products indexed to the ISO/RTO day-ahead energy market, at least within specific regions. For example, one supplier offers a Guaranteed Savings product in NMPC's service territory, where the default service is a pass-through of dayahead spot market prices, and thus so is the supplier's product offering. Another supplier offers day-ahead pricing for their customers in New England because of a peculiarity in the ISO-NE's market that makes purchasing in the real time market more expensive. ${ }^{73}$ A third supplier offers customers the option of scheduling their load in the day-ahead market and paying the day-ahead spot market price for their scheduled load, with any imbalance from the scheduled amount settled at the real-time spot market price.

\section{Block and index}

All suppliers in our sample offer a product that allows customers to purchase blocks of load at a fixed price and "float" the remaining portion of their load at the real-time or day-ahead market price. Customers typically have a high degree of flexibility regarding the size of the load block relative to their total load, as well as some choice regarding the shape of the load block (i.e., the hours and days of the week covered by the block). One supplier, which offers fixed price blocks for peak and off-peak periods, indicated that their customers typically purchase a load block that covers at least $75 \%$ of their peak usage. ${ }^{74}$

Different suppliers offer different pricing terms associated with how load reductions below the block level are settled. Some suppliers offer symmetric pricing around the block level, whereby the customer purchases the entire load block regardless of how much energy they actually consume, and if they consume less than the block amount, they are credited for the difference at the prevailing spot market price (just as the customer is charged for consumption above the block at the spot market price). Alternatively, some suppliers offer asymmetric pricing around the block level. One example is where the customer is credited back at the fixed load block price, i.e., they simply pay for whatever portion of the load block they actually consume at the fixed price, and pay for additional energy at the spot market price. Another example is a take-orpay contract, where the customer pays for the entire load block, regardless of how much they consume, but receives no credit for load reductions below the block level. Depending on which of these types of pricing terms apply, the customer faces a different price incentive for load reductions below their block level. From the perspective of communicating a price incentive for DR (and an efficient price signal, more generally), the most desirable arrangement is where load reductions below the block level are credited back at the spot market price, since the customer then faces the hourly spot market price on the margin at all times, no matter what their usage level.

\footnotetext{
${ }^{72}$ Most of suppliers interviewed are active only in regions with an ISO/RTO, or the individual interviewed was familiar with the company's product offerings only in those regions.

${ }^{73}$ In particular, regulation costs are allocated to load serving entities proportionally based on the volume of load purchased in the real-time market.

${ }^{74}$ This is consistent with the analysis of Goldman et al. (2005), which found that Niagara Mohawk’s large C\&I customers, who were offered a one-time choice to hedge a portion of their load at a fixed-price and float the remaining portion at the day-ahead spot market price, typically chose to hedge $60-80 \%$ of their peak period load.
} 
$\underline{\text { Indexed to hourly spot market with price cap or collar }}$

Three suppliers offer other types of financial hedging options in combination with spot market indexed pricing, such as price caps and collars, to their largest customers in particular regions. Several suppliers that do not offer such financial hedging products explained that the administrative cost of developing these products and the lack of liquidity in the wholesale market for energy derivatives make these types of products too costly for most retail consumers.

\section{Price overcall on energy or capacity charge}

Four suppliers offer a discounted energy and/or capacity charge for customers that are willing to give the supplier the option to overcall that fixed price. Most of these product offerings are affiliated with PJM's ALM program, which allows LSEs to deduct interruptible load from their installed capacity requirements. LSEs typically translate this wholesale market mechanism into a retail product by offering customers the option to nominate a portion of their load as firm and avoid or receive a discount on capacity charges for load above their firm load level.

Alternatively, customers with onsite generation may receive a discount based on the capacity of their generator. The size of the discount in either case reflects the market value of capacity over the duration of the non-firm retail supply contract. Several suppliers indicated that they do not offer non-firm pricing options specifically because, in their view, the market value of capacity in the PJM region has been too low to attract customer interest in non-firm pricing, given the magnitude of the non-compliance penalties associated with the ALM program. Another supplier indicated that they previously offered a non-firm pricing option, but that these options could not compete with utility interruptible tariffs that provided larger discounts.

\subsubsection{Unbundled DR programs}

Competitive suppliers can also motivate DR by offering unbundled DR programs that provide payments or bill credits for load reductions separate from the provision of retail supply. All competitive suppliers in our sample offer some type of unbundled DR product in at least one of the regions where they are active. With only one exception, these unbundled DR products are associated with an ISO/RTO-administered DR program, whereby the supplier serves as the DRSP for the retail customer and offers a retail product with similar, if not identical, terms to the ISO/RTO program (see Text Box 4-2 in Section 4.8.1). ${ }^{75}$ The types of unbundled DR programs offered by retail suppliers in our sample is therefore a function of three basic factors: 1) the ISO/RTO regions in which the suppliers are active, 2) the types of DR programs offered by these ISOs/RTOs, and 3) which ISO/RTO DR programs the suppliers choose to offer to their retail customers (see Table 5-3). We count a supplier as “participating in”, or "offering”, a particular ISO/RTO DR program if the company is currently registered with the ISO/RTO as a DRSP and if the individual interviewed confirmed that the company is actually willing to serve as a DRSP for that program.

\footnotetext{
75 The one program not associated with an ISO-administered DR program is a voluntary DR program offered by a supplier operating in ComEd's service territory in northern Illinois. However, now that this region has been integrated into PJM, the supplier indicated that they are planning to phase out the existing program and replace it with a new set of products linked with the PJM DR programs.
} 
Table 5-3. ISO/RTO DR Program Participation among Retail Suppliers Interviewed

\begin{tabular}{|c|c|c|c|c|c|c|c|}
\hline \multirow[b]{2}{*}{$\begin{array}{l}\text { Supplier } \\
\text { Number }\end{array}$} & \multicolumn{4}{|c|}{ PJM } & \multicolumn{3}{|c|}{ NYISO } \\
\hline & ALM & $\begin{array}{c}\text { Economic } \\
\text { Program } \\
\text { Day Ahead } \\
\text { Option }\end{array}$ & $\begin{array}{c}\text { Economic } \\
\text { Program } \\
\text { Real Time } \\
\text { Option }\end{array}$ & $\begin{array}{c}\text { Emergency } \\
\text { Load } \\
\text { Response } \\
\text { Program }\end{array}$ & ICAP/SCR & DADRP & EDRP \\
\hline 1 & $\mathrm{x}$ & $\mathrm{X}$ & $\mathrm{x}$ & $\mathrm{x}$ & $\mathrm{x}$ & $\mathrm{x}$ & $\mathrm{x}$ \\
\hline 2 & $\mathrm{x}$ & $\mathrm{x}$ & $\mathrm{x}$ & $\mathrm{x}$ & & & $\mathrm{x}$ \\
\hline 3 & & & & & \multicolumn{3}{|c|}{ not active in region } \\
\hline 4 & $\mathrm{x}$ & $\mathrm{x}$ & $\mathrm{x}$ & $\mathrm{x}$ & $\mathrm{x}$ & $\mathrm{x}$ & $\mathrm{x}$ \\
\hline 5 & & & $\mathrm{x}$ & & & & \\
\hline 6 & $\mathrm{X}$ & $\mathrm{X}$ & $\mathrm{x}$ & $\mathrm{x}$ & \multicolumn{3}{|c|}{ not active in region } \\
\hline 7 & & & & & $\mathrm{x}$ & & $\mathrm{X}$ \\
\hline 8 & & & & & & & \\
\hline Totals & 4 & 4 & 5 & 4 & 3 & 2 & 4 \\
\hline
\end{tabular}

Notes: " $\mathrm{x}$ " indicates that the supplier is registered as a DRSP with the ISO/RTO and offers that program to their customers.

Of the eight supplies interviewed, all are active in the PJM footprint and six are active in New York. In both regions, some suppliers offer all, some offer none, and some offer a subset of the ISO/RTO DR programs. Several of the individuals interviewed offered explanations for why their company does not participate in particular DR programs. For example, one supplier that is not participating in any of PJM's DR programs explained that the company decided that there is not enough money in the programs to make participation worthwhile. Another offered a similar comment, suggesting that the administrative costs associated with the settlement process are prohibitive, given the limited revenue potential. (During the past several years, the PJM Emergency program has not been called; and energy and capacity prices have been low compared to historical levels, dampening customers' financial incentive to participate in the Economic and ALM programs.) Suppliers also cited issues associated with competition from utility programs; e.g., one supplier suggested that when state regulators require utilities to offer a retail tariff that allows customers to participate in ISO/RTO DR programs and pass through all or most of the incentive payment, the opportunity for competitive suppliers to offer such products is eroded.

\subsubsection{Products and services to build DR capabilities}

The third general category of DR-related products or services that might be provided by competitive retail supplies are those that enhance customers' capability to modify their load, on short notice, in response to information about market prices or system reliability. We asked suppliers to describe the services of this type that they integrate into their retail supply service or DR programs. In general, the individuals interviewed indicated that their company offers few, if any, services of this type, and many cited a lack of customer demand as the fundamental cause.

Three types of DR-enabling services were offered by one or more suppliers in our sample (see Table 5-4). Three suppliers offer customers internet-based access to their hourly interval load data with a one-day or shorter time delay, in most cases for an additional fee. One supplier commented that a very small portion of their customers on hourly pricing have shown an interest in the EIS product. Four suppliers indicated that they offer a price alert service whereby they notify customers, via email or pager, if hourly prices reach a threshold level specified by the 
customer. One of the suppliers offering this service indicated that it was most popular among customers that are participating in ISO/RTO economic DR programs. Finally, one supplier indicated that they have recently started to offer technical assistance to customers enrolled in the ISO-NE DR programs, to help them develop and/or implement load curtailment strategies.

Table 5-4. Products and Services to Build DR Capabilities

\begin{tabular}{|l|c|}
\multicolumn{1}{|c|}{ Product or Service } & $\begin{array}{c}\text { Number of Suppliers Interviewed that } \\
\text { Offer This Type of Product } \\
\text { (n=7) }\end{array}$ \\
\hline Internet-based access to hourly load data & 3 \\
\hline Price alert & 4 \\
\hline Technical assistance & 1 \\
\hline
\end{tabular}

Most of the suppliers in our sample do have a separate energy services group within the company or an affiliated ESCO that offers various technical services to help customers reduce their energy costs. However, many of the suppliers indicated that their ESCO affiliate or group focuses primarily on energy efficiency measures, not DR. Moreover, none of these companies currently integrate their ESCO services with their retail supply function or have any formal process for marketing ESCO services to customers on hourly pricing or vice-versa. Two suppliers indicated that, in the past, they tried to more formally integrate these two parts of their business, but that customer interest in the ESCO services was insufficient. Another supplier suggested that integrating ESCO services with retail supply was inherently challenging as a result of the fact that the payback period for most energy efficiency and demand response measures is much longer than typical retail supply contract terms.

\subsection{DR from Customers on Spot Market Indexed Contracts with Competitive Suppliers}

The extent to which spot market pricing options offered by competitive retail suppliers contribute to the development of DR depends, first, on how many customers opt for these types of pricing arrangements and, second, on the price responsiveness of those customers. To gauge each of these parameters, we asked suppliers to estimate the market penetration of spot market indexed pricing options among their C\&I customers and to describe the extent to which customers that have opted for these arrangements appear to respond to hourly prices. As a point of comparison, we also asked suppliers to estimate the market penetration of DR programs among their C\&I customers. ${ }^{76}$

\subsubsection{Market penetration of spot market indexed pricing and DR programs for retail suppliers}

Six suppliers provided estimates of the percentage of their large C\&I load in various geographical markets that is purchasing their commodity requirements either entirely at hourly spot market prices or on a block-and-index type product as well as the percentage that is participating in each DR program offered by the supplier (see Table 5-5). ${ }^{77}$ When possible, market penetration estimates were obtained specifically for the large C\&I customer classes in

\footnotetext{
${ }^{76}$ More comprehensive data on ISO/RTO DR program enrollment and customer price response is published by the ISO/RTOs, some of which is summarized in Section 4.8.2

${ }^{77}$ For the purpose of summarizing DR program market penetration, we use the three basic categories of DR programs defined in Section 3.2.2.
} 
particular states for which RTP has been established as the default service (e.g., New Jersey CIEP, Maryland Type III, and NMPC SC-3A). However, given the limitations of individuals' off-hand knowledge at the time of the interview and/or their willingness to divulge information about contracts in specific geographical markets, some of the market penetration estimates apply to relatively broad regions and/or to the loosely-defined class of "large C\&I customers".

Table 5-5. Market Penetration of Spot Market Indexed Pricing and DR Programs offered by Competitive Retail Suppliers

\begin{tabular}{|c|c|c|c|c|c|}
\hline \multirow[b]{2}{*}{ Supplier } & \multirow[b]{2}{*}{$\begin{array}{c}\text { Large C\&I } \\
\text { Market }\end{array}$} & \multicolumn{4}{|c|}{$\%$ of Total C\&I Load } \\
\hline & & $\begin{array}{l}\text { Hourly spot- } \\
\text { market indexed } \\
\text { pricing for retail } \\
\text { supply }\end{array}$ & $\begin{array}{l}\text { Price overcall or } \\
\text { load reduction } \\
\text { call option }^{\text {program }}{ }^{\mathrm{d}}\end{array}$ & $\begin{array}{c}\text { Scheduled load } \\
\text { reduction } \\
\text { program }^{\text {e }}\end{array}$ & $\begin{array}{c}\text { Voluntary load } \\
\text { reduction } \\
\text { program }^{f}\end{array}$ \\
\hline \multirow[t]{2}{*}{1} & $\begin{array}{c}\text { ComEd service } \\
\text { territory }\end{array}$ & not offered & not offered & not offered & $5 \%$ \\
\hline & ISO-NE region & $10 \%$ & not offered & not offered & $2 \%$ \\
\hline \multirow{2}{*}{2} & $\begin{array}{c}\text { NMPC } \\
\text { SC-3A class }^{a}\end{array}$ & $>90 \%$ & $<1 \%$ & $<1 \%$ & $<1 \%$ \\
\hline & $\begin{array}{l}\text { New Jersey } \\
\text { CIEP class }\end{array}$ & $75 \%$ & $0 \%$ & $0 \%$ & $<1 \%$ \\
\hline 3 & PJM region & $10 \%$ & not offered & not offered & not offered \\
\hline 4 & PJM region & $<25 \%$ & not offered & not offered & $<10 \%$ \\
\hline \multirow{2}{*}{5} & $\begin{array}{l}\text { New Jersey } \\
\text { CIEP class }\end{array}$ & $50-60 \%$ & \multirow{2}{*}{$0 \%$} & \multirow{2}{*}{$0 \%$} & \multirow{2}{*}{$0 \%$} \\
\hline & $\begin{array}{c}\text { Maryland } \\
\text { Type III class } \\
\end{array}$ & $5 \%$ & & & \\
\hline \multirow{3}{*}{6} & $\begin{array}{l}\text { New Jersey } \\
\text { CIEP class }\end{array}$ & $50 \%$ & \multirow{3}{*}{ not offered } & \multirow{3}{*}{ not offered } & \multirow{3}{*}{ not offered } \\
\hline & $\begin{array}{c}\text { Maryland } \\
\text { Type III class } \\
\end{array}$ & $20 \%$ & & & \\
\hline & NYISO region & $10-15 \%$ & & & \\
\hline
\end{tabular}

a. C\&I customers $>2,000 \mathrm{~kW}$ in Niagara Mohawk Power Company’s service territory in New York, for whom the default service is a pass-through of day-ahead spot market prices

b. C\&I customers $>1,500 \mathrm{~kW}$ in New Jersey, for whom the default service is a pass-through of real-time spot market prices

c. C\&I customers $>600 \mathrm{~kW}$ in Maryland, for whom the default service (starting in June 2005) is a pass-through of real-time spot market prices

d. PJM ALM program and NYISO ICAP/SCR program

e. PJM Economic Load Reduction Program - Day-Ahead Option and NYISO DADRP

f. PJM Economic Load Reduction Program - Real-Time Option, PJM Emergency Load Reduction Program, NYISO EDRP, ISO-NE Real-Time Demand Response Program, ISO-NE Real-Time Price Response Program, and an independent voluntary load reduction program offered by a supplier in ComEd's service territory

\section{Spot Market-Indexed Pricing}

Suppliers reported a wide range in the market penetration of spot market indexed pricing among large C\&I customers, which, to some extent, vary according to the corresponding region. Specifically, suppliers reported relatively high market penetration rates, ranging from $50 \%$ to $>90 \%$, for large C\&I customers in New Jersey and in NMPC's service territory in New York. In comparison, the estimates for other markets (i.e., large C\&I customers in Maryland, PJM as a 
whole, New York state as a whole, and the ISO-NE region) were consistently lower, ranging from $5 \%$ to $25 \%$.

Differences in the reported market penetration rates may reflect a number of factors related to customer demographics. First, we defined the large C\&I market to correspond to the default RTP threshold in each applicable state (i.e., 2,000 kW in NMPC's service territory, 1,500 kW in New Jersey, and $600 \mathrm{~kW}$ in Maryland). Second, different suppliers specialize in different types of C\&I customers, which may have systematic differences in their propensity for spot market indexed pricing. Finally, the different geographical regions may, themselves, have characteristic differences in the make-up of their large C\&I customer class.

Suppliers identified several general factors driving demand for spot market indexed pricing. First, some customers reportedly have a preference for competitive retail pricing arrangements that provide predictable savings off of the default rate. Thus, in regions where RTP has been established as the default service, some customers have opted for spot market indexed pricing arrangements with a guaranteed savings on ICAP charges or the retail adder. Second, some suppliers expressed the opinion that some fraction of customers currently on spot market indexed pricing arrangements are simply "riding the market" and waiting until fixed price offers drop to an attractive level before moving to a hedged supply option. ${ }^{78}$ Accordingly, many suppliers indicated their belief that much of the current demand was temporary, due to mild weather and low spot market volatility, and that customers would start locking-in fixed price contracts if price volatility increased. ${ }^{79}$ Finally, a few suppliers suggested that some customers have opted to purchase all of their commodity requirements at hourly spot market prices to avoid the risk premium incorporated into a fixed price service, although most mentioning this factor doubted whether this particular source of demand would persist once more typical levels of price volatility returned. When asked, all of the suppliers doubted whether potential cost savings from responding to hourly prices was a significant driver behind customer demand for hourly pricing, perhaps with the rare exception of customers with on-site generation that could be used for price response.

\section{$\underline{\text { Price overcall and load reduction call option programs }}$}

Suppliers offering price overcall arrangements (e.g., interruptible contracts) and/or call option type load reduction programs all reported that either none or a very small percentage of their C\&I load had elected such an option. They cited several factors affecting the market penetration of these types of pricing arrangements. Several suppliers operating in PJM explained that customer interest has been limited as a result of low ICAP prices during the past several years and/or unfavorable terms associated with PJM's ALM program (e.g., penalty size, program complexity). ${ }^{80}$ Another supplier cited competition from utility interruptible tariffs.

\footnotetext{
${ }^{78}$ A key question here is whether these customers will move predominately to full-requirements fixed supply arrangements or to block and index type products.

${ }^{79}$ One might also draw the opposite conclusion: that demand for spot market indexed prices will increase with spot market volatility as customers find that they can hedge their exposure more cost-effectively by adjusting their load in response to hourly prices than with a financial hedge or fixed price supply contract. If movement occurs in both directions, the net impact on market penetration will simply depend on the relative magnitude of each effect.

${ }^{80}$ Interruptible load customers that qualify as an ALM resource receive a credit from their load serving entity based on the avoided ICAP purchases. In 2003 and 2004, the average price of capacity in PJM capacity markets has been less than \$20/MW-day, compared three to five times as much in years past (PJM 2005).
} 
$\underline{\text { Scheduled load reduction programs }}$

Suppliers participating in PJM's Economic Load Reduction Program - Day Ahead option and/or NYISO's Day-Ahead Demand Bidding Program all reported that either none or a very small percentage of their C\&I customers were enrolled in these programs. The dominant factor cited by these suppliers is that low price volatility in PJM and New York in recent years has significantly dampened interest in these programs. In PJM, for example, the real-time spot market price has exceeded \$200/MWh in only one hour during 2003-2004, and exceeded \$150/MWh in only 22 hours (PJM 2005).

\section{Voluntary load reduction programs}

The market penetration rates reported for voluntary load reduction programs are generally higher than those reported for the other types of DR programs, but are still relatively low $(<10 \%)$. Several suppliers expressed the view that voluntary DR programs offer the greatest prospect for widespread adoption, given customers' reluctance to subject themselves to the risk of nonperformance penalties, with one supplier estimating that a 15\% market penetration rate for voluntary DR programs is plausible over the longer term.

\subsubsection{Estimated total market penetration of spot market indexed pricing in three large C\&I markets}

We estimated the total market penetration of spot market indexed pricing among load served by competitive suppliers in three large C\&I markets: the New Jersey CIEP class, the Maryland Type III class, and the NMPC SC-3A class (see Figure 5-1). Based on the methodology described below, we estimate that $23-55 \%$ of the load in New Jersey's CIEP class that has switched to a competitive supplier has opted for spot market indexed supply contracts, and 5$22 \%$ of the switched load in Maryland's Type III class has opted for such arrangements. We estimate that $43 \%$ of NMPC SC-3A load that has switched has opted for a spot market indexed contract, and can definitively assert that at least $13 \%$ has opted for this type of arrangement. Given the large range in our estimates, it would be advisable for state and federal policymakers to collect information periodically that would allow for more definitive estimates of the amount of load served by competitive retailers that is exposed to hourly prices, if demand response is an important policy goal. 


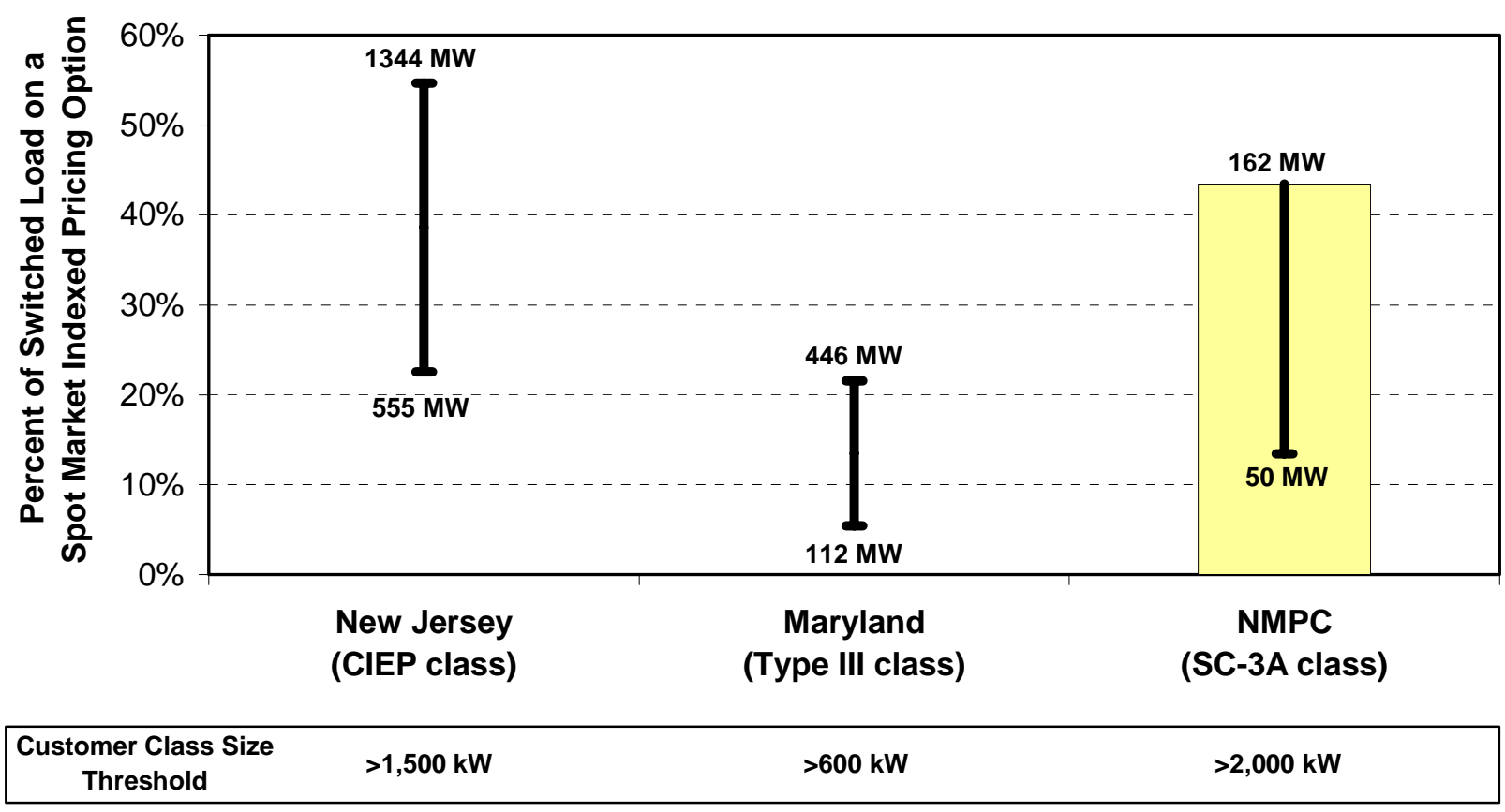

Figure 5-1. Estimated Market Penetration of Spot Market Indexed Pricing Arrangements in Three Large C\&I Markets in Late 2004/Early 2005

For the New Jersey and Maryland classes, we estimated the C\&I load on spot market indexed pricing served by the suppliers in our interview sample, based on their reported market penetration rates (see Table 5-5) and their market share in each state. ${ }^{81}$ For suppliers that reported market penetration rates only for the PJM region as a whole, and not for NJ and MD separately, we estimated state-specific values based on the supplier's C\&I load in each market and the differences in the penetration of spot market pricing in the two markets reported by other suppliers. For several suppliers in our sample, we stipulated their market penetration values based on relevant quantitative or qualitative information provided by the supplier. ${ }^{82} \mathrm{We}$ extrapolated to the remaining portion of the switched C\&I load in each state (38\% in NJ and $47 \%$ in MD) by stipulating upper and lower bounds for the market penetration of spot market indexed pricing: 60\% and 20\% for NJ CIEP, and 20\% and 5\% for MD Type III.

We used a different, and presumably more reliable, approach to estimating the total market penetration of spot market pricing among customers in NMPC's SC-3A class. Goldman et al. (2005) interviewed SC-3A customers and asked those that had switched to a competitive supplier about the structure of their supply contract. Approximately $30 \%$ of the customers (in terms of total billing demand) that had switched to a competitive supplier in 2004 could identify

\footnotetext{
${ }^{81}$ For suppliers' market share in New Jersey, we used 2003 C\&I sales data reported by EIA (2005), and for Maryland, we used May 2004 estimates reported by KEMA (2004c). Several suppliers in our sample had no C\&I load in these markets at the time that these data were collected but have since entered the market and have signed up customers, in which case we stipulated their market share (1-5\%, depending on the supplier).

${ }^{82}$ For example, one supplier operating in New Jersey indicated that "very few" of their C\&I customers were on a spot market indexed product, and based on this information, we assumed that $5-10 \%$ of their C\&I load is on such an arrangement. Another supplier indicated that 5-10\% of their C\&I customers nationally are on some type of dynamic pricing arrangement; based on this information, we assumed that 5-20\% of their NJ C\&I load and 5-10\% of their MD C\&I load is on such an arrangement.
} 
the pricing structure of their supply contract, and, of those, $43 \%$ opted for some type of spot market indexed arrangement. Given the information available, our best estimate is that the same percentage (43\%) of all SC-3A customers that have switched have opted for a spot market indexed contract. As a lower bound, we assume that only those customers that positively confirmed that they were on a spot market indexed contract were on such an arrangement, which corresponds to $13 \%$ of the switched load (see Figure 5-1).

\subsubsection{Price responsiveness of customers on spot market indexed contracts}

We asked suppliers a series of questions related to the load response (e.g., load shedding) from customers facing spot market prices on the margin, including:

- The extent to which the company focuses on cost savings opportunities associated with load response in their marketing activities;

- Whether the company has analyzed the load response from customers facing spot market prices on the margin, and if so, what magnitude of load response has been observed; and

- Whether the company incorporates price response from these customers into their scheduling and procurement activities.

All suppliers indicated that, when discussing potential pricing options with prospective customers, they typically do not emphasize or substantively discuss cost savings opportunities associated with load response. Several suppliers indicated that they may do this on a very limited basis, for example, with customers who have backup generation onsite or who, for other reasons, are deemed to be particularly capable of price response. However, it is not part of their routine marketing activities.

All of the suppliers indicated that they have not formally analyzed the load response of their customers on hourly pricing. Nevertheless, most did state their belief that their customers on hourly pricing do not modify their usage in response to these prices, and that most customers do not even regularly monitor spot market prices. A few suppliers did suggest that they have a small number of customers that do respond to spot market prices in a very discrete manner (e.g., by running onsite generation or altering a specific production process), but that these customers are an exception. To explain this apparent lack of price response by most customers, many of the suppliers cited the low spot market price volatility in PJM and the Northeast in recent years. However, many also seemed to think that customers on these pricing options are, in general, not particularly interested in or capable of actively managing their load in response to spot market prices. ${ }^{83}$ Given that the suppliers don't attribute a high degree of price responsiveness to their customers on hourly pricing, it is not surprising that they all indicated that their company does not incorporate load response from these customers into their scheduling and procurement activities beyond those few customers who are known to respond in some discrete manner.

\footnotetext{
${ }^{83}$ For example, one supplier indicated that most of their customers are commercial real estate, and that, in their opinion, these customers cannot respond without sacrificing tenant comfort, which they are unwilling to do. Another supplier suggested that, in general, their customers on hourly pricing are much more concerned about potential revenue loss associated with load response than they are with any associated savings on energy costs. The same supplier related these customers' apparent lack of price responsiveness to a belief that their choice of supply products mainly has to do with their view of whether the market is going up or down, and that they don't think about spot market indexed products in terms of cost savings associated with load response.
} 


\section{Discussion}

In this section, we summarize key findings related to the development of DR in the eight case study states and identify implications for policymakers and other stakeholders seeking to develop DR in both regulated and competitive retail markets.

\subsection{Key Findings}

(1) With the exception of Georgia Power (GPC), optional RTP tariffs have generated relatively limited levels of participation.

In five of the six optional RTP tariffs included in our case studies, less than $2 \%$ of the load of eligible customers enrolled in RTP. The reasons for low participation rates include factors such as: RTP provides minimal bill savings relative to the tariff alternative at current market prices, except for those customers that undertake substantial load modifications (New York and PGE); the tariff has only been available and actively marketed over a short period of time (all cases except GPC); and the tariff design is based on a one-part commodity charge and thus exposes participants' entire load to volatile prices (New Jersey, Maryland, New York, and ComEd).

In contrast, 83\% of the eligible load is enrolled in Georgia Power's RTP tariffs. The notable success of GPC in enrolling customers in RTP can be attributed largely to the opposite set of factors, namely: most customers on RTP can reasonably expect to achieve long-run bill savings, regardless of whether or not they are price responsive (see Text Box 6-1 for details); GPC has aggressively marketed RTP for more than a decade to a broad group of C\&I customers, and the tariff design allows customers to hedge a portion of their load at a fixed price. 


\section{Text Box 6-1. How has Georgia Power been so successful with RTP?}

GPC's success with RTP derives fundamentally from the unique retail market structure in Georgia, where most new facilities with a connected load $>900 \mathrm{~kW}$ have a one time choice of supplier, and all of the state's regulated utilities are allowed to compete for this load. In the 1990s, GPC recognized that RTP could play an integral role in their efforts to compete for customer choice load and, as a result, adopted an RTP tariff design that allowed them to be competitive, where conventional rates were not. GPC also committed significant resources in the form of aggressive marketing efforts and ongoing customer support activities.

Three specific elements of GPC's RTP tariff design have been critical to its success.

- Two-part, tariff design with a CBL. Customers participating in GPC's RTP tariffs purchase a portion of their load (their CBL) at one of the utility's fixed, cost-of-service based rates, and face hourly RTP energy prices for deviations from their CBL. This type of tariff structure exposes customers to less price risk than one that assesses hourly-varying prices on all of the customer's load.

- $\quad$ Procedures for establishing and maintaining each customer's CBL. GPC allows many of its RTP participants to establish and/or maintain a CBL that is below their normal load. Three specific tariff provisions are important in this regard. First, all RTP participants are allowed expand their facilities or add load without adjusting their CBL upward. Second, customers that were previously on the utility's Supplemental Energy tariff (a curtailable rate) were able to receive, when they enrolled in RTP, a CBL equal to their previous firm service level. Finally, new industrial customers receive, by default, a CBL equal to $60 \%$ of their projected load, and all new customers (industrial and commercial) are eligible for a CBL below their default level if they can demonstrate that they are able to reduce their load by a proportional amount. The net effect of these tariff provisions is that RTP participants have an average CBL equal to $60 \%$ of their total load and purchase the remaining $40 \%$ at marginal cost-based hourly prices. Because these prices have historically been lower, on average, than the all-in (energy plus demand) price of the utility's standard cost-of-service based rates, RTP participants are able to accrue bill savings compared to what they would pay if their CBL were equal to $100 \%$ of their typical load.

- Supplemental financial risk management products. The utility offers a wide range of supplemental financial risk management products that customers can purchase to reduce their exposure of their incremental RTP load to hourly price volatility. The value of these products is heightened by the fact that many RTP participants have a large fraction of their load exposed to hourly prices.

(2) In each of the three default RTP tariffs in place in early 2005, most of the load has switched to a different supply option, although the percentage remaining on RTP varies significantly.

In DLC's service territory, only 3\% of the load in the default RTP class is enrolled in RTP; the remaining customers have switched to either a competitive supplier or to the temporary fixed price alternative offered by the utility. In comparison, a larger fraction of the load in the NMPC and, to a lesser extent, New Jersey default RTP classes have remained on RTP (34\% and 16\%, respectively). Differences in participation rates among these three cases reflect a number of factors related to tariff design and retail market development: the amount of advance notice with which customers have knowledge of hourly prices (day-ahead for NMPC vs. real- time, afterthe-fact for the other two cases); the availability of an alternative fixed price supply option with the utility (which only DLC offers); the size of the default threshold (300 kW for DLC, compared to 1,500 kW and 2,000 kW for New Jersey and NMPC, respectively); and the general availability of competitive retail supply offers.

Some of the switching activity in these three case studies likely reflects many customers' aversion to being exposed to hourly pricing; however that does not fully account for or explain the switching behavior. First, in DLC's case, much of the switching in the default RTP class 
occurred prior to the introduction of default RTP. ${ }^{84}$ Second, we know from our supplier interviews that some customers have switched to competitive supply contracts that incorporate hourly spot market pricing for some or all of their usage (i.e., either a full pass through of spot market prices for all of the customer's commodity requirements or a block-and-index type product where customers purchase a portion of their load at a fixed price and their residual load at spot market prices).

(3) The case studies revealed several indirect impacts that default RTP might have on the development of DR in competitive retail markets; however more formal analysis is needed before firm conclusions can be drawn.

The amount of load remaining on the default RTP rate represents a small fraction of the system peak $(<3 \%)$ in all three cases where default RTP has been implemented. Thus, the potential direct impact of these RTP tariffs on the development of DR has necessarily been limited. However, the case studies highlight three plausible (but untested) indirect positive impacts that default RTP might have on the development of DR in competitive retail markets. First, having RTP as the default service may create additional demand for spot market indexed pricing options offered by competitive suppliers, because some customers use the default rate as a benchmark and seek out competitive supply contracts with a comparable pricing structure but lower prices. ${ }^{85}$ Recognizing this market dynamic, a number of suppliers explicitly market their spot market indexed pricing option as a "Guaranteed Savings" product in states with default RTP. Second, customer demand for spot market indexed pricing may also be enhanced as a result of customer education and training activities conducted in concert with default RTP implementation, as well as from customers' direct experience on the default RTP tariff. Through these experiences, customers that might otherwise be unfamiliar with, or disinclined towards, hourly pricing may become more knowledgeable about the potential benefits and the range of risk management options available. ${ }^{86}$ Third, several states have deployed interval meters across a wide base of C\&I customers as part of their implementation of default RTP. As a result, some customers that might otherwise be deterred because of metering costs may decide to participate in DR programs or may opt for retail supply contracts with dynamic pricing elements.

(4) Competitive retail suppliers reported a wide range of values for the market penetration of spot market indexed pricing options, ranging from 5\% to 75\% of their C\&I load in different regions.

The competitive retail suppliers we interviewed all offer spot market indexed retail supply contracts to C\&I customers, including arrangements where the customer purchases all of their commodity requirements at hourly prices indexed to the real-time or day-ahead spot market as

\footnotetext{
${ }^{84}$ One year prior to default RTP implementation, 32\% of all C\&I load in DLC's service territory had switched to a competitive supplier, compared to 52\% three months after implementation (POCA 2005). Note that these switching trends are for all C\&I customers; data on switching trends in DLC's default RTP class does not appear to be publicly available.

${ }^{85}$ In the case of default RTP, competitive suppliers may be able to offer a fixed discount on ICAP or ancillary services charges, or a mark-up on the commodity charges that is smaller than the default service retail adder.

${ }^{86}$ For example, one supplier indicated that some customers that had inadvertently remained on default RTP in New Jersey decided that facing hourly spot market prices was acceptable and, when they switched to a competitive supplier, sought out a similar pricing arrangement. A comprehensive study of NMPC RTP experience found many customers switched from default RTP to a similar arrangement with a competitive supplier (Goldman et. al, 2005).
} 
well as block-and-index type products (i.e., the customer purchases blocks of load at a fixed price and pays hourly spot market prices for their additional usage). The reported market penetration rates for spot market indexed pricing options varied substantially among the different suppliers, depending in part on the particular region. Three suppliers reported that, in New Jersey, $50 \%$ to $75 \%$ of their C\&I load in the default RTP class has opted for a spot marketindexed supply contract. In comparison, two suppliers reported market penetration rates of 5\% and 20\% among the default RTP class in Maryland. The values for C\&I customers in other regions (e.g., PJM as a whole, New York, and the ISO-NE region) varied between $10 \%$ and $25 \%$. We believe that several factors may account for differences in reported market penetration rates: size threshold of the default customer class (e.g., $>1.5 \mathrm{MW}$ in New Jersey vs. $>600 \mathrm{~kW}$ in Maryland), the types of C\&I customers targeted by particular suppliers (e.g., mid-market C\&I vs. exclusive focus on large industrials), regional differences in mix and type of customers (e.g., higher concentration of industrial customers in New Jersey vs. New England) and default service tariff options (e.g., default RTP with or without a utility hedged tariff alternative).

Comments by suppliers provide insight into several dynamics driving the current demand for spot market indexed products. First, some C\&I customers seek out a guaranteed discount off of their default service rate. Second, some customers with spot market indexed supply contracts are reportedly riding the market, waiting until fixed price offers drop to an attractive level before moving to a hedged supply option. ${ }^{87}$ Third, a number of suppliers suggested that some customers were willing to buy some or all of their loads at spot market prices to avoid the risk premium incorporated into a fixed price, full-requirements service. All suppliers doubted whether cost savings from DR was a significant driver behind customer demand for hourly pricing, perhaps with the exception of customers with on-site generation. Some suppliers also indicated their belief that much of the current interest in RTP-type products was temporary, due to mild weather and low spot market volatility, and that more customers would start locking-in fixed price contracts if price volatility increases.

(5) From one to ten percent (1-10\%) of the system load in several retail markets appears to be exposed to spot market prices, although there is significant uncertainty in these estimates.

Very little information is available in the public domain regarding the amount of load in competitive retail markets facing hourly spot market prices through their retail supply contract. As an initial step towards filling this void, we estimated the amount of load in three large C\&I markets (the New Jersey CIEP class, the Maryland Type III class, and the NMPC SC-3A class) that has switched to a spot market indexed competitive supply contract (see Section 5.2.2). We combined these estimates with data on enrollment in optional and/or default RTP tariffs offered by utilities in these states in order to provide an indication of the total load exposed to hourly spot market prices.

Based on this approach, we estimate that, as of early 2005, 1-4\% of the system peak load in Maryland, 6\% in NMPC's service territory and 6-10\% in New Jersey was facing hourly spot market prices on the margin through either a utility RTP tariff or a retail supply contract with a

\footnotetext{
${ }^{87}$ A key question here is whether these customers will move predominately to full-requirements fixed supply arrangements or to block and index type products.
} 
competitive provider (see Figure 6-1). ${ }^{88}$ One key driver for the relatively low percentage of system peak load exposed to spot market prices in each of these markets is that the default RTP class only accounts for $10-20 \%$ of the total system load. The fact that the exposure to spot market pricing is lower in Maryland than in the other two cases primarily reflects the fact that, during the period for which these estimates were developed, RTP was an optional service for large C\&I customers in Maryland but was the default service for large C\&I customers in the other two regions.

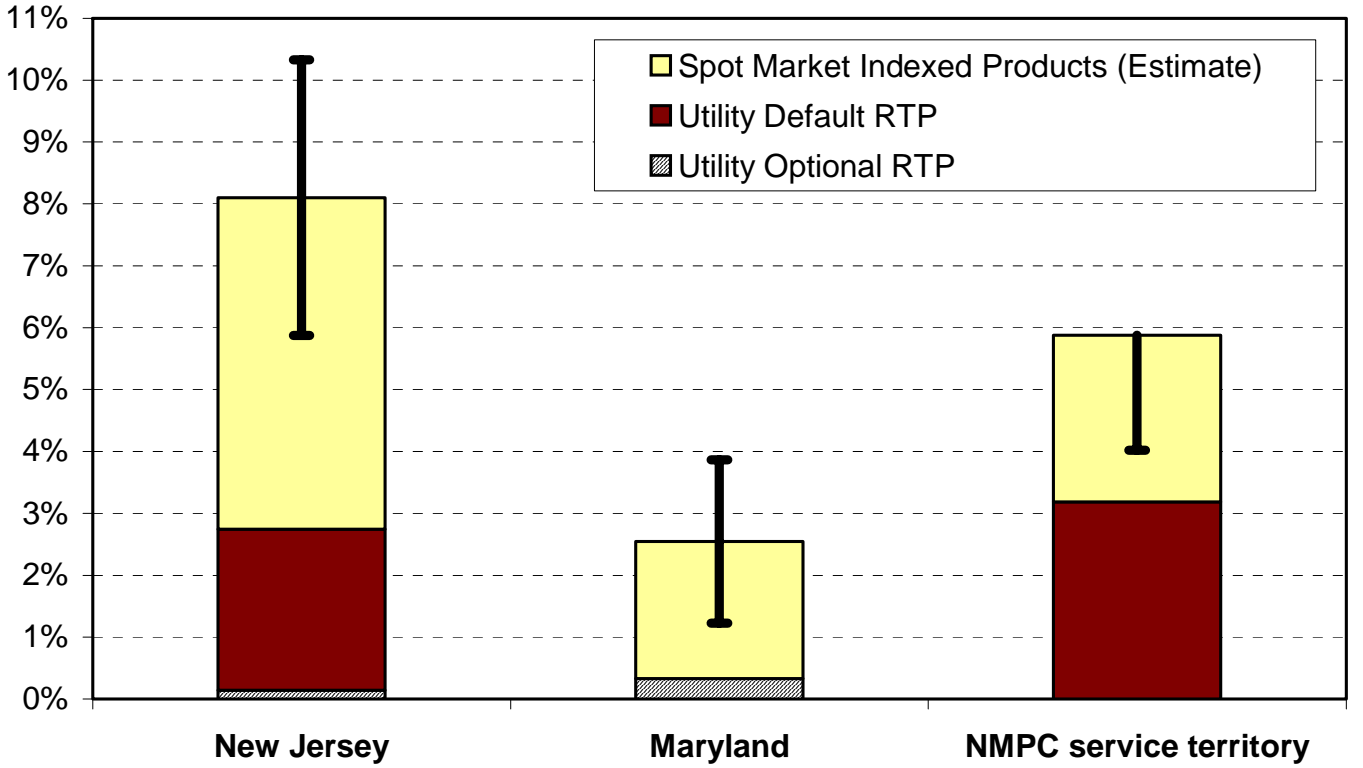

Figure 6-1. Percent of System Peak Load Exposed to Hourly Spot Market Prices in Three Regions

(6) RTP tariffs that provide C\&I customers with advance notice of prices have demonstrated the capability of eliciting load reductions in the range of $10-15 \%$ of participants' aggregate billing demand at very high prices.

Of the case studies examined in this report, formal analyses of customers' price responsiveness have been performed only for NMPC and GPC. Goldman et al. (2005) estimated the substitutional price elasticities of customers in NMPC's default RTP class, using five years' of hourly billing data. Based on these estimates, customers remaining on RTP in 2004 would be expected to reduce their peak load by approximately $10 \%$, in total, when peak period prices are five times greater than off-peak prices (e.g., a peak period price of $\$ 0.50 / \mathrm{kWh}$ and an off-peak price of $\$ 0.10 / \mathrm{kWh}$ ), which represents the extreme level of NYISO day-ahead prices to date. ${ }^{89}$

\footnotetext{
${ }^{88}$ In Figure 6-1, the yellow bars for New Jersey and Maryland are the averages of the upper and lower bound estimates for the load exposed to hourly spot market prices through competitive retail supply contracts. The yellow bar for NMPC represents our best estimate of the load facing hourly spot market prices through a competitive supply contract in NMPC's service territory, based on extrapolating the survey results of Goldman et al. (2005). Refer to Section 5.2.2 for a full explanation of our approach.

${ }^{89}$ At NMPC, peak period prices were five times higher than off-peak period prices on only 2 days during summer 2000-2004.
} 
GPC has reported, albeit in a less detailed manner, on its evaluation of the price responsiveness of customers on their RTP tariffs. The utility attributes approximately a $500 \mathrm{MW}$ peak load reduction to their RTP tariffs, under expected summer peak-coincident prices, as part of its system planning process (i.e., integrated resource plan filings). This corresponds to roughly $10 \%$ of RTP participants’ aggregate billing demand. Braithwait and O’Sheasy (2001) used customer price elasticity estimates to calculate the load reduction on one day when customers on the dayahead RTP rate faced a maximum hourly price of $\$ 1.93 / \mathrm{kWh}$, and customers on the hour-ahead RTP rate faced a maximum hourly price of $\$ 6.43 / \mathrm{kWh}$. They estimate that day-ahead and hourahead RTP customers reduced their load by approximately $500 \mathrm{MW}$ and $250 \mathrm{MW}$, respectively. The combined $750 \mathrm{MW}$ load reduction is equal to approximately 15\% of RTP participants' aggregate billing demand.

Goldman et al (2005) forecast the aggregate DR impacts of NMPC's customers that faced hourly prices and estimated that they would reduce their peak demand by 50 MW (which is $0.8 \%$ of NMPC's system peak) during periods when peak period prices were five times higher than offpeak prices. ${ }^{90}$ If we extrapolate from the NMPC and Georgia Power RTP study results, their experience suggests that large C\&I customers representing about $10 \%$ of system peak load and that are exposed to hourly spot market prices with advance notice (i.e., day-ahead) may be able to reduce system peak load by $\sim 1-1.5 \%$ at high prices.

(7) Little is currently known about the price responsiveness of customers participating in RTP tariffs that are indexed to real time spot markets, although regulatory staff and utilities in states with RTP tariffs of this type generally expressed the belief that few customers actively monitor or respond to hourly prices.

RTP tariffs that have been recently implemented in New Jersey, Maryland, and DLC's service territory employ prices that are indexed to the PJM real time spot market, and these prices are not known until after the applicable hour has elapsed. To date, no formal evaluations have been conducted to assess the extent to which customers remaining on these default RTP tariffs respond to hourly prices. Thus, without any analysis, no definitive conclusions can be drawn at this point about the extent to which RTP tariffs of this type might induce price response from participating customers. Utility and regulatory staff in New Jersey, Maryland, and Pennsylvania generally doubted whether customers on the default RTP tariffs in these states are actively monitoring or responding to hourly prices. ${ }^{91}$

(8) The competitive retail suppliers interviewed indicated that they have not formally analyzed the price response of their customers with spot market indexed supply contracts; however,

\footnotetext{
90 The NMPC RTP study population included 149 SC-3A customer accounts with 550 MW of aggregate billing demand; about 120 accounts were excluded by NMPC because of confidentiality or data availability concerns (e.g. individually negotiated contracts, customers with New York Power Authority allocations) [see Goldman et al 2004]. ${ }^{91}$ To the extent that this characterization is accurate, it may reflect the moderate price volatility in the PJM real-time spot market over the past several years. More fundamentally, it is questionable what level of price response might reasonably be expected from customers that have no advance notice of firm prices. To make an informed decision about when load reductions would be economically justified, customers would need to derive or purchase a forecast of hourly spot market prices (e.g., based on a correlation between day-ahead and real-time market prices), which increases the uncertainty in the financial benefits of, and/or the costs associated with, load response.
} 
all expressed the belief that no more than a handful of these customers currently monitor or respond to hourly prices.

Most of the suppliers we interviewed stated their belief that the vast majority of customers on spot market indexed pricing options do not monitor or respond to hourly prices, although none had systematically examined the question. Accordingly, they indicated that they do not account for price response from customers facing hourly spot market prices in their scheduling and procurement activities, other than for perhaps a small handful of customers with pre-established load response routines (e.g., customers that operate on-site generation when spot market prices reach some threshold level).

In general, competitive retail suppliers and, by their account, customers do not view spot market indexed pricing options as an opportunity for customers to reduce their energy costs by responding to hourly prices. Suppliers typically do not focus on DR in marketing these product offerings, except perhaps to customers with onsite generation, and offer few products and services to assist customers in responding to hourly prices. This lack of emphasis on DR in connection with spot market indexed pricing may partly reflect current market conditions, characterized by relatively stable prices. Perhaps greater levels of price volatility will spur customer interest in price response, and prompt suppliers to more aggressively offer products and services to help customers respond or adapt.

(9) A variety of DR programs offered by utilities and ISO/RTOs have demonstrated the ability to elicit load reductions in the range of 1-3\% of the respective entities' system peak.

In all of the case studies, utilities or an ISO/RTO offers a variety of DR programs to C\&I customers. In 2004, participation in most of these DR programs (reported in terms of customers' contracted or nominated load reduction quantity) was in the range of $1-4 \%$ of the utility or statewide system peak load in each case study (see section 4.8.2). ${ }^{92}$ Participation in most of the DR programs offered by NYISO and PJM has grown significantly during the last 3-4 years. Participation trends for DR programs offered by utilities in our case study states are generally less bullish. ${ }^{93}$

Operational activity in many programs has been limited in recent years due to an absence of system reliability contingencies and/or low spot market prices. The call option/interruptible type programs and voluntary load reduction programs for which recent performance data is available have demonstrated load reductions in the range of $1-3 \%$ of the system peak. Call option/interruptible programs have historically elicited load reductions at or near participants' contracted level, because of customers' incentive to avoid non-compliance penalties. Voluntary emergency load reduction programs that offer relatively high incentive payments when called (e.g.., \$500/MWh floor price offered by NYISO EDRP) have also generated a substantial load response. In contrast, scheduled load reduction programs thus far have not demonstrated an ability to elicit load reductions on the same order of magnitude as the other types of DR

\footnotetext{
${ }^{92}$ Note the difference in how participation is reported for DR program compared to RTP - i.e., customers' contracted or nominated load reduction as opposed to customers' combined billing demand or coincident peak demand.

${ }^{93}$ Some utilities reported a decline in participation due to customer migration to competitive suppliers or reduced program incentives as a result of lower market prices or a re-evaluation of program costs and benefits. A number of utilities have recently canceled their DR programs or limit their offerings to those implemented by the ISO.
} 
programs, either because little load has enrolled or because the customers that have enrolled have not actively participated. In part, this may be attributable to low spot market prices prevailing since these programs have been introduced and market barriers related to customers' knowledge of electricity markets and load response strategies (Neenan et al. 2003).

\subsection{Policy Implications and Recommendations for Competitive Retail Markets}

In states that have restructured their electricity markets, development of default service has been primarily driven by policy objectives related to retail market development rather than DR. However, there are a number of opportunities for policymakers that are also interested in stimulating the development of DR to integrate these policy goals into the design and implementation of default service.

(1) Day-ahead default RTP can be an effective strategy for simultaneously meeting retail market development and DR-related goals.

In those states that have adopted RTP as the default service primarily to facilitate retail market development, this type of tariff has been attractive because it always reflects current market conditions, does not require the use of class average load profiles for setting the commodity charge, and is amenable to limited switching restrictions. At the same time, default RTP has the potential to stimulate DR, both from customers that remain on the default service and from those that switch to a competitive supply arrangement that is indexed to the default service. Evidence to date suggests that default RTP that is indexed to the day-ahead energy market may be more effective at stimulating DR than default RTP that is indexed to the real-time spot market, because it provides customers with greater levels of advance notice. Day-ahead default RTP may therefore be one potential strategy for simultaneously advancing retail market development and DR-related goals. ${ }^{94}$

(2) If C\&I customers in the default RTP class are to be offered a temporary fixed price hedge for a multi-year period, policymakers should consider structuring this hedge as a fixed price load block rather than as a full-requirements hedged service.

Policymakers in several states (e.g. Maryland, Pennsylvania, and New York) that have adopted default RTP have deemed it necessary to also offer the affected customers some type of fixed price hedge for a defined transitional time period. In Maryland and New York, this feature was an important element of the consensus settlement reached by the parties and adopted by the regulatory commissions. The rationales for offering a fixed price option during a transition period are that the retail market may not be sufficiently mature to offer a variety of service offerings or that some customers, particularly smaller C\&I customers, won't find an acceptable offer for hedged service from a competitive supplier, either because they lack the savvy or because few retailers serve that segment. The primary argument against offering a hedged, fixed

\footnotetext{
94 If day-ahead default RTP is established as the default service, and the utility is responsible for scheduling and procurement, policymakers should ensure that appropriate charges are included to account for any costs and risks associated with forecasting the default service load a day in advance. Otherwise, competitive retail suppliers' ability to offer similar pricing arrangements may be negatively affected.
} 
price option is that it may slow the entry of competitive suppliers into the market and deter customer switching.

If regulators decide that utilities should offer a hedged service during a transition period, key issues to consider are the duration of that transitional period and how to structure the hedged service option. In Maryland, customers in the default RTP class were offered a separate, full requirements hedged service for a one-year period, while DLC's default RTP customers are offered a similar hedged option for a two-and-a-half year period. NMPC opted for a different approach, offering customers in the default RTP class a one-time, up-front option to purchase a fixed price load block (under take-or-pay terms) for up to five years and purchase their residual load either through the default RTP tariff or from a competitive supplier. From a demand response perspective, the advantage of this latter approach is that customers that opt for the temporary hedge are potentially exposed to spot market prices on the margin. Thus, in the shortrun, these customers may still have an incentive to respond to hourly price changes. In the longrun, introducing customers to block-and-index type pricing arrangements through the default service may stimulate adoption of such pricing arrangements in the competitive market. The disadvantage of this approach is that it may be more complicated to implement (e.g., the procurement process and billing system). Thus, if the transition period is relatively long (e.g. 3-5 years), it may be worth considering whether to structure the hedge as a block-and-index type arrangement, given the potential DR-related benefits. On the other hand, if the transition period is only one year, then the added complication of such an approach may not be warranted.

(3) State regulators and utilities should consider installing interval meters over a wider population of C\&I customers than just the default RTP class, and should also consider specifying features in the metering infrastructure that facilitate DR.

Large scale deployment of interval metering among C\&I customers has been conducted in several states to support implementation of default RTP. Such efforts represent another opportunity to leverage DR goals with retail market restructuring activities, in this case by installing interval meters across a wider customer population than the default RTP class, as was done in New Jersey, and by specifying metering systems with features that facilitate price response. $^{95}$ Policymakers should consider whether these incremental measures are warranted, in light of the potential benefits they could yield in terms of the development of DR (e.g., by facilitating participation in ISO/RTO DR programs and/or bolstering the price responsiveness of customers facing hourly spot market prices through default RTP or a competitive supply contract).

(4) Rigorous collection and analysis of data related to customer exposure and response to spot market-indexed competitive supply contracts is needed.

A variety of policy and planning decisions (e.g., related to continuation of wholesale market price caps or certain types of DR programs) hinge upon assumptions about the price

\footnotetext{
95 Advanced metering infrastructure features that could enhance DR capability include hardware or software that allows customers to directly access their own metered usage data at intervals more frequently than once during each 24 hour period, meters with data ports that allow customers to take a direct feed from their meter for an EMCS, EIS, or load control device, and training on optimizing energy information systems (EIS) and energy management control systems for DR applications.
} 
responsiveness of retail electricity consumers. Yet, little information is currently being collected in regulated or competitive markets to measure how and why customers respond to prices. Federal and state regulators and ISO/RTOs should consider undertaking efforts to regularly collect and analyze data on retail customers' supply arrangements and response to hourly pricing and other dynamic pricing options, to support policy and planning decisions that require knowledge about the price responsiveness of retail consumers. Given the sensitive nature of this information, appropriate measures would need to be taken to ensure that data released to the public does not compromise the position of individual suppliers or customers.

(5) The development of DR in competitive retail markets may require addressing market barriers.

Spot market indexed pricing arrangements with flexible hedging options appear to be widely available in many competitive retail markets. However, competitive suppliers currently offer few services to help customers identify, analyze, or implement load response strategies. At this point, it is unclear to what extent this is a temporary condition (i.e., a natural response to low spot market prices and low price volatility) or a more fundamental feature of competitive retail markets. In either case, the potential for DR to develop in competitive retail markets will likely be limited in the near-to-mid term without a concerted effort on the part of some entity to help customers develop their load response capabilities.

Some set of policy interventions may therefore be warranted to enhance customers' capability and willingness to respond to dynamic prices. In many states that have implemented customer choice, the state regulatory commission and/or utilities have conducted general customer education activities to provide basic information about restructuring and/or default service. Policymakers should consider incorporating into these activities information to help customers better understand the potential cost savings and risk management benefits associated with load response to hourly spot market prices as well as technical information to help customers identify load response strategies. Additional programmatic efforts, such as facility DR audits and financial assistance with DR enabling technologies may also be warranted.

\subsection{Policy Implications and Recommendations for Regulated Retail Markets}

Our case studies of RTP experience are drawn from states where there is retail competition to serve large customer load and in most cases, where an ISO/RTO has been established to ensure system reliability and administer specified wholesale markets. In this section, we discuss whether and how these experiences are useful to policymakers in states without retail competition that are seeking to foster the development of DR.

(1) The implications of implementing default RTP in a regulated market, in terms of customer acceptance and DR impacts, depend on what types of hedging options are offered to customers in the default RTP class.

In competitive retail markets where RTP has been established as the default service, concerns about the fairness of forcing customers to bear price risk have been tempered, as customers that prefer price certainty can choose to switch to a hedged retail supply contract with a competitive provider. In cases where there has been doubt about the immediate availability of competitively- 
priced hedged contracts, policymakers have required that the utility offer a temporary fixed price service, to give the retail market time to more fully develop.

In contrast, if RTP is established as the default service in regulated retail markets, the ability of customers in the default RTP class to financially hedge their exposure to price risk will depend largely on whether state regulators decide to make hedging options available. Several options are available for state policymakers that want to implement default RTP but do not want to force all customers in the default RTP class to face volatile prices for their entire load.

One option is to allow customers to opt out of RTP onto an alternative, fixed price rate. Experiences in competitive retail markets where customers have been offered a choice between an unhedged RTP tariff and a full-requirements, fixed price service have suggested that the large majority of customers will choose the fixed price service. Thus, if the goal is to stimulate DR, this approach does not seem particularly promising. Rather, if a significant portion of the applicable customer population is to remain on RTP with minimal objection, the RTP tariff must incorporate some type of hedge.

A second option is to structure the default RTP tariff as a traditional two-part RTP tariff, where each customer receives a CBL equal to their historical usage profile. The advantage of this approach is that customers' bills and the utility's revenues are affected only to the extent that customers' usage patterns change. However, the process of developing an hourly load profile for each individual customer can be quite time consuming, prone to contention, and, for new customers and other customers without an established history of interval load data, rather subjective.

A third option, which avoids some of the difficulties associated with the CBL-based tariff design, is to implement a default RTP tariff similar to the block and index type of arrangements available in competitive markets, where customers can nominate blocks of load to purchase at a fixed price and face hourly prices for the remaining portion of their load. Little experience has been accumulated with such an approach in regulated, cost-of-service settings, although a host of potential issues can be identified, such as: how to structure the load blocks and how to determine their price (i.e., based on embedded costs or some representation of a market-based risk premium).

(2) If RTP is to provide a significant source of DR in regulated retail markets, the RTP tariff will need to offer, to a wide range of customers, substantial and/or fairly predictable financial benefits compared to fixed price tariff options available to the same customer class.

Nearly all of the optional RTP tariffs in our case study states have generated limited levels of participation, which is consistent with the experience of most other utilities in the U.S. that have offered optional RTP (Barbose et al. 2004). Georgia Power Company's (GPC) RTP tariffs are a notable exception and provide an existence proof that high participation rates in optional RTP can be achieved.

A key lesson to emerge from GPC's experience is that, to attract a substantial fraction of the system load to an optional RTP tariff, it may be necessary for the tariff design to incorporate a fairly predictable financial benefit for a large population of customers. Customers benefit from participating in GPC's RTP tariffs by adjusting their usage in response to prevailing hourly 
prices (e.g., shedding load during high priced periods and/or rescheduling load from high to low priced periods). Customers also receive financial benefits as a result of the procedures GPC uses to establish and maintain participants' CBL. GPC allows certain customers to receive an initial CBL less than their typical or projected load and allows all customers to expand their facilities without adjusting their CBL upward. ${ }^{96}$ The net result is that most RTP participants are able to purchase some fraction of their typical usage at marginal cost based prices that, on average, are less than the utility's embedded cost based rates, and thereby achieve cost savings over the longrun that are independent of their load response to high or volatile hourly prices. GPC also offers a variety of financial hedges that allow RTP participants the flexibility to temporarily adjust the amount of load exposed to hourly prices. ${ }^{97}$

Can GPC’s approach be directly translated to traditional, regulated retail settings? GPC's practice of offering new customers the option to receive a reduced CBL constitutes a departure from traditional, cost-of-service ratemaking practices by allowing some customers to make a smaller contribution to embedded costs in exchange for accepting greater price risk. ${ }^{98}$ The utility has successfully defended this practice on the grounds that it is necessary for the company to successfully recruit customer choice load, which benefits all ratepayers by spreading embedded costs over a larger amount of load. However, in most monopoly retail markets, where the utility already has the exclusive right to serve new customers, this particular line of reasoning would presumably be less compelling. ${ }^{99}$

A fundamental question for regulators in traditional regulated markets that want to encourage the development of price response, then, is: Can some type of fairly predictable financial benefit for RTP participants be justified on the grounds that all ratepayers benefit from RTP participants' price response, or that risk is transferred from other ratepayers to RTP participants? If so, how large of an incentive or discount is warranted - i.e., what is it worth to all ratepayers to have a significant subset of them be price-responsive and how can that be dealt with in the design of an optional RTP tariff? And is that level of financial benefit likely to induce widespread participation in RTP? Finally, how best to structure the incentive? In GPC's case, the discount is provided implicitly by applying a different cost responsibility standard to incremental RTP load than to load billed under other rates. An alternative approach that policymakers may want to consider, and evaluate through pilot programs, is to explicitly link the "incentives" offered to customers to enroll in RTP to their response during high price periods.

\footnotetext{
96 This tariff design element is part of GPC's strategy for recruiting customer choice load.

${ }^{97}$ Customers can reduce the coverage by in effect buying out the desired level of typical load, thereby exposing more load to RTP prices. Alternatively, they can buy additional coverage that converts load exposed to RTP into typical load that is priced at the alternative tariff rates.

${ }^{98}$ For the purpose of establishing retail rates, Georgia Power allocates embedded costs to RTP customers based on their CBL profile, not their actual load. However, the company determines their long term resource requirements based on RTP customers' total load.

${ }^{99}$ However, it is worth noting that, even in monopoly retail markets, C\&I customers do have choice to the extent that they can choose in which state to locate their facilities.
} 


\section{References}

Barbose, G., C. Goldman, and B. Neenan, 2004, “A Survey of Utility Experience with Real Time Pricing,” Lawrence Berkeley National Laboratory, LBNL-54238, December.

Best, K.F., M.W. Crisp, E.D. Evans, P.M. Hayet, J.W. Smith, and D.R. Cearfoss Jr., 2004, "Panel Direct Testimony and Exhibits of Kathleen F. Best, Mark W. Crisp, Evan D. Evans, Philip M. Hayet, Jerry W. Smith, and Daniel R. Cearfoss,” Georgia Public Service Commission, Docket No. 17687-U, May 14.

BGE (Baltimore Gas \& Electric), 2004, Personal communication with BGE staff, December 20.

BGE, 2005, Retail Electric Service Tariff.

BGS Auction, 2005, BGS-CIEP Opt-Ins, January 19. Available online at: http://www.bgsauction.com/bgs.dataroom.occ.asp.

Braithwait, S. and M. O'Sheasy, 2001, "RTP Customer Demand Response - Empirical Evidence on How Much Can You Expect” in Electricity Pricing in Transition, A. Faruqui and K. Eakin (eds.), Kluwer Academic Publishers.

Cearfoss, D.R. and J.W. Wilson, 2004, "Panel Direct Testimony and Exhibits of Daniel R. Cearfoss, Jr. and John W. Wilson, Ph.D on Behalf of the Georgia Public Service Commission Adversary Staff,” Georgia Public Service Commission, Docket No. 18300-U, October 14.

CG\&E, (Cincinnati Gas \& Electric), 2004, Personal communication with CG\&E staff, December 17.

CHG\&E (Central Hudson Gas \& Electric), 2004, “Joint Proposal - Retail Access Collaborative,” NYPSC Case 00-E-1274, November 1.

CHG\&E, 2005, Personal communication with CHG\&E staff, January 13.

Chupka, M.W., 2003, “Direct Testimony of Marc W. Chupka on Behalf of Federated Department Stores,” Georgia Public Service Commission, Docket No. 16896-U, June 20.

Civic, T., C. Martin, J. Stanway, and R. Swiontek, 2004, “Direct Testimony on Behalf of BJ's, Kohl's, Lowe’s, and Wal-Mart,” Georgia Public Service Commission, Docket No. 18300-U, October 8.

Clarkson, James H., 2003, “Direct Testimony of James H. Clarkson on Behalf of Federated Department Stores,” Georgia Public Service Commission, Docket No. 16896-U, June 20.

ComEd (Commonwealth Edison Company), 1999, "Schedule of Rates, Rate 6 - General Service,” Effective January 1.

ComEd, 2002, “Schedule of Rates, Rate 6L - Large General Service,” Effective December 1. 
ComEd, 2003, “Schedule of Rates, Rate HEP - Hourly Energy Pricing,” Effective March 31.

ComEd, 2004, Personal communication with ComEd staff, December 13.

ComEd, 2005a, “Historical HEP Prices.” Available online at: http://www.rtp.ceco.com/HEP.asp.

ComEd, 2005b, “Smart Returns Program.” Available online at: http://www.exeloncorp.com/ourcompanies/comed/comedind/energy_savings_products_and services/smart_returns.htm

DLC (Duquesne Light Company), 2004a, "Schedule of Rates, Supplement No. 22 to Tariff No. 23,” Effective November 1.

DLC, 2004b, Personal communication with DLC staff, November 30.

DLC, 2004c, “2004 Summer Assessment,” Presentation to the Pennsylvania Public Utilities Commission, May 27. Available at: http://www.puc.state.pa.us/electric/pdf/Duquesne_Summer_Reliability052704.pdf.

DLC, 2005, Personal communication with DLC staff, April 20.

Eber, J., 2004, “Peak Load Management from a Supplier’s Perspective,” Presentation to the Peak Load Management Association Spring 2004 Conference by Jim Eber, March 24. Available at: http://www.peaklma.com/files/public/eber.ppt.

EIA (Energy Information Administration), 2005, “Electric Sales and Revenue 2003 Spreadsheets C2 and C3,” January. Available online at: http://www.eia.doe.gov/cneaf/electricity/esr/esr_tabs.html.

GAP (General Assembly of Pennsylvania), 1996, House Bill No. 1509.

Goldman, C., G. Heffner, and G. Barbose, 2002, "Customer Load Participation in Wholesale Markets: Summer 2001 Results, Lessons Learned and 'Best Practices',” Lawrence Berkeley National Laboratory, LBNL-50966, February. http://eetd.lbl.gov/EA/EMP/drlm-pubs.html

Goldman, C., N. Hopper, O. Sezgen, M. Moezzi, R. Bharvirkar, B. Neenan, R. Boisvert, P. Cappers, and D. Pratt, 2004, "Customer Response to Day-ahead Wholesale Market Electricity Prices: Case Study of RTP Program Experience in New York,” Report to the California Energy Commission, Lawrence Berkeley National Laboratory, LBNL-54761, June. http://eetd.lbl.gov/EA/EMP/drlm-pubs.html

Goldman, C., N. Hopper, R. Bharvirkar, B. Neenan, R. Boisvert, P. Cappers, D. Pratt, and K. Butkins, 2005, "Customer Strategies for Responding to Day-Ahead Market Hourly Electricity Pricing,” Lawrence Berkeley National Laboratory, LBNL-57128, July. http://eetd.lbl.gov/EA/EMP/drlm-pubs.html 
GPC (Georgia Power Company), 2004a, “Georgia Power Company’s 2004 Integrated Resource Plan,” Georgia Public Service Commission, Docket No. 17687, January 30.

GPC, 2004b, Personal communication with rate department staff, November 22.

GPC, 2004c, "Response to hearing request by GPSC staff,” Georgia Public Service Commission, Docket No. 18300-U, October 6.

GPC, 2004d, "Response to data requests”, Georgia Public Service Commission, Docket No. 18300-U, September 2.

GPC 2001, “Integrated Resource Plan,” Georgia Public Service Commission, Docket No. 13305U, January 31.

GPSC (Georgia Public Service Commission), 1998, “Georgia Public Service Commission Staff Report on Electric Industry Restructuring,” Georgia Public Service Commission, Docket No. 7313-U, January 23.

GPSC, 2000, “Order for certain modifications to the Real Time Pricing tariff structure,” Georgia Public Service Commission Docket No. 11708-U, April 18.

GPSC, 2003, "Staff Report to the Georgia Public Service Commission,” Georgia Public Service Commission Docket No. 16896-U, November 14.

GPSC, 2004a, Personal communication with GPSC staff, September 30.

GPSC, 2004b, “Adversary staff proposed order,” Georgia Public Service Commission, Docket No. 18300-U, December 13.

GTMA and GIG (Georgia Textile Manufacturers Association and Georgia Industrial Group), 1999, Petition for Rule Nisi to Examine Georgia Power Company’s Real Time Pricing Structure, Georgia Public Service Commission, Docket No. 11708, December 23.

Harper-Slaboszewicz, P., 2004, “Utility Metering: Measure When and How Much?” Issue Alert, Utilipoint International Inc., October 15.

Hinson, R., J.M. Kubler, and M.T. O’Sheasy, 2000, “Testimony of Ron Hinson, Jonathan M. Kubler, and Michael T. O’Sheasy,” Georgia Public Service Commission, Docket No. 11708U, March 17.

ICC (Illinois Commerce Commission), 1998, ICC Order, Docket number 98-0362, September 23.

ICC, 2002, "Dissenting Opinion of Commissioner Kretschmer on the Order Entered by the Commission on November 14, 2002,” Docket number 02-0479, November 27.

ICC, 2003, ICC Order, Docket number 02-0479, March 28. 
ICC, 2004a, “The Post-2006 Initiative: Final Staff Report to the Commission,” December 2.

ICC, 2004b, Personal communication with ICC staff, September 23.

ICC, 2005a, “Electricity Switching Statistics: 2004 Filings,” Available online at: http://icc.state.il.us/ec/switchstats.aspx.

ICC, 2005b, "Plug-in Illinois, Power to Choose: List of Certified Suppliers,” Available online at: http://www.icc.state.il.us/pluginillinois/consumer/plugin/certlist.htm.

IGA (Illinois General Assembly), 1997, Public Utilities Act, Article XVI, Electric Service Customer Choice and Rate Relief Law of 1997, Sections 16-103, 16-107, 16-110, 16-113, and 16-119A.

IGA, 2002, Public Utilities Act, Article XVI, Electric Service Customer Choice and Rate Relief Law of 1997, Section 16-111.

JCP\&L (Jersey Central Power \& Light), 2004, Personal communication with JCP\&L staff, December 20.

JCP\&L, 2005, Personal communication with JCP\&L staff, January 26.

KEMA, 2003a, “Garden State to Bloom This Summer,” Retail Energy Foresight, December/January.

KEMA, 2003b, “Is the Illinois Market Competitive,” Retail Energy Foresight, December/January.

KEMA, 2004a, “Current Switch Rates,” Retail Energy Foresight, June/July.

KEMA, 2004b, “Spotlight: Duquesne Light Innovation,” Retail Energy Foresight, October/November.

KEMA, 2004c, “Spot Light: Maryland Wakes Up,” Retail Energy Foresight, April/May.

KEMA, 2005, “Current Switch Rates,” Retail Energy Foresight, December/January.

Kubler, J.M., 2001, “Direct Testimony of Jonathan M. Kubler on Behalf of Georgia Power Company” Georgia Public Service Commission, Docket No. 14000-U, June 29.

Kubler, J.M., 2003, “Direct Testimony of Jonathan M. Kubler on Behalf of Georgia Power Company” Georgia Public Service Commission, Docket No. 16986-U, July 11.

Maryland Code, 2005, “Title 7 Gas, Electric, and Water Companies: Subtitle 5 Electric Industry Restructuring." 
McNeil, W., 2004, "Dealing with Free Markets and Demand Response,” Presentation to the Peak Load Management Association Fall 2004 Conference, September 29. Available online at: http://www.peaklma.com/files/public/McNeil.ppt.

MDPSC (Maryland Public Service Commission), 2002, “Order 77806: In the Matter of the Commission's Inquiry into the Competitive Selection of Electricity Supplier/Standard Offer Service,” May 30.

MDPSC, 2003a, “Order 78400: In the Matter of the Commission’s Inquiry into the Competitive Selection of Electricity Supplier/Standard Offer Service,” April 29.

MDPSC, 2003b, “Order 78710: In the Matter of the Commission's Inquiry into the Competitive Selection of Electricity Supplier/Standard Offer Service,” September 30.

MDPSC, 2004, Personal communication with MDPSC staff, September 7.

MDPSC, 2005a, "Status Report by the Public Service Commission of Maryland on Electricity Procurement and Restructuring in Maryland,” February 23.

MDPSC, 2005b, Directory of electric suppliers licensed in Maryland, June 6. Available online at: http://webapp.psc.state.md.us/Intranet/SupplierInfo/searchSupplier_E.cfm.

MDPSC, 2005c, "Electric Choice Enrollment: Monthly Report, All Utilities Where Choice is Available in Maryland, Month Ending April 2005,” June 7. Available online at: http://www.psc.state.md.us/psc/electric/enrollmentrpt.htm.

NEDRI (New England Demand Response Initiative), 2003, "Dimensions of Demand Response: Capturing Customer Based Resources in New England’s Power Systems and Markets," Report and Recommendations of the New England Demand Response Initiative, July 23.

Neenan, B., D. Pratt, P. Cappers, J. Doane, J. Anderson, R. Boisvert, C. Goldman, O. Sezgen, G. Barbose, R. Bharvirkar, M. Kintner-Meyer, S. Shankle and D. Bates, 2003, "How and Why Customers Respond to Electricity Price Variability: A Study of NYISO and NYSERDA 2002 PRL Program Performance,” Report to the New York Independent System Operator (NYISO) and New York State Energy Research and Development Agency (NYSERDA), Lawrence Berkeley National Laboratory: LBNL-55209, January.

NJBPU (New Jersey Board of Public Utilities), 1999, The Electric Discount and Energy Competition Act, July.

NJBPU, 2001, Decision and Order, Docket Numbers EX01050303, EO01100654, EO01100655, EO01100656, and EO01100657, December 10.

NJBPU, 2002, Decision and Order, Docket Numbers EX01110754 and EO02070384, November 6.

NJBPU, 2003, Decision and Order, Docket Number EO03050394, October 22. 
NJBPU, 2004a, Decision and Order, Docket Number EO04040288, October 22.

NJBPU, 2004b, Personal communication with NJBPU staff, October 13.

NJBPU, 2005a, CIEP Switching Data. Available online at: http://www.bpu.state.nj.us/wwwroot/energy/CIEP.pdf.

NJBPU, 2005b, Electric Switching Data. Available online at: http://www.bpu.state.nj.us/energy/elecSwitchData.shtml.

NJBPU, 2005c, List of Licensed Suppliers of Electricity. Available online at: http://www.bpu.state.nj.us/home/supplierpage.shtml\#ElectricSuppliers.

NYISO (New York Independent System Operator), 2004, “Seventh Bi-Annual Compliance Report on Demand Response Programs and the Addition of New Generation in Docket No. ER01-3001-00,” December 1.

NYPSC (New York Public Service Commission), 2003a, “Order Instituting Proceeding: Proceeding on Motion of the Commission Regarding Expedited Implementation of Mandatory Hourly Pricing for Commodity Service,” NYPSC Case 03-E-0641, April 30.

NYPSC, 2003b, “Order on Expansion of Voluntary Real-Time Pricing Programs,” NYPSC Case 03-E-0641, October 30.

NYPSC, 2004a, "Statement of Policy on Further Steps Toward Competition in Retail Energy Markets,” NYPSC Case 00-M-0504, August 25.

NYPSC, 2004b, Personal communication with NYPSC staff, September 29.

OAC (Ohio Administrative Code) 2005, Chapter 4901:1-35: Market-Based Standard Service Offer and Competitive Bidding Process for Electric Utilities.

OLA (Oregon Legislative Assembly), 1999, Senate Bill 1149, June 29.

OLA, 2001, House Bill 3633, June 22.

OPUC (Oregon Public Utilities Commission), 2003, "Demand Response Programs for Oregon Utilities,” Prepared by Lisa Schwartz for the Oregon Public Utilities Commission, May.

OPUC, 2004, Personal communication with Electric Rates and Planning staff, September 23.

OPUC, 2005, “Electric Restructuring Monthly Status Report for January 2005.” Available online at: http://www.puc.state.or.us/erestruc/indices/statrpt.htm

ORC (Ohio Revised Code), 2005a, Chapter 4928: Competitive Retail Electric Service.

ORC, 2005b, Section 4928.14: Market-Based Standard Service Offer; Competitive Bidding Process; Failure to Provide Service. 
O’Sheasy, M.T., 2003, “Direct Testimony of Michael T. O’Sheasy on Behalf of Georgia Power Company,” Georgia Public Service Commission, Docket No. 16896-U, July 11.

PGE (Portland General Electric), 2003, “Delivering New Choices for PGE’s Customers:

Supplement, 2002 Integrated Resource Plan,” February.

PGE, 2004, Personal communication with rate department staff, December 7.

PEPCO, 2004, Personal communication with PEPCO staff, November 23.

PJM, 2005a, Personal communication with PJM staff, April 17.

PJM, 2005b, “2004 State of the Market Report,” March 8.

POCA (Pennsylvania Office of the Consumer Advocate), 2004, "Pennsylvania Electric Shopping Statistics: October 1, 2004.” Available online at: http://www.oca.state.pa.us/cinfo/instat.htm.

Pollock, J., 2000, “Direct testimony, Petition for Rule Nisi to Examine Georgia Power Company’s Real Time Pricing Structure,” Georgia Public Service Commission, Docket 11708, March 6.

PPUC (Pennsylvania Public Utilities Commission), 2004a, "Motion of Commissioner Glenn R. Thomas: Provider of Last Resort Regulations,” Docket number M-00041792, March 4.

PPUC, 2004b, “Demand Side Response Technology Deployment Subgroup Report,” June 30.

PPUC, 2004c, “Opinion and Order: Petition of Duquesne Light Company for Approval of Plan for Post-Transition Period Provider of Last Resort Service,” Docket number P-00032071, August 19.

PPUC, 2004d, "Motion of Commissioner Kim Pizzingrilli: Petition of Duquesne Light Company for Approval of Plan for Post-Transition Period Provider of Last Resort Service,” Docket number P-00032071, September 30.

PPUC, 2004e, Personal communication with PPUC staff, November 11.

PPUC, 2005, “Electric Suppliers List.” Available at online: http://www.puc.state.pa.us/electric/electric_suppliers_list.aspx.

PSE\&G (Public Service Electric \& Gas), 2004, Personal communication with PSE\&G staff, November 22.

PSE\&G, 2005, Personal communication with PSE\&G staff, February 17.

PUCO (Public Utilities Commission of Ohio), 2003a, PUCO Order, Case No. 03-93-EL-ATA, January 10. 
PUCO, 2003b, “The Ohio Retail Electric Choice Programs: Report of Market Activity 20012002,” A Report by the Public Utilities Commission of Ohio, May.

PUCO, 2003c, PUCO Order, Case No. 01-2164-EL-ORD, December 17.

PUCO, 2003d, “PUCO 2003 End-of-Year-Review.”

PUCO, 2004a, PUCO Order, Case No. 01-2164-EL-ORD, 03-93-EL-ATA, December 22.

PUCO, 2004b, PUCO Opinion and Order, Case No. 03-93-EL-ATA, September 29.

PUCO, 2004c, “Summary of Switch Rates from EDUs to CRES Providers in Terms of Customers For the Month Ending March 31, 2004,” Available online at: http://www.puc.state.oh.us/Puco/StatisticalReports/Report.cfm?doc_id=365

PUCO, 2004d, "Summary of Switch Rates from EDUs to CRES Providers in Terms of Sales For the Month Ending March 31, 2004,” Available online at: http://www.puc.state.oh.us/Puco/StatisticalReports/Report.cfm?doc_id=365

PUCO, 2004e, Personal communication with PUCO staff, September 29.

PUCO, 2005, PUCO Order, Case No. 01-2164-EL-ORD, April 13.

Rogers, J., 2001, “Preparation for Summer 2001,” Presentation to the Indiana Utility Regulatory Commission, May 11. Available online at: http://www.in.gov/iurc/utilities/energy/01energy/psi.ppt.

Rogers, J., 2002, “Preparation for Summer 2002,” Presentation to the Indiana Utility Regulatory Commission, May 10. Available online at: http://www.in.gov/iurc/utilities/energy/02energy/psi.ppt.

Rogers, J., 2003, “Preparation for Summer 2003,” Presentation to Indiana Utility Regulatory Commission, May 2. Available online at: http://www.in.gov/iurc/utilities/energy/03energy/psi.ppt.

Suez (Suez Energy Resources North America, 2004, “Texas 2004 Energy Usage and Sourcing Trend Survey Analysis,” October 26. Available online at: http://www.suezenergyresources.com/Ourexp/ourexp_whitepapers.shtm.

Suez, 2005, “Northeast Trend Survey,” January 24. 